UNIVERSIDADE DE SÃO PAULO

ESCOLA POLITÉCNICA

PABLO DANIEL PAZ SALAZAR

Monitoramento em tempo real da estabilidade de tensão usando redes neurais artificiais

São Paulo 
UNIVERSIDADE DE SÃO PAULO

ESCOLA POLITÉCNICA

PABLO DANIEL PAZ SALAZAR

Monitoramento em tempo real da estabilidade de tensão usando redes neurais artificiais

Dissertação apresentada à Escola Politécnica da Universidade de São Paulo para obter o título de Mestre em Ciências.

São Paulo 
UNIVERSIDADE DE SÃO PAULO

ESCOLA POLITÉCNICA

PABLO DANIEL PAZ SALAZAR

Monitoramento em tempo real da estabilidade de tensão usando redes neurais artificiais

Dissertação apresentada à Escola Politécnica da Universidade de São Paulo para obter o título de Mestre em Ciências.

Área de Concentração: Sistemas de Potência.

Orientador: Prof. Dr. Carlos Eduardo de Morais Pereira

São Paulo 
Este exemplar foi revisado e corrigido em relação à versão original, sob responsabilidade única do autor e com a anuência de seu orientador.

São Paulo, de de

Assinatura do autor:

Assinatura do orientador:

Catalogação-na-publicação

\section{Salazar, Pablo Daniel Paz}

Monitoramento em tempo real da estabilidade de tensão usando redes neurais artificiais / P. D. P. Salazar -- versão corr. -- São Paulo, 2018.

$108 \mathrm{p}$.

Dissertação (Mestrado) - Escola Politécnica da Universidade de São Paulo. Departamento de Engenharia de Energia e Automação Elétricas.

1.Estabilidade de tensão 2 .Sistemas elétricos de potência 3.Redes neurais 4. Estabilidade de sistemas 5.Fluxo de carga continuado I.Universidade de São Paulo. Escola Politécnica. Departamento de Engenharia de Energia e Automação Elétricas II.t. 


\section{Agradecimentos}

Agradeço a minha família pelo apoio e carinho brindado em todo momento.

A minha esposa, Andrea, pela compreensão e motivação brindada.

A meu professor e orientador Carlos Eduardo de Morais Pereira pela excelente orientação, companheirismo e amizade.

A CAPES pelo apoio financeiro que possibilitou a realização deste trabalho.

A Universidade de São Paulo pelo ensino gratuito e de qualidade.

Ao departamento de Engenharia de Energia e Automação Elétricas pela oportunidade brindada de realizar este trabalho.

Enfim, a todos os professores e amigos que conheci e motivaram para seguir adiante. 


\section{Resumo}

Nos dias atuais, há muitos casos em que sistemas de potência estão operando perto dos seus limites de estabilidade devido a restrições econômicas e leis ambientais.

A estabilidade de tensão é uma matéria de muita pesquisa e interesse devido a que é considerado como uma das maiores ameaças na segurança dos sistemas.

Uma prevenção exitosa de colapso do sistema baseia-se na precisão do método, a simplicidade dos índices, e muito baixo tempo de computação.

Este trabalho apresenta uma rede Perceptron Multicamada (PMC) como proposta para monitoramento em tempo real da estabilidade de tensão de sistemas de potência usando como principais dados de entrada medidas obtidas do sistema SCADA. Os dados de treinamento são obtidos com cálculos de fluxo de potência continuado.

A rede Perceptron Multicamadas é apresentada como um aproximador universal de funções, que diminui o tempo computacional dos métodos convencionais como o fluxo de potência continuado.

Por fim, a topologia da rede PMC proposta é avaliada com o sistema de 30 barras do IEEE, e os resultados em relação ao tempo de computação e precisão são comparados com o método de fluxo de potência continuado.

Palavras-chave: Estabilidade de tensão. Monitoramento em tempo real. Redes Neurais Artificiais. Fluxo de potência continuado. 


\section{Abstract}

Nowadays, many power systems are operating near their limits of stability due to economic restrictions and environmental laws.

Voltage stability is a subject of great interest because it is considered one of the greatest threats for power systems security.

The keys to preventing blackouts are the accuracy of the method, speed indication, and low computation time.

This work presents a Multi-layer Perceptron (PMC) network as a proposal for realtime monitoring of voltage stability in power systems using input data obtained from the SCADA system. The training data are obtained by running Continuation Power Flow (CPF) routine.

The multi-layer Perceptron network is presented as a universal approximator, reducing the computation time of conventional methods such as the continuation power flow.

Finally, the proposed PMC network is evaluated in the IEEE 30-bus system. Computation time and accuracy are compared with the continuation power flow method.

Keywords: Voltage Stability. Online Monitoring. Artificial Neural Network. Continuation Power Flow. 


\section{Lista de Figuras}

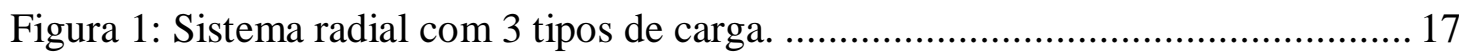

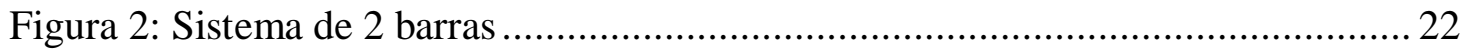

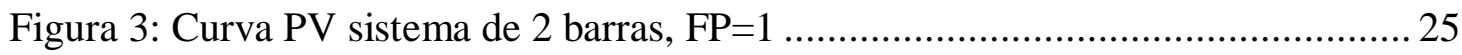

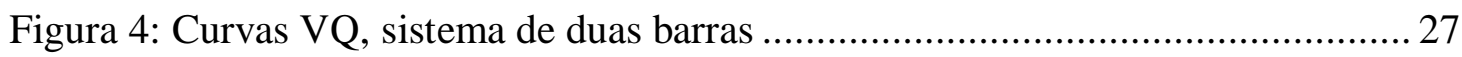

Figura 5: Curvas VQ de barras com diferente carregamento.................................. 28

Figura 6: Curva VQ de uma barra com compensação shunt .................................... 29

Figura 7: Construção da curva PV na região de baixo carregamento .......................... 50

Figura 8: Processo preditor - corretor na região de bifurcação …............................. 51

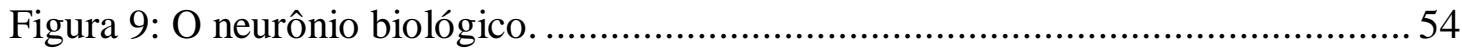

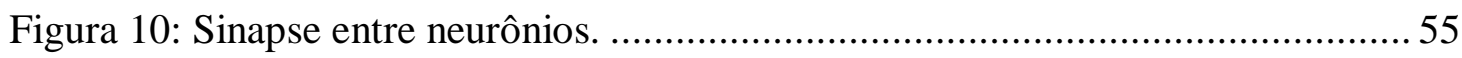

Figura 11: Modelo matemático do neurônio........................................................ 55

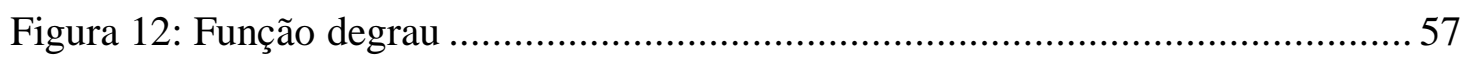

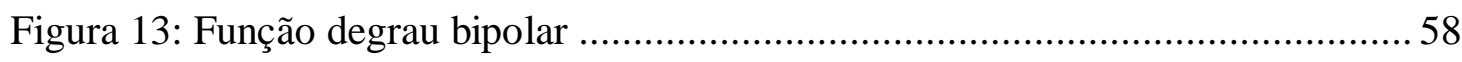

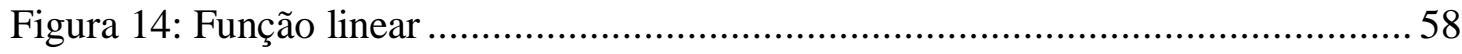

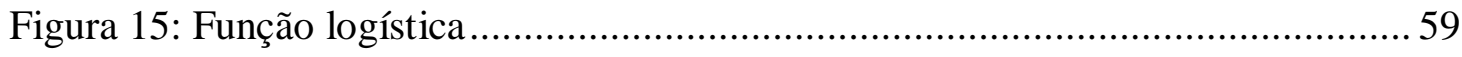

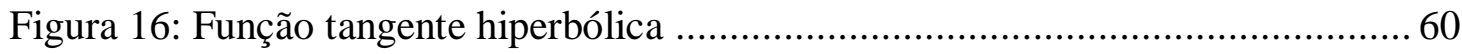

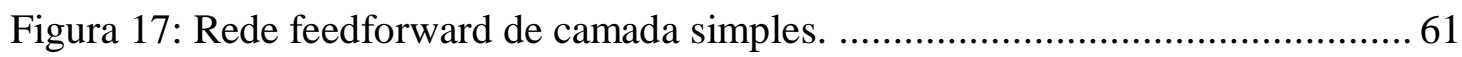

Figura 18: Rede feedforward de camadas múltiplas ..............................................62 62

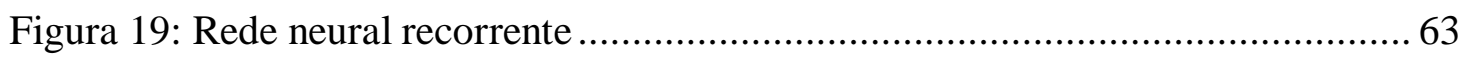

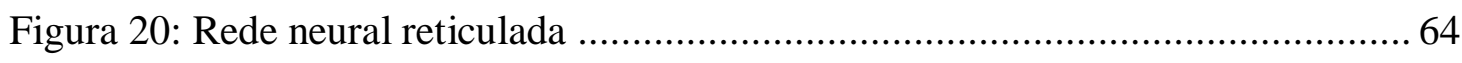

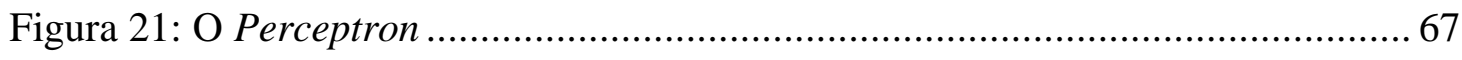

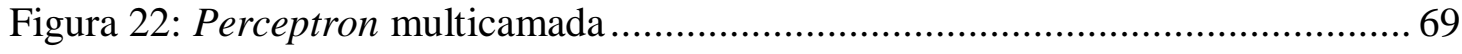

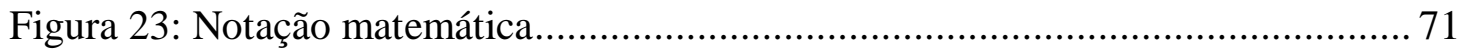

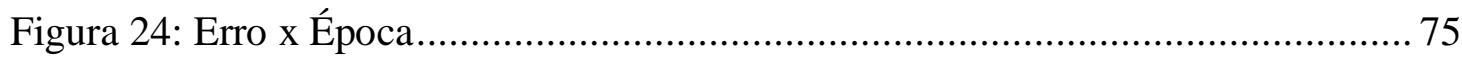

Figura 25: Amostragem aleatória para validação cruzada ...................................... 78

Figura 26: Curva V-Q da barra 14 para o caso base................................................ 91

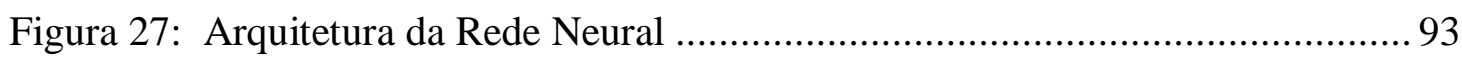

Figura 28: Desempenho do treinamento da rede neural. ........................................... 94

Figura 29: Teste da RNA versus o resultado real (FPC) para a barra 14 ................... 95

Figura 30: Teste da RNA versus o resultado real (FPC) para a barra 30 .................... 95

Figura 31: Sistema IEEE de 30 barras ................................................................... 105 


\section{Lista de Tabelas}

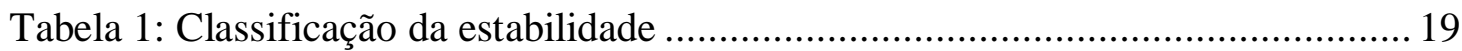

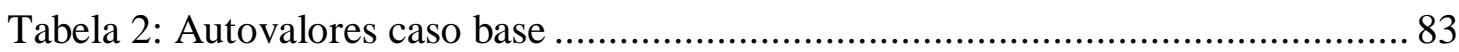

Tabela 3: Índices de participação de barras para os 5 mínimos autovalores ................ 84

Tabela 4: Potência reativa de reserva dos geradores. ............................................... 86

Tabela 5: Contribuição individual dos geradores às barras críticas. .......................... 88

Tabela 7: Impedância equivalente em p.u. entre os geradores e as barras críticas para a

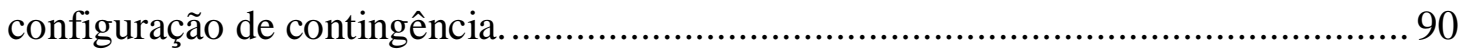

Tabela 8: Momentos P e Q para o caso base, configuração normal ........................... 91

Tabela 9: Erro máximo dos 94 cenários .................................................................... 96

Tabela 10: Dados de barras sistema IEEE 30-barras............................................ 106

Tabela 11: Dados de linhas e transformadores do sistema IEEE 30-barras .............. 107 


\section{Lista de Siglas}

LTC: Load Tap Changer

RNA: Redes Neurais Artificiais

AVR: Automatic Voltage Regulator

PMC: Perceptron Multicamadas

PMU: Phasor Measurement Unit

FPC: Fluxo de Potência Continuado

MSE: Mean Squared Error

PCA: Principal Component Analysis

VSM: Voltage Stability Margin

VCPI: Voltage Collapse Prediction Index

BPF: Bus Participation Factor

SCADA: Supervisory Control and Data Acquisition 


\section{Lista de símbolos}

$\rho \quad$ Fator de crescimento de carga global

$k \quad$ Fator de crescimento de carga de barra

$t_{k} \quad$ Vetor tangente

$\sigma \quad$ Escalar multiplicador do vetor tangente no passo preditor

$r \quad$ Escalar inicial para o cálculo de $\sigma$

$\gamma \quad$ Valor do parâmetro de continuação obtido no passo preditor

$e_{k} \quad$ Vetor linha que multiplica por 1 o parâmetro de continuação

$Y_{k m} \quad$ Admitância da linha entre a barra $k$ e a barra $m$

$\theta_{k m} \quad$ Diferencia angular entre a barra $k$ e a barra $m$

$J_{R} \quad$ Matriz jacobiana reduzida

$\Lambda \quad$ Matriz diagonal de autovalores

$\lambda \quad$ Autovalor

$\Sigma \quad$ Matriz diagonal de valores singulares

$w_{i} \quad$ Peso sináptico

$\theta \quad$ Limiar de ativação

$\eta \quad$ Taxa de aprendizagem do algoritmo supervisionado

$\delta_{j}^{(n)} \quad$ Gradiente do neurônio j na camada n

$Y_{i}^{(n)} \quad$ Saída da função ativação do neurônio i na camada $\mathrm{n}$

$I_{j}^{(n)} \quad$ Valor de entrada para a função de ativação

$x_{i} \quad$ Dados de entrada da rede neural

$Z_{\text {th }} \quad$ Impedância equivalente de Thevenin 


\section{Sumário}

Sumário

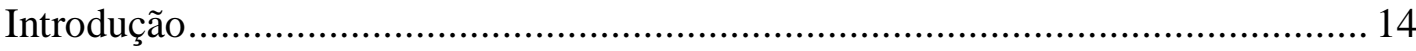

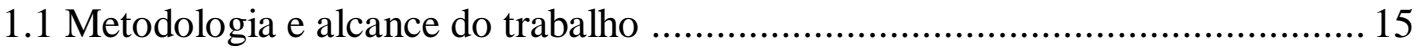

$1.2 \mathrm{O}$ fenômeno da estabilidade de tensão. ........................................................ 16

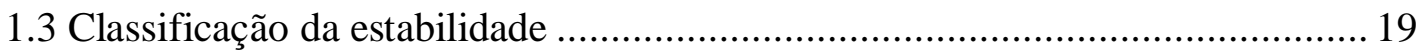

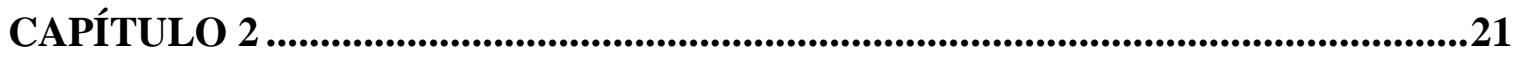

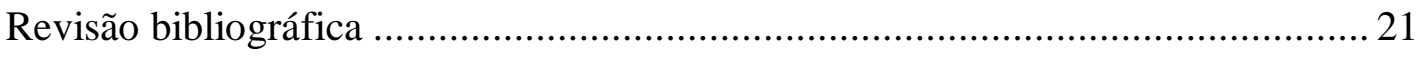

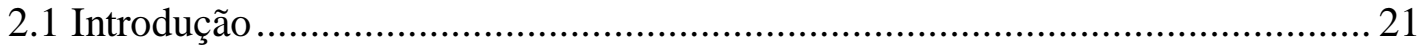

2.2 Análise de técnicas clássicas para o estudo de estabilidade de tensão............... 21

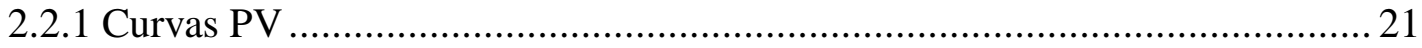

2.2.2 Curva VQ e método da reserva de potência reativa ................................... 26

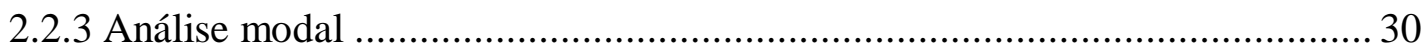

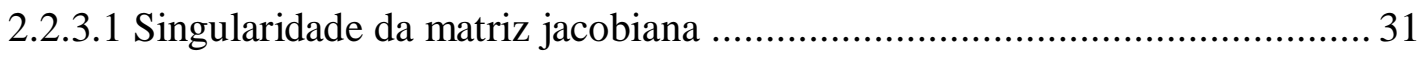

2.2.3.2 Fator de participação de barra ................................................................ 37

2.3 Revisão de técnicas para análise em tempo real da estabilidade de tensão ......... 38

2.4 Revisão de técnicas para análise em tempo real da estabilidade de tensão com suporte de Redes Neurais Artificiais

CAPÍTULO 3 45

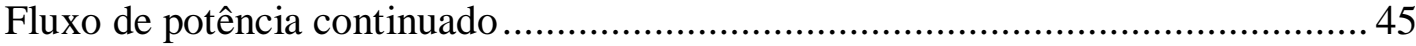

3.1 Método do fluxo de potência continuado.................................................... 45

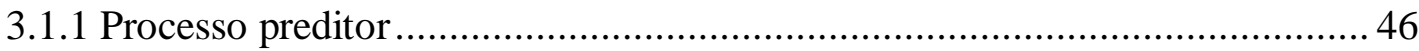

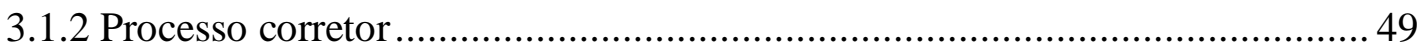

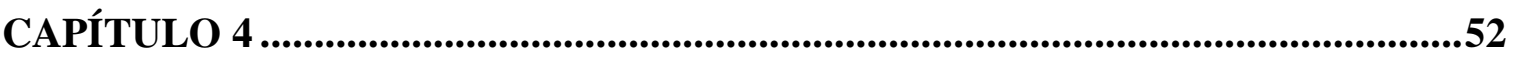

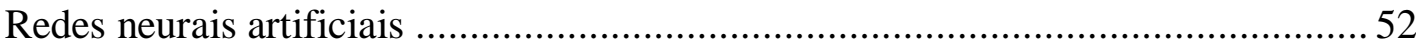

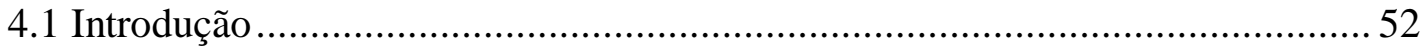

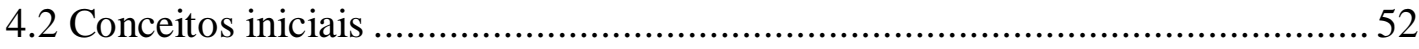

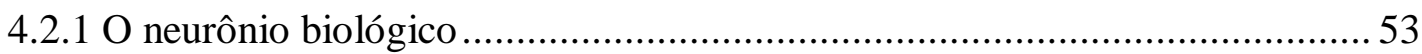




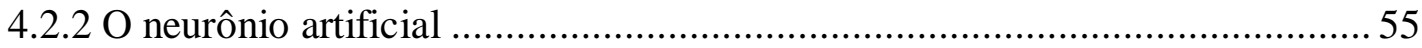

4.2.3 Tipos de funções de ativação ............................................................ 56

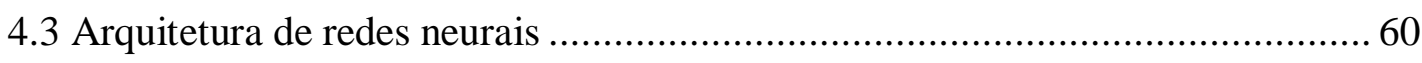

4.3.1 Redes feedforward de camada simples .................................................. 61

4.3.2 Redes feedforward de camadas múltiplas............................................... 62

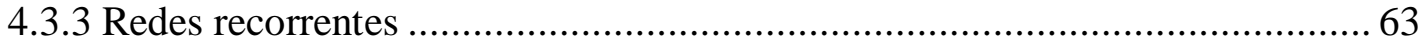

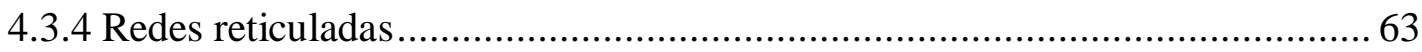

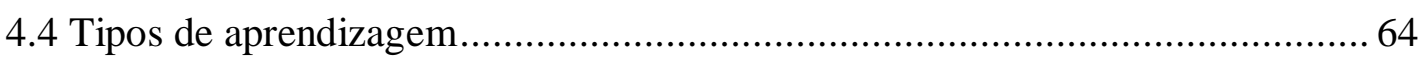

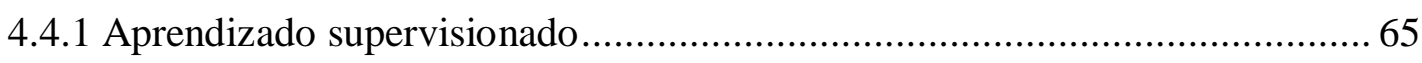

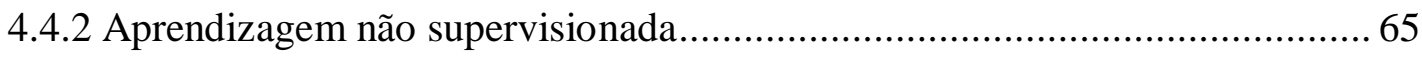

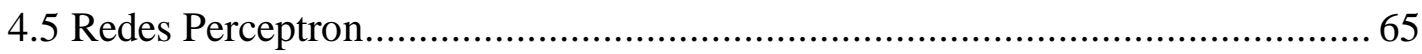

4.5.1 Principio de funcionamento do Perceptron............................................. 67

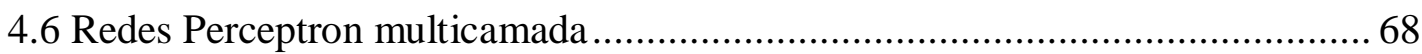

4.6.1 Algoritmos de aprendizagem supervisionada do PMC .............................. 69

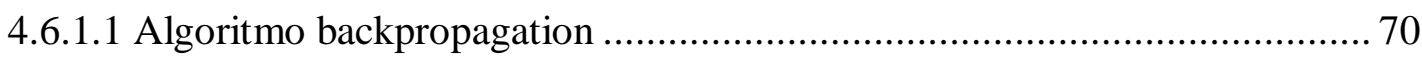

4.6.1.1.1 Fase de propagação adiante................................................................. 71

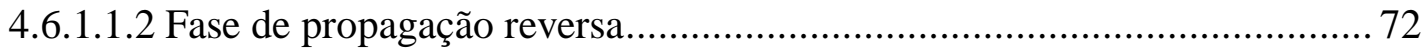

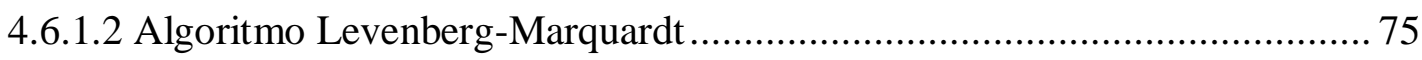

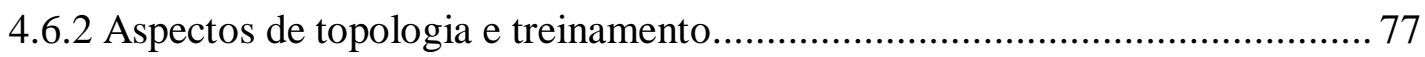

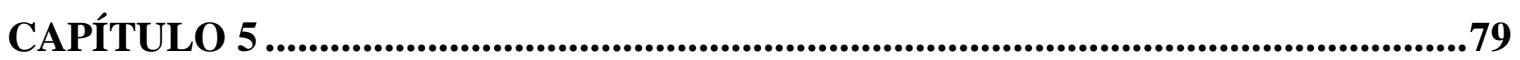

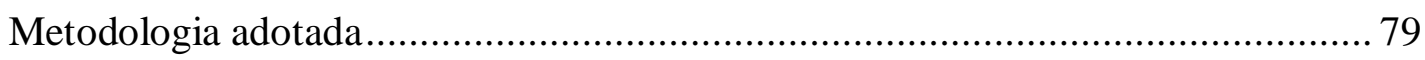

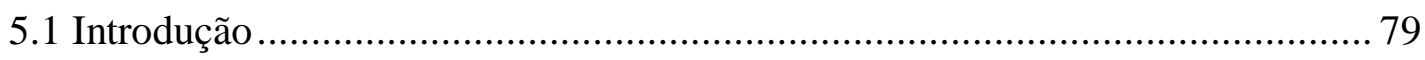

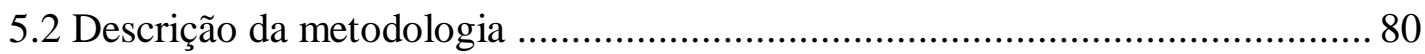

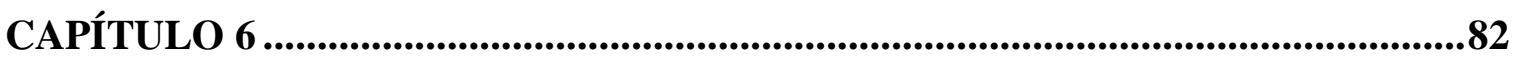

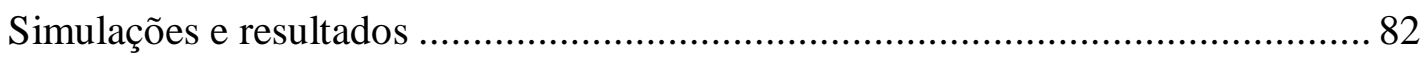

6.1 Cálculo do fluxo de carga para cada fator de carga ...................................... 82

6.2 Análise modal para determinação das barras críticas ..................................... 82

6.3 Dados de entrada para o treino da rede neural.............................................. 85

6.4 Potência reativa de reserva dos geradores .................................................... 85

6.5 Cálculo dos momentos de potência .............................................................. 86

6.6 Cálculo da contribuição individual de cada gerador .................................... 86

6.7 Cálculo da impedância equivalente de Thevenin entre duas barras.................. 89

6.8 Valores desejados de saídas ............................................................... 91 


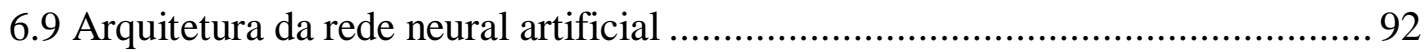

6.10 Resultados do treinamento da RNA ........................................................ 94

6.11 Sugestões para aplicação em centros de controle ......................................... 96

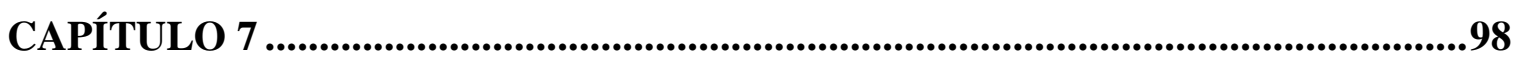

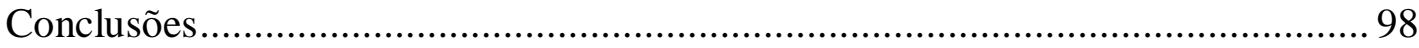

7.1 Perspectivas para trabalhos futuros ............................................................. 99

Referências bibliográficas.............................................................................100

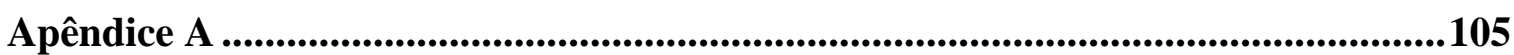

Diagrama sistema IEEE - 30 barras ............................................................. 105

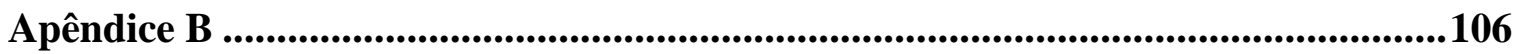

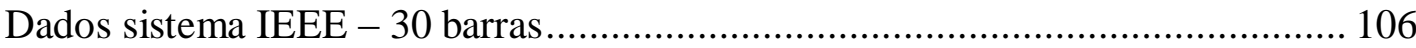




\section{CAPÍtULO 1}

\section{Introdução}

A estabilidade de tensão é um assunto de muita pesquisa e interesse devido ao risco de colapso que tem os sistemas de potência muito carregados.

Muitas concessionárias de energia elétrica são obrigadas a operar perto de seus limites de capacidade, devido à dificuldade de construção de uma nova linha de transmissão por causa das regulações ambientais e políticas, ou para reduzir seus custos operacionais e maximizar seus lucros, aumentando os riscos do colapso.

A perda de estabilidade de tensão tem sido o causador do colapso total de sistemas de potência na América do Norte, Brasil, Europa e Ásia.

Antigamente, a instabilidade de tensão era associada a sistemas fracos e linhas longas. $\mathrm{Na}$ atualidade, tem sido o causador do colapso em sistemas muito fortes devido ao fato de que esses sistemas serem carregados ao limite da sua capacidade de transmissão.

Tradicionalmente, o planejamento e expansão de sistemas de potência baseavam-se em monitorar a instabilidade eletromecânica do rotor e dos limites térmicos dos equipamentos.

Na década de oitenta, quando apareceu a discussão do impacto ambiental como central em todos os principais desenvolvimentos tecnológicos, os requerimentos legais para construção de novas linhas de transmissão e usinas geradoras ficaram mais difíceis e burocráticos. Somado ao fato da depressão econômica a nível mundial na década de oitenta, fez que muitas expansões necessárias de sistemas de potência fossem adiadas, o que obrigou as companhias elétricas a operar os sistemas no limite de carregamento, o que trouxe também problemas pouco pesquisados até então como a estabilidade de tensão.

A pesquisa na área procura, principalmente, um indicador preciso e confiável da proximidade do colapso e que possa ser usado para a operação segura do sistema em tempo real. 
Esses índices são utilizados nos centros de controle para tomada de decisões com o objetivo principalmente de evitar o colapso do sistema. O índice tem que ser confiável para não rejeitar desnecessariamente carga ou tomar ações impróprias.

$\mathrm{Na}$ tentativa de diminuir o esforço computacional, os pesquisadores vêm desenvolvendo novos métodos para o cálculo de índices on-line, já que o cálculo destes índices em tempo real com os métodos tradicionais precisa de cálculos periódicos, requerendo um alto esforço computacional que o torna uma ferramenta não adequada para monitoramento online.

\subsection{Metodologia e alcance do trabalho}

O trabalho primeiramente descreve o fenômeno da estabilidade de tensão e como ela poderia terminar no colapso total, logo será feita a classificação do fenômeno do ponto de vista da escala de tempo e das técnicas utilizadas para análise, e apresenta os métodos clássicos para estudar o fenômeno.

Apresenta-se uma revisão bibliográfica da evolução do estudo de estabilidade de tensão referente a monitoramento e índices para monitoramento em tempo real.

Aborda-se a evolução histórica do uso das redes neurais artificiais (RNA's) para problemas de estabilidade de tensão, os conceitos e definições básicas das RNA's serão apresentados.

É apresentada uma revisão do estado da arte para encontrar as técnicas mais modernas de utilização de RNA's no problema de estabilidade de tensão e será escolhida uma técnica para ser aplicada no presente estudo.

Para avaliar a metodologia escolhida é utilizado o sistema de 30-barras do IEEE. 


\section{$1.2 O$ fenômeno da estabilidade de tensão.}

Segundo a comissão IEEE/CIGRE o fenômeno da estabilidade de tensão se define como segue:

Um sistema de potência é considerado estável se os perfis de tensões forem mantidos dentro dos limites aceitáveis de operação para seu estado de equilíbrio, durante a operação do sistema ou depois de um distúrbio tal como a saída de um gerador, linha, curto circuito, etc. (IEEE/CIGRE, 2004).

Se os perfis de tensão estão fora dos limites aceitáveis de operação então o sistema é considerado instável.

O colapso de tensão é um caso extremo da instabilidade de tensão, e ocorre no ponto de bifurcação sela-nó da curva. Quando não se toma medidas necessárias para restituir as tensões e o sistema sofre um colapso total ou parcial.

É importante ressaltar que neste trabalho se estudará o tipo de bifurcação sela-nó, também chamada de bifurcação estática, que é basicamente onde ocorre o limite de carregamento que o sistema de potência pode suportar. Existe também o tipo de bifurcação de Hopf que é muito estudado em sistemas de potência e trata o problema do ponto de vista dinâmico que não está no escopo deste trabalho. Assim nesta dissertação, o término de ponto de bifurcação será entendido que é do tipo sela-nó.

A seguir é apresentado um exemplo de mecanismo clássico de instabilidade de tensão que leva ao colapso do sistema:

Considere na figura $1 \mathrm{um}$ sistema radial muito carregado (muito perto do ponto de máximo carregamento) contendo 3 tipos de cargas:

1. Carga residencial com controle de tensão e com fator de potência relativamente alto.

2. Carga industrial com controle de tensão e baixo fator de potência.

3. Carga industrial sem controle de tensão. 
Figura 1: Sistema radial com 3 tipos de carga.

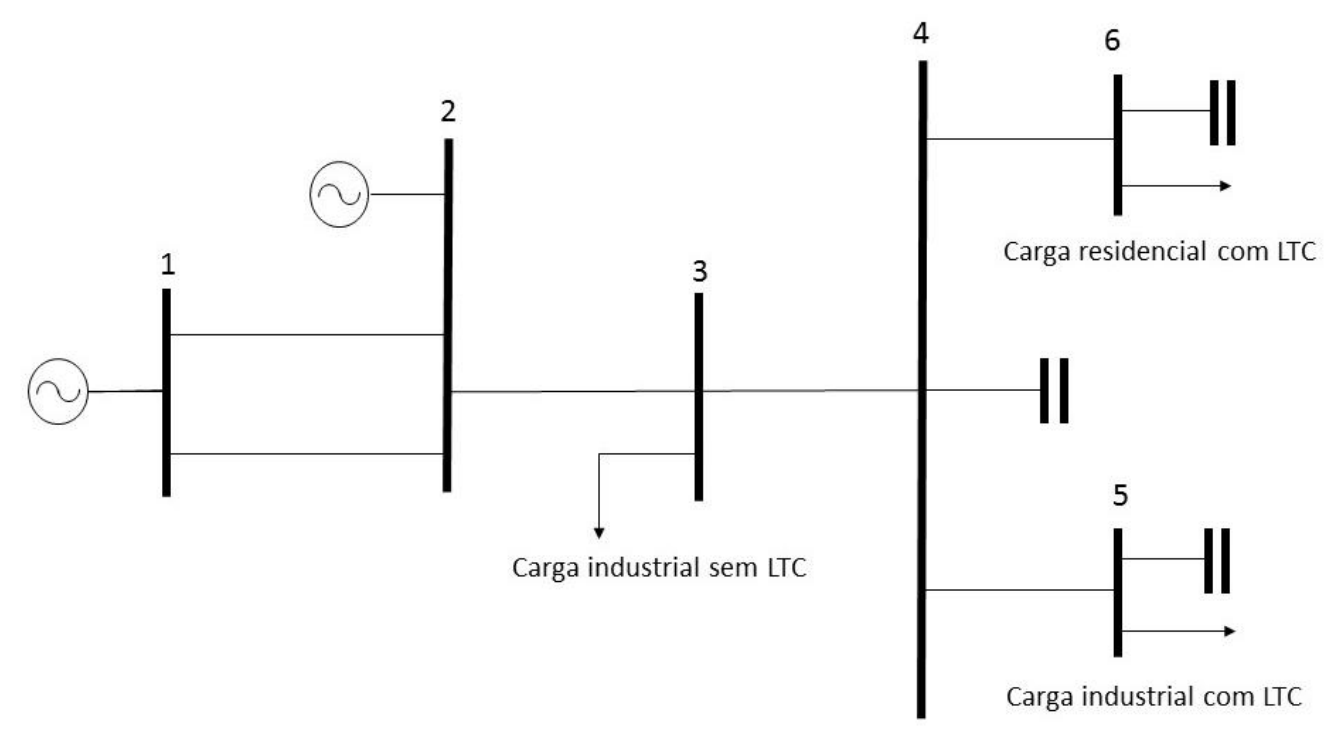

Fonte: Autor

Considerando que o sistema está muito carregado, um pequeno incremento da carga, seja potência ativa ou reativa, já pode gerar a perda de um gerador, ou uma linha pode levar o sistema ao ponto de máximo carregamento, ativar a instabilidade de tensão e levar ao colapso.

Quando alguma dessas alterações acontecer, a tensão nas cargas cairá levemente e os sistemas de controle começam a atuar.

A carga residencial diminuirá em relação à queda de tensão (considerando que parte da carga é tipo impedância constante) e a carga industrial diminuirá muito pouco, se mantendo quase constante.

Até aqui a tensão no primário dos transformadores é estabilizada a uma magnitude $\mathrm{x}$ menor que a tensão inicial.

O primeiro controle que atuará será os LTC's (Load tap changer), que são mecanismos de alteração de Tap sob carga, para voltar e estabilizar a tensão no secundário dos transformadores a valores próximos aos valores nominais.

Quando os LTC's normalizarem a tensão no secundário dos transformadores, a carga residencial crescerá de novo. 
O aumento de carga residencial é maior do que a perda de carga industrial. Devido a esse crescimento de carga, a corrente nas linhas também crescerá e a tensão no primário dos transformadores voltará a decrescer.

Em decorrência, a tensão no primário diminui e a corrente acrescenta às perdas reativas, as quais também crescem proporcionalmente ao quadrado da corrente e reatância da linha.

Para sistemas muito carregados, a linha torna-se um dreno de potência reativa e é necessário mais de um MVAr por unidade para cada MW adicional transportado. Como foi dito, isso é devido ao fato de que a perda reativa da linha cresce em uma relação não linear proporcional a $I^{2} X$. Por isso a disponibilidade de potência reativa é um aspecto chave na estabilidade de tensão.

A tensão no primário dos transformadores pode chegar ao limite mínimo para manter a tensão secundária ao valor nominal com Tap máximo.

A tensão na carga industrial sem controle de tensão cairá, podendo ocasionar bloqueio dos motores dessas indústrias. Se isso acontecer a corrente reativa aumentará e a tensão cairá ainda mais.

A tensão poderá cair até o ponto de desligar a carga dos motores. Quando a tensão crescer novamente, e os motores puderem ser ligados de novo, haverá uma alternância de queda e a recuperação de tensão.

A regulação automática de tensão (AVR) aumentará o reativo gerado até chegar ao limite de corrente de campo, podendo ter a perda de um gerador por limite de reativo, e um posterior colapso do sistema.

O fenômeno acima explicado pode demorar de vários segundos até minutos.

Pode se verificar que o fenômeno é muito ligado ao tipo de carga e a recuperação dela, pelo que, antigamente, o fenômeno se chamava estabilidade de carga. 


\subsection{Classificação da estabilidade}

A seguir apresenta-se a classificação da estabilidade de tensão no contexto geral de estabilidade de sistemas de potência. Na tabela1 mostram-se os tipos de estabilidade tomando dois critérios: o tempo do fenômeno e a causa principal do fenômeno (CUTSEM; VOURNAS, 1998).

Tabela 1: Classificação da estabilidade

\begin{tabular}{l|l|l}
\hline $\begin{array}{l}\text { Escala de } \\
\text { tempo }\end{array}$ & Causado pelo gerador & Causado pela carga \\
\hline De curto prazo & $\begin{array}{l}\text { Estabilidade do ângulo de } \\
\text { rotor }\end{array}$ & $\begin{array}{l}\text { Estabilidade de tensão } \\
\text { de curto prazo }\end{array}$ \\
\hline De longo prazo & Estabilidade de frequência & $\begin{array}{l}\text { Estabilidade de tensão } \\
\text { de longo prazo }\end{array}$ \\
\hline
\end{tabular}

Fonte: Autor

Embora exista estabilidade de rotor e de tensão na curta escala de tempo (short-term), o principal fenômeno de estudo nesta escala de tempo é a estabilidade do rotor. Assim também, na longa escala do tempo, o principal fenômeno é a estabilidade de tensão.

Porém, na estabilidade de tensão os fenômenos são estudados chamando-se "Dynamic voltage stability" para o fenômeno na curta escala de tempo e "long-term voltage stability" para o fenômeno na longa escala do tempo (VAN CUTSEM; VOURNAS, 1998).

O fenômeno explicado no ponto 1.2, pode levar ao colapso parcial ou total do sistema e, como foi dito, ocorre quando o sistema se encontra perto do ponto de bifurcação.

O objetivo neste trabalho é conhecer em tempo real (online) a distância até o ponto de bifurcação. Para isso são amplamente utilizadas, com bons resultados e eficácia, as ferramentas estáticas, tais como as ferramentas modificadas de fluxo de potência.

A análise estática para os estudos da estabilidade de tensão são uma boa ferramenta e ajudam a mostrar quanto estressado está o sistema e quão próximo se encontra da região de instabilidade. 
Neste ponto é muito importante esclarecer que embora se utilizem ferramentas estáticas, o fenômeno não é estático. O fenômeno é de natureza dinâmica lenta, por isso é chamado de long-term (VAN CUTSEM; VOURNAS, 1998).

Como as ferramentas estáticas são ideais para estudar o fenômeno na longa escala do tempo, aliás, são mais simples e utilizam pouco esforço computacional em relação às ferramentas dinâmicas, essas ferramentas serão o foco desta dissertação.

Apesar do fenômeno não ser estático, e que existe muito desenvolvimento de técnicas para o estudo dinâmico do fenômeno, as quais envolvem equações algébrico-diferenciais, alguns autores sugerem que as técnicas de estudo dinâmico do fenômeno não são adequadas para o uso no monitoramento online (CUTSEM; VOURNAS, 1998).

Para entender o problema da estabilidade de tensão desde o ponto de vista estático, serão apresentadas as curvas PV e VQ. 


\section{CAPÍTULO 2}

\section{Revisão bibliográfica}

\subsection{Introdução}

Nesta dissertação, as técnicas para avaliação em tempo real da estabilidade de tensão serão divididas em três partes:

- Análise de técnicas clássicas para o estudo de estabilidade de tensão.

- Revisão de técnicas para análise em tempo real da estabilidade de tensão.

- Revisão de técnicas para análise em tempo real da estabilidade de tensão com suporte de Redes Neurais Artificiais.

\subsection{Análise de técnicas clássicas para o estudo de estabilidade de tensão}

\subsubsection{Curvas PV}

Para explicar a curva PV (potência versus tensão) de um sistema de potência se estudará um sistema simples de 2 barras, como é mostrado na figura 2, a qual tem uma barra de geração e outra de carga.

Com este exercício poderemos compreender facilmente o conceito de ponto de bifurcação sela-nó, também chamado ponto máximo de carregamento, ou limite de estabilidade. 
Figura 2: Sistema de 2 barras

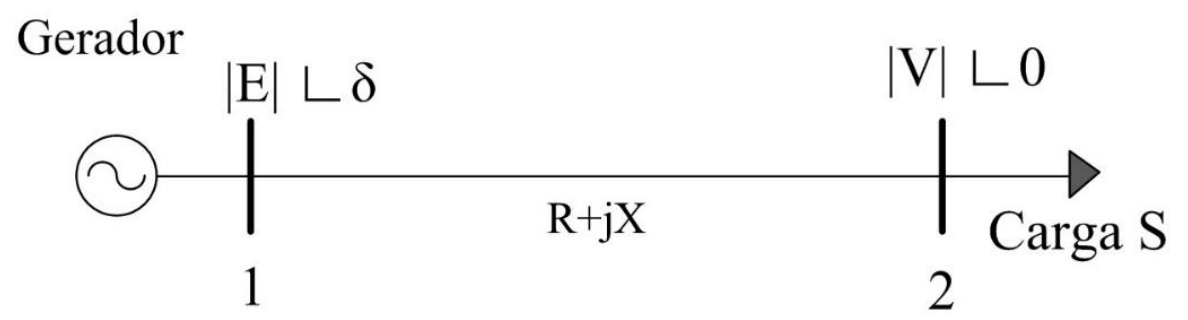

A potência complexa absorvida pela carga é:

$$
\begin{gathered}
S=P+j Q=V I^{*}=V \frac{E^{*}-V^{*}}{R-j X} \\
S=\frac{E V(R+j X)(\cos \delta-j \sin \delta)-V^{2}(R+j X)}{R^{2}+X^{2}}
\end{gathered}
$$

Que se pode decompor em potência ativa e reativa separando as partes reais e imaginária.

$$
\begin{aligned}
& P=\frac{E V}{R^{2}+X^{2}}(X \sin \delta+R \cos \delta)-V^{2} R \\
& Q=\frac{E V}{R^{2}+X^{2}}(X \cos \delta-R \sin \delta)-V^{2} X
\end{aligned}
$$

Elevando ao quadrado as equações 3 e 4 , somando-se sabendo que $\cos ^{2} \delta+\operatorname{sen}^{2} \delta=$ 1 e rearranjando temos:

$$
\left(V^{2}\right)^{2}+\left[2(R P+X Q)-E^{2}\right] V^{2}+\left(X^{2}+R^{2}\right)\left(P^{2}+Q^{2}\right)=0
$$

A qual é uma equação de quarto grau que pode ser tratada como uma equação quadrática fazendo:

$$
\begin{aligned}
& a=1 \\
& b=2(R P+X Q)-E^{2} \\
& c=\left(X^{2}+R^{2}\right)\left(P^{2}+Q^{2}\right)
\end{aligned}
$$

A equação de quarto grau para o delta positivo tem 4 soluções, duas positivas e duas negativas. 
Consideram-se apenas as soluções positivas como solução do problema, porque são as que tem interpretação com sentido físico:

$$
\begin{aligned}
& V_{1}=\sqrt{\frac{-b-\sqrt{b^{2}-4 a c}}{2 a}} \\
& V_{2}=\sqrt{\frac{-b+\sqrt{b^{2}-4 a c}}{2 a}}
\end{aligned}
$$

Portanto, para uma determinada carga existem duas possíveis tensões como solução do problema, uma com alta tensão correspondente ao valor $V_{1}$ da equação (6) e outra de baixa tensão correspondente ao valor $V_{2}$ da equação (7). $O$ valor da corrente é baixo para a solução de alta tensão e alto para a solução de baixa tensão.

Na figura 3 é mostrada a curva PV onde podem ser apreciadas as duas soluções, a parte superior da curva é a parte estável do sistema e a parte inferior da curva é a parte instável.

Um sistema de $\mathrm{N}$ barras é instável se pelo menos uma barra passa a região de instabilidade (KUNDUR, 1994).

Quando $b^{2}=4 a c$ o valor de delta é apenas $-b$ para as equações (6) e (7), ou seja, quando isso ocorre há apenas uma solução de tensão, essa tensão é chamada tensão crítica e ocorre no ponto de bifurcação sela-nó da curva.

A situação de $b^{2}=4 a c$ ocorre apenas para um valor de carga $\mathrm{P}$ e Q que é o limite de carregamento.

Para fazer um exemplo do gráfico da tensão na barra de carga em função da potência ativa (sem limite de potência ativa e reativa do gerador) tem-se os seguintes dados:

$$
\begin{aligned}
& E=1,0112[p . u .] \text { (Tensão na barra geradora) } \\
& Z=0,05+j 0,01[\text { p.u. }] \text { (Impedância da linha) }
\end{aligned}
$$


Na figura 3 é mostrada a curva PV do sistema de duas barras descrito acima para 3 fatores de potência: $0.85,1$ e 0.9 capacitivo (sobre compensado).

Como pode se observar na figura 3, o sistema descrito de 2 barras com fator de potência $\mathrm{FP}=1$ tem um limite de potência ativa a ser retirada da barra 2 com valor de 838,27 MW.

O valor da tensão na barra 2 para essa carga retirada tem um valor de 0,6538 p.u. Esse limite é chamado ponto de bifurcação, ou ponto de máximo carregamento. Nesse ponto limite, o sistema entra em colapso. Para uma situação real em que o gerador tem limite de potência reativa, a tensão no ponto de bifurcação tem valores mais próximos ao valor nominal, mas por simplicidade não é o caso neste exemplo.

Na medida em que o fator de potência diminui, o ponto de bifurcação aparece para um carregamento menor, como pode se observar na figura 3 , a curva pertencente a carga com fator de potência $\mathrm{FP}=0.85$, tem o ponto de bifurcação quando a potência ativa é igual a 507 MW.

Quando o sistema é sobre compensado, o ponto de bifurcação aparece para um carregamento maior, mas esse ponto de bifurcação ocorre com uma tensão muito perto da nominal, podendo parecer uma queda de tensão normal, como pode se observar na figura 3 , a curva pertencente a carga com fator de potência $\mathrm{FP}=0.9$ sobre compensada, onde o ponto de bifurcação aparece com um valor de potência ativa de 1205 MW, correspondente a uma tensão de 0,826 p.u.

A figura 3 tambem mostra que todo fluxo de carga tem duas soluções: uma com tensão alta e baixa corrente que é o estado estável (linha azul) e outra com baixa tensão e corrente alta que representa a regiao instável (linha vermelha). 
Figura 3: Curva PV sistema de 2 barras, $\mathrm{FP}=1$

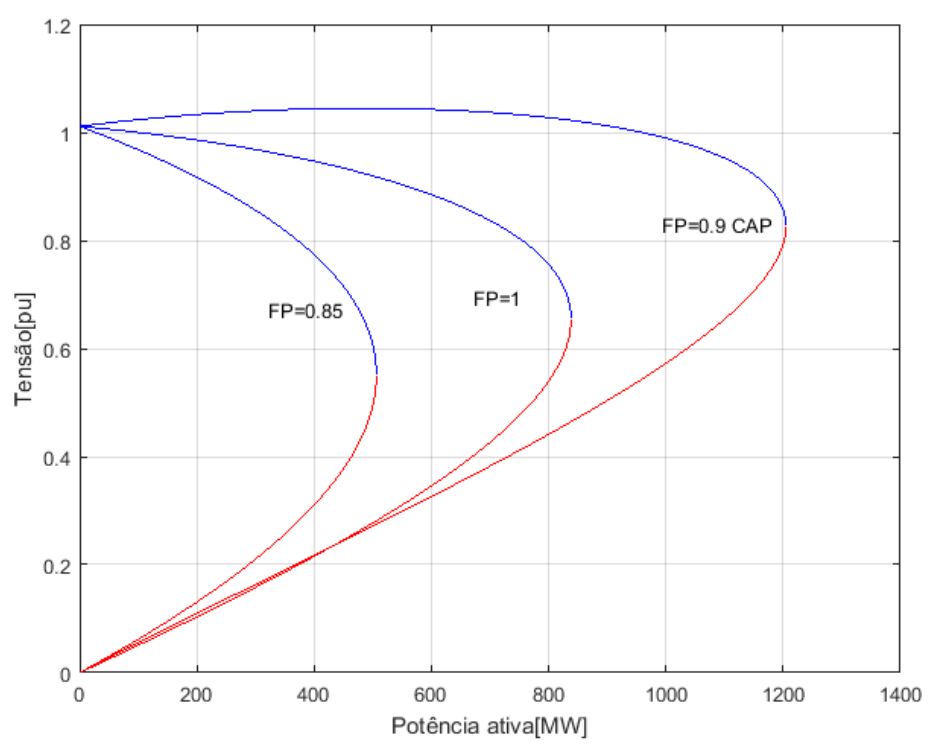

Fonte: Autor

Pode-se fazer as seguintes observações com relação a curva PV (CUTSEM, COSTAS, 1998).

- Pode-se ver que para cargas sobre compensadas $(\tan \theta<0)$ a tensão aumenta com a potência consumida.

- Operando num ponto qualquer na parte superior da curva, um aumento na carga traz o sistema mais perto do ponto de bifurcação. Pelo contrário operando na parte inferior um aumento na carga faz o sistema instável. A instabilidade não só pode ser causada pelo aumento de carga, também pode ser causada por uma combinação de outros fatores tais como a atuação dos LTC, controle de tensão dos geradores, sensibilidade da carga em relação à tensão, etc.

- Em um sistema que tenha muitas barras, cada barra tem sua curva PV, e basta que só uma barra chegue ao ponto de bifurcação para que todo o sistema conectado seja instável.

- O método mostra a margem do sistema antes de chegar ao ponto de máximo carregamento.

- Para sistemas radiais, a tensão na barra crítica é monitorada em relação às mudanças na potência ativa da carga. 
- Para sistemas malhados, é possível representar o sistema em uma única curva PV, sendo $P$ a potência ativa da área e $V$ a tensão na barra mais crítica ou representativa.

- Na prática é possível encontrar o equivalente de Thevenin para qualquer sistema em relação a barra em consideração. Mas deve-se ter em conta que para cada mudança da carga a condição de geração é alterada, assim também para cada alteração na topologia da rede. Isto pode afetar na precisão do método.

- O método funciona bem para sistemas de barramento infinito e cenários de carga isolados.

Conclui-se que as curvas PV revelam qual a margem de estabilidade de tensão, mas não indicam o tipo de medida preventiva que resultaria numa melhoria das margens do sistema.

\subsubsection{Curva VQ e método da reserva de potência reativa}

O método da curva VQ é um dos mais utilizados para o estudo da instabilidade de tensão. A tensão da barra em estudo ou da barra crítica é calculada em relação à potência reativa dessa barra. Um gerador fictício é conectado na barra em estudo com potência ativa nula e sem limite de potência reativa (compensador síncrono). Um programa de fluxo de carga é usado para fazer o cálculo e a barra em questão é tratada como barra de geração (CUTSEM; COSTAS, 1998).

É fixada uma gama de tensões para a barra e o programa calcula a potência reativa do gerador síncrono que é necessária para ter essa tensão.

A partir desse cálculo pode-se obter o gráfico da potência reativa em função da tensão fixada pelo gerador. Neste caso como o cálculo e feito a partir da tensão fixada pelo gerador, ela vai ser tratada como a variável independente (eixo X) e a potência reativa como a variável dependente (eixo Y) ao contrário do que se tinha com a curva PV. 
Dessa maneira, pode-se calcular a margem de seguridade da barra em função da tensão e a potência reativa de reserva na barra. A margem de segurança é a distância entre a potência reativa real operando a uma determinada tensão e a potência reativa do nariz da curva, que é o limite da operação com tensão alta e corrente baixa.

O lado direito da curva é a região de estabilidade, análogo ao que se tinha na curva PV.

Na figura 4 é mostrada a curva VQ do mesmo sistema de duas barras utilizado para explicar a curva PV.

Figura 4: Curvas VQ, sistema de duas barras

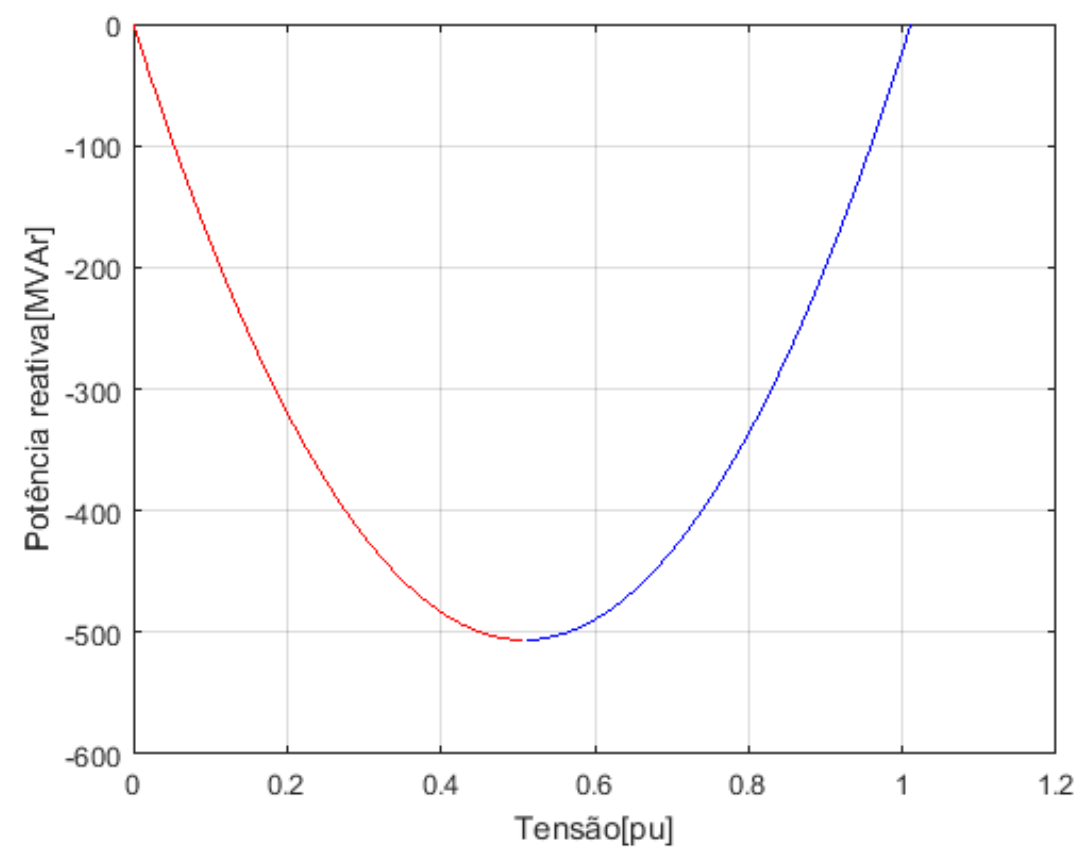

Fonte: Autor

Para ter a curva VQ do exemplo de duas barras (figura 4), um valor de potência ativa primeiro (zero para o exemplo) é calculado o ângulo $\delta$ para cada valor de $\mathrm{V}$ a partir da equação 3 e, logo com esses valores de $\delta$ é calculado Q com a equação 4 e assim é obtida a curva VQ. 
Neste exemplo, a potência reativa é apenas a variável que muda deixando a potência ativa em zero, sendo a potência limite do sistema para este caso particular de 506 MVAr e a tensão limite de 0.51 p.u.

Na figura 5, são apresentadas 3 curvas VQ que são de uma barra com diferentes carregamentos de potência ativa.

Figura 5: Curvas VQ de barras com diferente carregamento

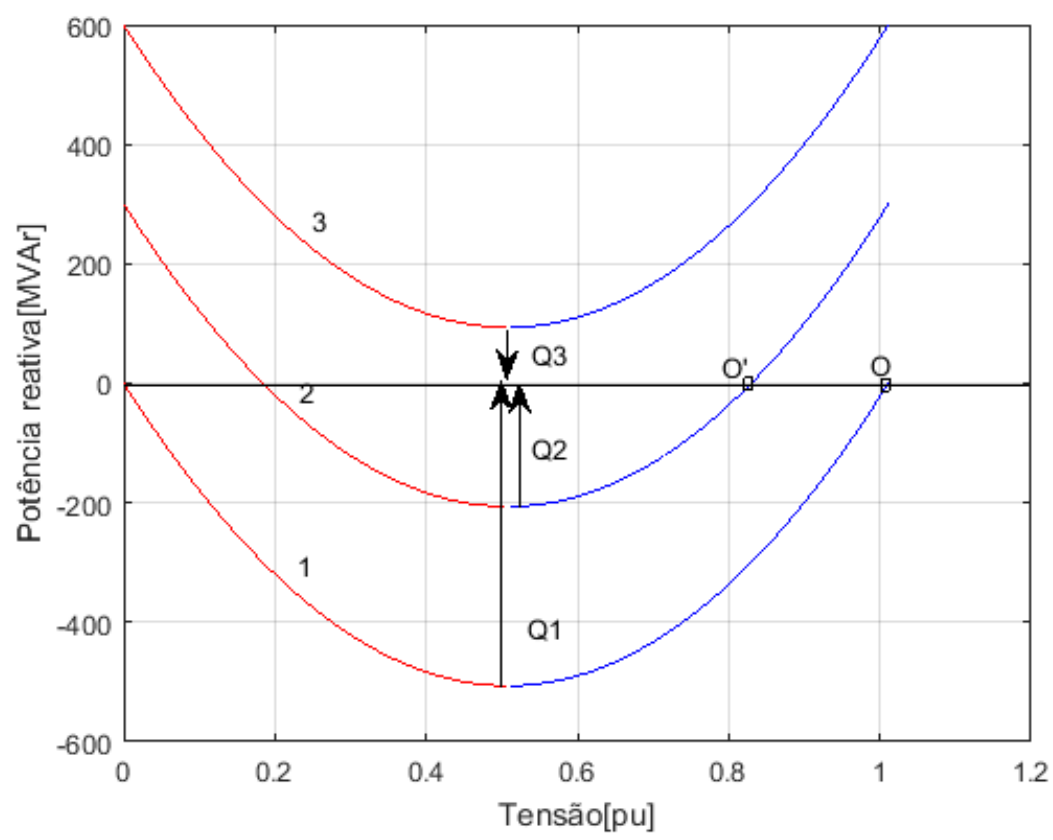

Fonte: Autor

A curva 1 representa uma barra não muito carregada, ou seja, com potência ativa pequena. Pode-se ver que tem muita margem de seguridade já que o valor Q1 é alto. O valor Q1 representa a potência reativa incrementada na carga (ou a diminuição de reativo do gerador) necessária para que a tensão alcance o mínimo valor de estabilidade (ponto de bifurcação).

A curva 2 é a curva da mesma barra mais carregada (valor de potência ativa mais alto), pode se ver que há pouca margem de seguridade já que o valor de Q2 é baixo. Um incremento de potência reativa na barra 2, equivalente ao valor Q2 pode causar a instabilidade de tensão.

Os valores $\mathrm{O}$ e O' das curvas 1 e 2 respetivamente representam o ponto de operação normal onde não se tem nenhum tipo de compensação. 
A curva 3 é a barra com valor de potência ativa muito alta, quase ao limite, já que não pode operar sem compensação e o valor Q3 é negativo e representa o valor mínimo de compensação para que a barra opere na região de estabilidade.

A continuação é apresentado o comportamento de uma única barra com compensação shunt.

Na figura 6 mostra-se a curva QV de uma barra com compensação shunt.

Figura 6: Curva VQ de uma barra com compensação shunt

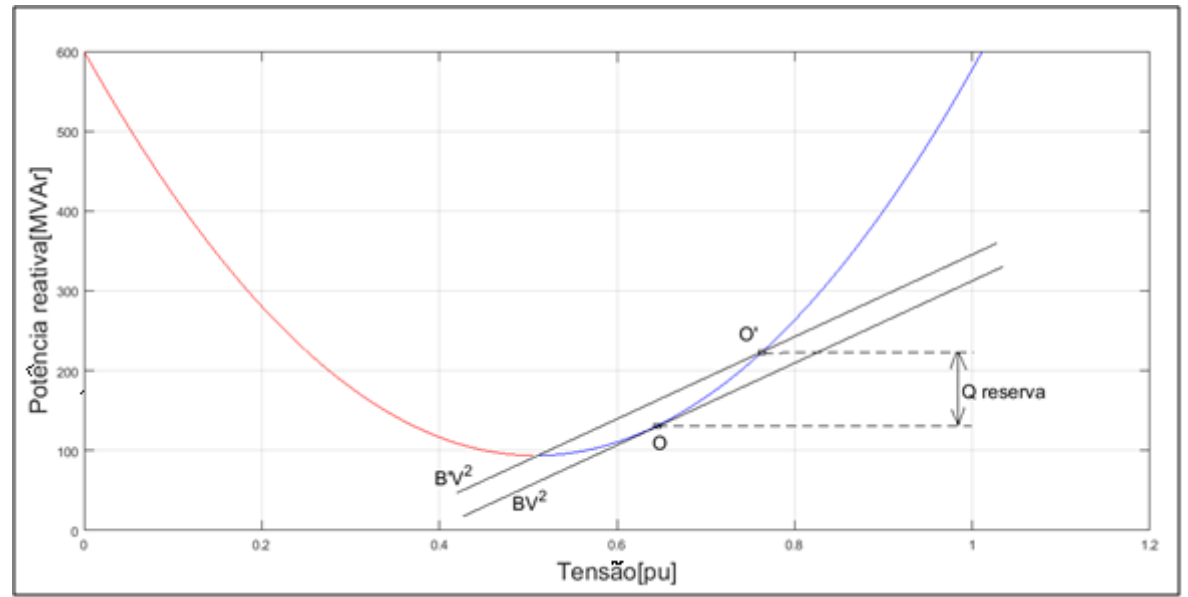

Fonte: Autor

O valor do reativo do capacitor shunt é variável com a tensão e tem um valor de $B V^{2}$. No gráfico a curva $B V^{2}$ é uma parábola tangente a curva $\mathrm{QV}$ no ponto $\mathrm{O}$, que é o ponto de operação com valor mínimo de compensação para que a barra seja estável (CUTSEM, COSTAS, 1998).

Para valores de tensão abaixo do ponto de operação $\mathrm{O}$, o capacitor shunt não fornece o valor requerido pela barra, o que o torna instável.

A parábola $B^{\prime} V^{2}$ representa o valor da compensação para ter a tensão desejada no ponto de operação O’. No gráfico pode se ver a reserva de reativo Q quando a barra opera no ponto O. É bom esclarecer que neste caso de compensação shunt a reserva não é calculada em relação ao ponto do nariz da curva $(d v / d q=0)$, e sim com relação ao ponto onde a parábola do compensador é tangente a curva VQ (ponto O) pelo que já foi explicado. 
Pode-se fazer as seguintes observações com relação a curva VQ: (VAN CUTSEM; COSTAS, 1998).

- Para um sistema de potência de n barras, a potência reativa de reserva da curva VQ, não representa a reserva reativa para o aumento de carga natural do sistema, devido ao fato de que a curva VQ de uma barra é calculada variando a potência reativa dessa única barra, o que não corresponde a um padrão de carregamento real de carga do sistema, porque na operação real enquanto aumenta o reativo de carga de uma barra, o reativo das outras barras também aumenta.

- A reserva de potência reativa da curva VQ, indica a disponibilidade ou a necessidade de reativo pontual na barra (Capacitor, SVC, condensador síncrono, etc.).

- A curva VQ indica se uma barra é reativo deficiente e ajuda a calcular o reativo mínimo necessário na barra para estabilizar o sistema.

Devido a que o problema da estabilidade está ligado à relação da sensibilidade V-Q, a curva VQ pode fornecer informação útil no sentido de índice de margem de estabilidade para ajudar a tomar ações corretivas nas barras mais críticas.

\subsubsection{Análise modal}

Quando é preciso fazer cálculo de autovalores e autovetores de uma matriz é muito comum falar do termo "análise modal", o qual deriva inicialmente do problema de autovalores no estudo de propriedades dinâmicas sob vibrações, ou seja, o estudo de modos de resposta no domínio da frequência.

Neste estudo, a análise modal é referida ao cálculo de autovalores e autovetores da matriz jacobiana calculada no fluxo de potência pelo método Newton - Raphson, a qual proporciona informação muito útil no sentido de quão perto um sistema se encontra do ponto de máximo carregamento, e quais barras são as que mais contribuem a que o sistema esteja perto do dito ponto. 


\subsubsection{Singularidade da matriz jacobiana}

Como já foi dito anteriormente, os métodos estáticos são uma ferramenta eficiente para o estudo de estabilidade. Neste sentido o fluxo de carga é a ferramenta mais utilizada para esse tipo de análise, e um dos métodos mais eficientes para o cálculo de fluxo de carga é o método de Newton-Raphson.

O problema do fluxo de carga consta de um sistema de equações não lineares, o que o torna impraticável para ser tratado por métodos analíticos, sendo resolvido por métodos iterativos.

O método de Newthon-Raphson e os métodos desacoplados são os mais eficientes para este tipo de problemas.

A seguir é explicado, brevemente, o método de resolução do fluxo de carga pelo método Newton-Raphson para que o leitor se familiarize com a matriz Jacobiana.

Num problema de fluxo de carga se tem as seguintes equações não lineares, deduzidas pela aplicação das leis de Kirchhoff (MONTICELLI, 1983) resultando:

$$
\begin{aligned}
& P_{k}=V_{k} \sum_{m \in k} V_{m}\left(G_{k m} \cos \theta_{k m}+B_{k m} \sin \theta_{k m}\right) \\
& Q_{k}=V_{k} \sum_{m \in k} V_{m}\left(G_{k m} \sin \theta_{k m}-B_{k m} \cos \theta_{k m}\right)
\end{aligned}
$$

onde:

$k$ : barra do equacionamento.

$m$ : conjunto de barras que estão ligadas a barra $k$ por meio de uma linha ou transformador.

$Y_{k m}=G_{k m}+j B_{k m}:$ Elemento km da matriz de admitância nodal do sistema.

$V$ : Módulo da tensão

$\theta_{k m}=\theta_{k}-\theta_{m}$ : Diferença angular das tensões na barra $k \mathrm{e} \mathrm{m}$. 
$P_{k}, Q_{k}$ : Potência ativa e reativa liquida na barra $k$ (Diferença entre o gerado e o consumido).

Existem 3 tipos de barras:

Barra Slack: A magnitude da tensão e ângulo da tensão são conhecidas, não tem incógnitas na resolução do processo iterativo.

Barra de geração ou barra PV: A potência ativa e a magnitude de tensão são conhecidas, o ângulo $\theta$ é a incógnita na resolução do processo iterativo.

Barra de carga ou barra PQ: A potência ativa e reativa são conhecidas, o ângulo $\theta$ e o modulo $V$ são incógnitas na resolução do processo iterativo.

Então, em linhas gerais o objetivo é encontrar $V$ e $\theta$ de maneira iterativa dando inicialmente um valor inicial a essas variáveis com o objetivo de que se cumpram as seguintes equações com uma margem mínima de erro $e \approx 0$ (MONTICELLI, 1983).

Para barras PQ e PV:

$$
\Delta P=P_{k e s p}-V_{k} \sum_{m \in k} V_{m}\left(G_{k m} \cos \theta_{k m}+B_{k m} \sin \theta_{k m}\right)=0
$$

Para barras PQ:

$$
\Delta Q=Q_{k e s p}-V_{k} \sum_{m \in k} V_{m}\left(G_{k m} \sin \theta_{k m}-B_{k m} \cos \theta_{k m}\right)=0
$$

onde:

$$
\begin{gathered}
P_{\text {kesp }}=P_{\text {Gerado }}-P_{\text {Consumido }} \\
Q_{\text {kesp }}=Q_{\text {Gerado }}-Q_{\text {Consumido }}
\end{gathered}
$$

O número de barras e o tipo PV ou PQ vão determinar o número de equações não lineares sendo o total de equações igual a $2 N P Q+N P V$. 
O sistema de equações não lineares pode ser representado por equações matriciais que são resolvidas pelo método Newthon-Raphson, que é o mais utilizado para resolver sistemas não lineares.

Basicamente o método lineariza a equação num ponto de partida utilizando o teorema de Taylor: se utilizam valores de partida aproximados para as incógnitas $V$ e $\theta$ (geralmente 1 p.u. e 0 graus) e o resultado nesse ponto é utilizado para a seguinte iteração, e assim sucessivamente até chegar ao erro desejado.

O sistema de resolução fica da seguinte forma:

$$
\left[\begin{array}{l}
\Delta P \\
\Delta Q
\end{array}\right]=\left[\begin{array}{ll}
\partial P / \partial \theta & \partial P / \partial V \\
\partial Q / \partial \theta & \partial Q / \partial V
\end{array}\right]\left[\begin{array}{l}
\Delta \theta \\
\Delta V
\end{array}\right]
$$

Onde a matriz com as derivadas parciais é chamada matriz jacobiana e é representada pelo símbolo $\boldsymbol{J}$.

Os valores $V$ e $\theta$ são obtidos somando $\Delta V$ e $\Delta \theta$, respetivamente em cada iteração, a partir dos valores inicias até que os valores $\Delta P$ e $\Delta Q$ cheguem ao valor de erro desejado. Como pode se ver para o cálculo dos valores $\Delta V$ e $\Delta \theta$ a matriz jacobiana $\boldsymbol{J}$ precisa ser invertida a cada iteração.

Até aqui, trata-se da teoria da análise de fluxo de carga. A seguir, será apresentada a matriz jacobiana como ferramenta na análise de estabilidade de tensão.

Como já foi observado na curva PV, à medida que o carregamento do sistema aumenta, a tensão vai diminuindo até chegar a um ponto chamado de limite de estabilidade ou nariz da curva (Fig.5). Nesse sentido a teoria da bifurcação nos sistemas não lineares é de muita importância, já que ela apresenta um aspecto peculiar dos sistemas não lineares: uma mudança abrupta surgindo de um comportamento suave. Nos sistemas de potência, esse tipo de bifurcação é chamado de sela-nó (saddle node), que é justamente o nariz da curva. A matriz jacobiana vai se tornando mais difícil de inverter na medida que vai chegando ao ponto sela-nó, e quando chega a esse ponto a jacobiana é singular e o fluxo não tem solução (KUNDUR, 1994). 
Uma matriz é singular se, e somente se, 0 é um autovalor da matriz. Nesse sentido, a análise modal da matriz jacobiana é a principal ferramenta para saber se a matriz é singular, e para saber se ela está perto da singularidade. Em outras palavras, a análise modal pode mostrar a margem de estabilidade do sistema.

Baseados na análise modal, vários autores vêm propondo índices em função dessa análise.

Nos anos 70, muitos pesquisadores tinham notado a relação entre a singularidade (não invertível) da matriz jacobiana e a instabilidade.

Na revisão bibliográfica é comentada a proposta de Tiranuchit e Thomas (1988) que propuseram um índice que relaciona a proximidade da instabilidade baseado no mínimo valor singular da matriz jacobiana e a proposta de Lof et al. (1993) que propuseram um índice similar, fazendo a análise modal na matriz jacobiana reduzida, que relaciona a tensão diretamente com a potência reativa.

Foi demostrado que o último índice é mais eficiente, então a análise modal de aqui em diante será feita para a matriz jacobiana reduzida que é calculada a seguir.

Para o cálculo da matriz jacobiana reduzida e a sensibilidade $\Delta \mathrm{V}-\Delta Q$ é considerado $\Delta P=0$. Então, a partir de (12):

$$
\begin{gathered}
\frac{\partial P}{\partial \theta} \Delta \theta+\frac{\partial P}{\partial V} \Delta V=0 \quad \text { ou: } \\
\Delta \theta=-\left(\frac{\partial P}{\partial \theta}\right)^{-1} \frac{\partial P}{\partial V} \Delta V
\end{gathered}
$$

Da segunda equação em (12):

$$
\Delta Q=\frac{\partial Q}{\partial \theta} \Delta \theta+\frac{\partial Q}{\partial V} \Delta V
$$

Substituindo (13) em (14): 


$$
\begin{gathered}
\Delta Q=-\frac{\partial Q}{\partial \theta}\left(\frac{\partial P}{\partial \theta}\right)^{-1} \frac{\partial P}{\partial V} \Delta V+\frac{\partial Q}{\partial V} \Delta V \\
J_{R}=\frac{\partial Q}{\partial V}-\frac{\partial Q}{\partial \theta}\left(\frac{\partial P}{\partial \theta}\right)^{-1} \frac{\partial P}{\partial V}
\end{gathered}
$$

Onde $J_{R}$ é chamada matriz jacobiana reduzida.

Então:

$$
\Delta Q=J_{R} \Delta V
$$

Ou:

$$
\Delta V=J_{R}^{-1} \Delta Q
$$

Calculando os autovalores da matriz $J_{R}$ :

$$
\Delta V=(Y \Lambda X)^{-1} \Delta Q=\left(X \Lambda^{-1} Y\right) \Delta Q \quad \text { (Do conceito } Y=X^{-1} \text { ) }
$$

Multiplicando ambas partes da equação por $Y$

$$
Y \Delta V=\left(Y X \Lambda^{-1} Y\right) \Delta Q
$$

Então:

$$
v_{m}=\Lambda^{-1} q_{m}
$$

Onde:

$v_{m}=$ Vetor modal da variação de tensão

$q_{m}=$ Vetor modal da variação de potência reativa

$\Lambda=$ Matriz diagonal de autovalores

$Y=$ Autovetor esquerdo da matriz $J_{R}$ 
$X=$ Autovetor direito da matriz $J_{R}$

Para cada barra:

$$
v_{m i}=\lambda^{-1} q_{m i} \quad \forall i=1,2,3 \ldots \ldots N B
$$

Para qualquer $\lambda_{i}>0$ significa que $v_{m i}$ e $q_{m i}$ estão na mesma direção e o sistema é estável.

Se $\lambda_{i}<0$, o sistema é instável. Se $\lambda_{i}=0$, o sistema não tem solução já que o inverso do autovalor tende ao infinito.

Portanto, a parte real de todos os autovalores do sistema tem que ter valor positivo para que o sistema seja estável (KUNDUR, 1994).

Para o leitor que está familiarizado com cálculo de autovalores, não se deve confundir com o cálculo de autovalores num sistema dinâmico, por exemplo: um espaço de estados onde a estabilidade requer valor negativo da parte real dos autovalores. Neste caso está-se analisando um sistema estático.

Nesse sentido, o autovalor com menor valor indica uma medida de "distância" à proximidade do ponto sela-nó, que é o limite de estabilidade.

Nos cálculos de máxima transferência é analisado o valor do carregamento do sistema antes que o menor autovalor atinja o valor zero.

A decomposição de valores singulares da matriz jacobiana, é também, uma análise modal que é mais usado na literatura moderna, apresentando este último um melhor desempenho.

Ambos valores (autovalores e valores singulares) estão relacionados: trazem a mesma informação e ambos são zero quando a matriz cai na singularidade.

A decomposição por valores singulares de uma matriz é um método de decomposição ortogonal. Seja a matriz $J_{R}$, real, quadrada, de dimensão $\mathrm{n} \times \mathrm{n}$, a decomposição por valores singulares é expressa como: 


$$
J_{R}=U \Sigma V^{T}
$$

Onde $U$ e $V$ são matrizes ortonormais de dimensão $n \times n$, e $\sum$ é uma matriz diagonal com os valores singulares $(\sigma)$ de $J_{R}$

Os valores singulares $(\sigma)$ da matriz diagonal $\sum$ indicam a proximidade do ponto de colapso, pelo qual, as barras com os menores valores singulares são as mais fracas, e que podem levar o sistema a instabilidade.

\subsubsection{Fator de participação de barra}

A participação relativa da barra $\mathrm{k}$ no modo $\lambda_{i}$ é dado pelo fator de participação de barra:

$$
P_{k i}=X_{k i} Y_{i k}
$$

Onde:

$$
\begin{gathered}
X_{k i} \text { é o elemento } i \text { da coluna } k \text { que é o autovetor da direita. } \\
Y_{i k} \text { é o elemento } i \text { da linha } k \text { que é o autovetor da esquerda. }
\end{gathered}
$$

O fator de participação determina a contribuição de cada barra com o modo $\lambda_{i}$. Por isso, o fator determina a área relacionada com cada modo, que é a área com as barras que tem maior fator de participação.

A soma de todos os fatores de cada barra é igual a unidade, pois os autovetores são normalizados.

O tamanho do fator de participação de um determinado modo determina a efetividade das ações corretivas na barra para estabilizar o modo (KUNDUR, 1994).

Existem dois tipos de modos. O primeiro com só umas poucas barras com fatores de participação elevados e o resto com fatores quase nulos, o que significa que o problema é localizado. (KUNDUR, 1994) 
O segundo modo é quando quase todas as barras têm participação similar, o que significa que o problema não é localizado, que é típico de um sistema muito carregado com o suplemento de reativo quase se esgotando.

O cálculo de todos os autovalores de um sistema com várias centenas de barras não é prático, e resulta num consumo de computação desnecessário. Normalmente, só é necessário o cálculo de 5 a 10 mínimos autovalores para identificar as barras mais críticas (KUNDUR, 1994).

Neste trabalho apenas os 5 mínimos autovalores são computados, e são calculadas as barras que tem os maiores fatores de participação desses 5 modos.

\subsection{Revisão de técnicas para análise em tempo real da estabilidade de tensão}

Tiranuchit e Thomas (1988) propuseram a avaliação da estabilidade baseado no mínimo valor singular da matriz jacobiana para determinar a proximidade de colapso de tensão. Além disso, é proposto um algoritmo para determinar uma nova localização dos geradores para uma operação ótima com relação ao mínimo valor singular.

Ajjarapu e Christy (1992) apresentaram a técnica da continuação para o cálculo da curva PV, encontrando o ponto de bifurcação sem que a matriz jacobiana seja singular. $\mathrm{O}$ processo consta de um passo preditor que é um vetor tangente, e um passo corretor que corrige o ponto preditor, a parametrização proposta elimina a singularidade da matriz jacobiana. O método basicamente resolve fluxos de potência progressivos pelo que consume bastante tempo e esforço computacional. Por ser denominado o método exato, esta técnica será apresentada no capítulo 3.

Lof et al. (1993) propuseram a avaliação da estabilidade baseado no mínimo valor singular da matriz jacobiana reduzida que relaciona diretamente a tensão com a potência reativa. A técnica praticamente é baseada no trabalho de Tiranuchit e Thomas com a diferença da modificação da matriz jacobiana. 
Overbye (1993) propôs o método energético para determinar a proximidade do colapso. O método é baseado na função de energia que utiliza as soluções de fluxo de potência com alta tensão (região estável da curva PV) e a solução com baixa tensão (região instável da curva PV). A função de energia vai diminuindo com o sistema mais carregado e é zero no ponto de bifurcação onde as soluções de baixa e alta tensão são as mesmas.

Moghavvemi e Faruque (1998) propuseram um índice de estabilidade de linha para determinar a proximidade de colapso. O índice Lmn é baseado no conceito simples de fluxo de potência através de uma linha. O método calcula o índice para todas as linhas e fornece as áreas fracas do sistema. A técnica tem pouco esforço computacional e demostrou eficiência em relação a outros métodos.

Moghavvemi e Faruque (1998) também propuseram no mesmo ano o uso do índice VCPI (Voltage Collapse Proximity Indicator) que é baseado no critério de máximo fluxo de potência através de uma linha. $O$ índice toma valor 0 para a condição sem carregamento e 1 para o valor de máximo carregamento pela linha. O índice é muito utilizado para monitoramento em tempo real.

Liu et al. (2000) utilizaram o conceito de distância elétrica para demonstrar a relação entre a tensão de uma barra e o reativo disponível nas barras vizinhas. A distância elétrica também é utilizada para escolher a área crítica de tensão após uma contingência fazendo cálculos rápidos. É proposto o índice RI para classificar as contingências de acordo com a severidade. Como o cálculo da distância elétrica e simples pode ser usado para monitoramento online.

De Souza et al. (2000) apresentaram uma metodologia para avaliar a estabilidade de tensão em tempo real baseada na predição assistida do estimador de estado e o método de extrapolação que calcula o ponto de colapso. O vetor tangente é usado para tomar ações preventivas de colapso e para determinar áreas críticas. As ações preventivas são de tipo de limitação de carregamento.

Bao et al. (2003) demostraram a correlação entre a margem de estabilidade da curva PV com o equivalente de potência reativa de reserva. Eles mostraram que a reserva individual de reativo de cada gerador não está relacionada com a margem de estabilidade, mas sim o equivalente de reativo que é calculado em base a relação linear que existe entre a reserva de 
apenas um gerador com a margem da curva PV para alguns cenários. Assim outro gerador do sistema terá uma relação linear com a margem de estabilidade para outros cenários distintos.

Balamourougan et al. (2004) usaram as medições de fasores de tensão (PMU's) para o cálculo do índice VCPI (Voltage Collapse Prediction Index) em todas as linhas do sistema. O índice é calculado a partir das equações do fluxo de potência e tem valor 0 quando o sistema não corre risco de colapso e 1 quando o sistema está no ponto limite. $O$ índice também funciona como indicador dinâmico de estabilidade.

Corsi e Taranto (2008) propuseram um novo indicador de risco de instabilidade baseado em amostras rápidas de medidores fasoriais PMU's. Eles também apresentam um algoritmo para o cálculo em tempo real do equivalente de Thevenin clássico para uma rede elétrica. $\mathrm{O}$ gerador equivalente e a impedância equivalente são calculados em todo momento. O índice proposto é calculado atraves do equivalente de Thevenin.

Leonardi e Ajjarapu (2011) utilizaram um modelo de regressão linear múltipla para determinar em tempo real o índice VSM (Voltage Stability Margin). O método é baseado na relação existente entre a RPR (Reserva de Potência Reativa) e O VSM. Os dados RPR e VSM são calculados previamente de modo off-line e logo são utilizados para o monitoramento em tempo real. Diversas direções de crescimento de carga e contingências são consideradas para o monitoramento em tempo real.

\subsection{Revisão de técnicas para análise em tempo real da estabilidade de tensão com suporte de Redes Neurais Artificiais}

$\mathrm{Na}$ literatura, pode se ver que a partir dos anos 90 começou a se desenvolver o uso de inteligência artificial como suporte para avaliação de estabilidade de tensão com o intuito de diminuir o esforço computacional. 
Entre os sistemas inteligentes, a ferramenta mais utilizada para o estudo de estabilidade de tensão são as redes neurais artificias e, a lógica fuzzy em segundo lugar. Nesta dissertação a revisão bibliográfica será focada em redes neurais artificiais.

As RNA's como suporte para monitoramento da estabilidade de tensão tem sido utilizada com eficiência, em todos os casos, para monitoramento online de diversos índices que indicam a proximidade do colapso.

Mori (1992) propôs o treino das RNA's para o cálculo do índice VIPI (voltage instability proximity index) que é baseado nas múltiplas soluções do fluxo de potência para se ter uma visão global do carregamento do sistema. A arquitetura de rede utilizada para o cálculo do índice VIPI é o Perceptron Multicamadas. Por outro lado, é utilizada a arquitetura self organization map para traçar a trajetória da condição do sistema de potência.

Jeyasurya (1994) propôs o treino das RNA's para o cálculo do índice L-index, que é baseado na solução do fluxo de carga. Esse índice determina a estabilidade do sistema completo e varia de 0 a 1 , sendo 0 o estado ótimo e 1 o estado de colapso. No documento também é exposto o treino da RNA para cálculo do índice baseado em função de energia. A arquitetura utilizada para ambos, os índices são Perceptron Multicamadas.

El-Keib e Ma (1995) propuseram uma RNA Perceptron Multicamadas com aprendizado padrão (backpropagation) para cálculo de margens de estabilidade de tensão (VSM). Com base no método de energia, uma relação de mapeamento direto entre as condições de carregamento do sistema de energia e os VSMs é configurada através da RNA. Um método sistemático para selecionar as variáveis de entrada da RNA, foi desenvolvido usando a análise de sensibilidade. Os efeitos dos problemas de sensibilidade do padrão de treinamento da RNA também foram estudados, dividindo as condições operacionais do sistema em vários níveis de carga com base na análise de sensibilidade. A principal diferença com o caso anterior é a análise de sensibilidade que indica as barras mais críticas.

La Scala et al. (1996) utilizaram o modelo dinâmico das redes para determinar o ponto de bifurcação. Com uma rede neural feedforward de 3 camadas calcularam o índice de proximidade de colapso. Esse índice é baseado na diferença de tensão entre a situação atual e a situação de máximo carregamento. A técnica permite determinar as barras críticas onde o colapso de tensão está mais perto de acontecer. 
Chakrabarti e Jeyasurya (2004) propuseram o monitoramento de estabilidade de tensão on-line usando uma RNA e uma forma sistemática de treinamento dela. As RNA separadas são usadas para diferentes contingências e para diferentes níveis de carga sob a mesma contingência. Os resultados da análise de contingência são utilizados juntamente com a análise de componentes principais (PCA) para a escolha dos mais importantes dados de treino. A implementação do esquema de seleção de recursos melhora a utilidade geral da rede neural.

Suthar e Balasubramanian (2007) propuseram o índice VCPI (voltage colapse proximity indicator) que é relacionado à margem de potência reativa nas barras críticas e que, no documento, é calculado com um programa de contorno da curva QV. Eles também fazem análise modal para determinar as barras mais críticas. O resultado obtido foi excelente e só uma rede neural para o treinamento dos casos com alteração de configuração da rede foi necessária. Os resultados obtidos com a rede neural treinada tiveram um erro mínimo. A vantagem é que o índice utilizado neste trabalho é diretamente a margem de potência reativa que é muito familiar para qualquer técnico da área.

Nakawiro e Erlich (2008) propuseram a aplicação de uma RNA para monitorar a estabilidade de tensão do sistema de potência. O treinamento da RNA é realizado adaptandose informações recebidas do sistema de medições chamadas PMU's (Phase Measurement Unit) que junto com o equivalente de Thevenin podem calcular índices úteis como o PTSI (Power Transfer Stability Index) e PVSM (Power Based Voltage Satability Margin). Além disso, o método é muito adequado para implementar dispositivos de proteção.

Zhou et al. (2010) propuseram o módulo e o ângulo nas barras como os melhores indicadores de proximidade de colapso, e uma rotina para determinar a melhor localização de PMU's, além de trabalhar com esses dados para o monitoramento online da estabilidade para situação normal e de contingência. A rede neural proposta tem a função de tomar esses dados de entrada. Os dados de saída serão parecidos aos resultados de um fluxo de potência continuado.

Balasubramanian e Singh (2011), baseados no trabalho de 2007, melhoraram a proposta calculando diretamente a margem de potência reativa em MVARs das barras mais críticas, substituindo o índice VCPI. A margem de potência reativa para os diferentes cenários de carregamento e configuração da rede é calculada analiticamente com o fluxo de potência 
continuado. Também é feita a análise modal para determinar as barras críticas mais frequentes nos diferentes cenários. Igual ao caso anterior, só é preciso uma rede neural para o treino dos casos com configuração normal e contingencia.

Rahi et al. (2011) propuseram o índice de estabilidade de tensão $L$-index, em relação a cada barra de carga, usando o circuito equivalente de Thevenin do sistema de potência referido a uma barra de carga. Barras com valores de fatores L-index próximos de 1 são identificados como as barras críticas. Logo, uma RNA é desenvolvida para o monitoramento da estabilidade da tensão.

Thakku e Sajith (2014), propuseram o índice L-index novamente como o indicador de instabilidade de tensão o qual é baseado na solução do fluxo de potência. O desempenho de uma RNA é avaliado fazendo o treino com 4 entradas, sendo a única saída o índice $L$-index. $\mathrm{O}$ erro entre a saída atual e a prevista foi pequeno.

No mesmo ano, Bahmanyar e Karami (2014) propuseram o uso das RNA's para monitoramento online da margem de estabilidade de tensão (VSM) em sistemas de potência. O VSM é calculado estimando a distância do estado de operação atual ao ponto limite máximo de estabilidade de tensão de acordo com o parâmetro de carregamento do sistema. Usando o processo de ortogonalização de Gram-Schmidt, juntamente com uma técnica de sensibilidade baseada em RNA; um método de seleção de característica eficiente é proposto para encontrar as poucas variáveis de entradas necessárias para aproximar o VSM com precisão suficiente e alta velocidade de execução. A principal vantagem desta metodologia, em relação a trabalhos publicados anteriormente, é que aquelas precisam treinar uma nova rede neural quando ocorre uma mudança na topologia do sistema de energia (configuração), enquanto, e, com a metodologia proposta, existe a possibilidade de empregar uma única RNA para estimar o VSM para várias configurações do sistema.

Goh et al. (2015) propuseram o índice de estabilidade de tensão da linha (LVSI) para determinar as linhas mais fracas do sistema de potência. Além disso, a implementação de monitoramento de estabilidade de tensão em tempo real usando uma Rede Neural Artificial. Os resultados demonstraram que a diferença entre os índices calculados e os índices estimados usando RNA são praticamente irrelevantes na predição do colapso de tensão no sistema. 
Puppala e Chandrarao (2015) propuseram a avaliação da estabilidade da tensão através da curva P-V e do fator de sensibilidade das barras. A margem de potência ativa é usada para medir a distância à instabilidade. A ferramenta de análise de estatísticas de dados é usada para executar regressão linear. Neste trabalho, o método de regressão linear com RNA é comparado com os métodos convencionais e tem um bom desempenho. 


\section{CAPÍTULO 3}

\section{Fluxo de potência continuado}

\subsection{Método do fluxo de potência continuado.}

No fluxo de potência convencional, a matriz jacobiana é singular quando o sistema está no ponto de bifurcação, por isso, quando o sistema está perto desse ponto o fluxo pode ter problemas de convergência, não se podendo calcular o ponto exato (AJJARAPU, 2006).

Para solucionar o problema da convergência do fluxo perto do ponto de bifurcação é usada a técnica matemática chamada "Método da continuação" (AJJARAPU, 2006).

O método da continuação é uma técnica matemática que utiliza uma metodologia de "seguindo o caminho" (path-following) para resolver sistemas de equações não lineares e bifurcações.

Em sistemas de potência, o método da continuação tem a grande aplicação de tornar possível o traçado completo da curva PV, incluindo a parte instável da curva com o método chamado "Fluxo de potência continuado" (FPC).

O FPC baseia-se num esquema de predição e correção de soluções de fluxo de potência para diferentes níveis de carregamento com ajuda da parametrização.

A parametrização é a solução matemática para identificar cada solução da curva, um tipo de medida das soluções ao longo da curva.

No sistema de equações do fluxo de carga é introduzido o parâmetro de carga $\rho$, que representa o nível de carregamento de uma ou de todas as barras.

Para cada valor de $\rho$ é possível identificar cada solução da curva, embora problemas surjam quando o valor de $\rho$ chega ao máximo possível. Neste ponto, é possível fazer uma parametrização local utilizando uma variável de estado própria das equações como a tensão ou o ângulo. 
O parâmetro $\rho$ é introduzido nas equações 21 a 24 da seguinte maneira:

$$
\begin{gathered}
P_{e s p}=P_{g}-P_{l}(\rho) \\
Q_{e s p}=Q_{g}-Q_{l}(\rho) \\
P_{l}(\rho)=P_{l 0}(1+\rho k) \\
Q_{l}(\rho)=Q_{l 0}(1+\rho k)
\end{gathered}
$$

Então a equação de fluxo de potência é:

$$
F(\theta, V, \rho)=0
$$

Os subíndices $g$ e $l$, significam gerado e consumido respectivamente.

$P_{l 0}$ e $Q_{l 0}$ é a carga do caso base, e $k$ é um fator de crescimento individual para cada barra e que determina as direções de crescimento do sistema.

\subsubsection{Processo preditor}

O processo preditor consiste em obter um resultado "prévio", que se encontra bem perto da solução exata, a partir de um ponto de operação com uma pequena variação do parâmetro que geralmente é $\rho$, podendo-se trocá-lo por um parâmetro local quando estiver perto do ponto de bifurcação (AJJARAPU, 2006).

Para o cálculo do preditor, as duas técnicas mais usadas são a do cálculo do vetor secante e a do vetor tangente, sendo este último o que será descrito e utilizado neste trabalho.

Para o cálculo do vetor tangente tem se que derivar a equação 25 e colocá-la na sua forma matricial.

$$
\left[\frac{\partial(F)}{\partial \theta} \frac{\partial(F)}{\partial V} \frac{\partial(F)}{\partial \rho}\right]\left[\begin{array}{l}
d \theta \\
d V \\
d \rho
\end{array}\right]=0
$$


A matriz da esquerda, é a matriz jacobiana, que neste caso está aumentada por uma coluna que é a derivada parcial da função $\mathrm{F}$ em relação a $\rho$.

O vetor que multiplica a matriz jacobiana aumentada é o vetor tangente:

$$
t=\left[\begin{array}{lll}
d \theta & d V & d \rho
\end{array}\right]^{t}
$$

Através do incremento de uma nova coluna, o sistema de equações passa a ter mais incógnitas do que equações, pelo que é preciso aumentar uma nova equação onde se impõe que o comprimento do vetor t seja diferente de zero (AJJARAPU, 2006).

A nova equação é:

$$
e_{k} t=t_{k}= \pm 1
$$

Onde $e_{k}$ é um vetor linha com todos os elementos iguais a zero com exceção do elemento $k$ que tem valor 1 , e corresponde a variável de parametrização.

$t_{k}$ é o valor da variável de parametrização que pode ser \pm 1 , positivo se a variável é crescente, e negativo para a decrescente.

Por exemplo, se o vetor linha $e_{k}$ tem valor 1 na ultima coluna $e_{k}=\left[\begin{array}{llll}0 & 0 & 0 & \ldots .\end{array}\right]$ significa que a variável $\rho$ foi escolhida como parâmetro, sendo crescente na parte superior da curva, se impõe a que o componente d $\rho$ tenha valor 1 .

$$
\left[\begin{array}{lll}
0 & 0 & 1
\end{array}\right]\left[\begin{array}{l}
d \theta \\
d V \\
d \rho
\end{array}\right]=1 \text {; que equivale a } d \rho=1
$$

Então, o vetor tangente é calculado resolvendo o seguinte sistema:

$$
\left[\begin{array}{cc}
\frac{\partial(F)}{\partial \theta} \frac{\partial(F)}{\partial V} \frac{\partial(F)}{\partial \rho} \\
e_{k}
\end{array}\right]\left[\begin{array}{l}
d \theta \\
d V \\
d \rho
\end{array}\right]=\left[\begin{array}{c}
0 \\
\pm 1
\end{array}\right]
$$


Depois do cálculo do vetor tangente, o preditor é calculado da seguinte forma:

$$
\left[\begin{array}{c}
\theta^{*} \\
V^{*} \\
\rho^{*}
\end{array}\right]=\left[\begin{array}{c}
\theta \\
V \\
\rho
\end{array}\right]+\sigma\left[\begin{array}{l}
d \theta \\
d V \\
d \rho
\end{array}\right]
$$

Onde '*' significa que é a solução do passo preditor, e $\sigma$, é um escalar que indica o tamanho do vetor tangente.

O vetor pode ser constante durante todo o processo de cálculo ou pode variar de acordo com o ponto de operação. O valor de $\sigma$ deve ser de tal maneira que o preditor esteja dentro do raio de convergência do passo corretor, especialmente, na região onde se tem a maior taxa de alteração que é a região que rodeia o ponto de bifurcação (AJJARAPU, 2006). Ele não pode ser muito alto, mas se é pequeno e fica constante durante todo o processo, se tem muito esforço computacional desnecessário na área de baixo carregamento, que apresenta pouca taxa de alteração nas variáveis. Então, o ideal é que a variação seja de acordo com a área onde se esteja calculando o fluxo, ou seja, valores medianos na área de baixo carregamento, e valores pequenos na área de alto carregamento.

Existem muitas técnicas para variar o valor do passo $\sigma$ de acordo com a necessidade explicada, algumas muito sofisticadas e, outras muito simples, uma das mais conhecidas é baseado na norma do vetor tangente (SOUZA et al. 1997). O tamanho do passo é definido como:

$$
\sigma=\frac{r}{\|t\|}
$$

Onde $r$ é um escalar predefinido e $\|t\|$ é a norma euclidiana do vetor $t$.

Outro método é o que baseado no número de iterações no passo corretor (SEYDEL et al. 1988).

$$
\sigma_{\text {novo }}=\frac{\sigma_{\text {antigo }} N_{o p t}}{N_{j}}
$$


Onde $N_{o p t}$ é o número ótimo de iterações do passo corretor (6 para uma tolerância de 1e-5) e $N_{J}$ e a quantidade de iterações realizadas no último passo corretor.

\subsubsection{Processo corretor}

Depois de ter realizado o passo preditor y ter uma solução aproximada $\left(\theta^{*}, V^{*}, \rho^{*}\right)$ é preciso fazer a correção desse valor para o valor exato, o que pode ser feito com qualquer método numérico, sendo o método Newton-Raphson o mais utilizado, e o que se será utilizado neste trabalho.

O valor do passo preditor é utilizado como valor inicial de "teste" para a solução com o método Newton-Raphson e, como os pontos estão pertos da solução exata e o mismatch inicial tem um valor pequeno, então são precisas poucas iterações para ter uma boa precisão da solução com um erro mínimo (AJJARAPU, 2006).

A parametrização feita no passo corretor consiste no aumento de uma equação ao sistema de equações:

$$
\left[\begin{array}{c}
F(\theta, V, \rho) \\
x_{k}-\gamma
\end{array}\right]=0
$$

Onde $x_{k}$ é a variável escolhida como parâmetro e $\gamma$ é o valor obtido no passo preditor.

Linearizando o sistema de equações para resolver com o método Newton-Raphson:

$$
\left[\begin{array}{c}
\Delta P \\
\Delta Q \\
0
\end{array}\right]=\left[\begin{array}{ccc}
\partial P / \partial \theta & \partial P / \partial V & \partial P / \partial \rho \\
\partial Q / \partial \theta & \partial Q / \partial V & \partial Q / \partial \rho \\
e_{k} &
\end{array}\right]\left[\begin{array}{c}
\Delta \theta \\
\Delta V \\
\Delta \rho
\end{array}\right]
$$

Onde $e_{k}$ é o vetor linha que tem o valor da unidade na coluna correspondente a variável de parametrização escolhida.

A escolha correta da variável de parametrização no passo corretor é o que soluciona o problema da singularidade na região do ponto de bifurcação. 
Uma boa escolha é utilizar $\rho$ como parâmetro de continuação na região de baixo carregamento e logo fazer a troca de parâmetro na região do ponto de bifurcação (AJJARAPU et al., 1992).

A figura 7 mostra o processo de predição, correção na região de baixo carregamento onde o parâmetro de continuação é $\rho$.

Quando $\rho$ é escolhido como parâmetro de continuação na região de baixo carregamento pode se observar que o vetor tangente $t$ sempre tem o componente $d \rho$ maior, mas quando o sistema está perto da região do ponto de bifurcação, a componente $d \rho$ fica menor, então é o momento de fazer a troca de parâmetro no passo corretor.

Figura 7: Construção da curva PV na região de baixo carregamento

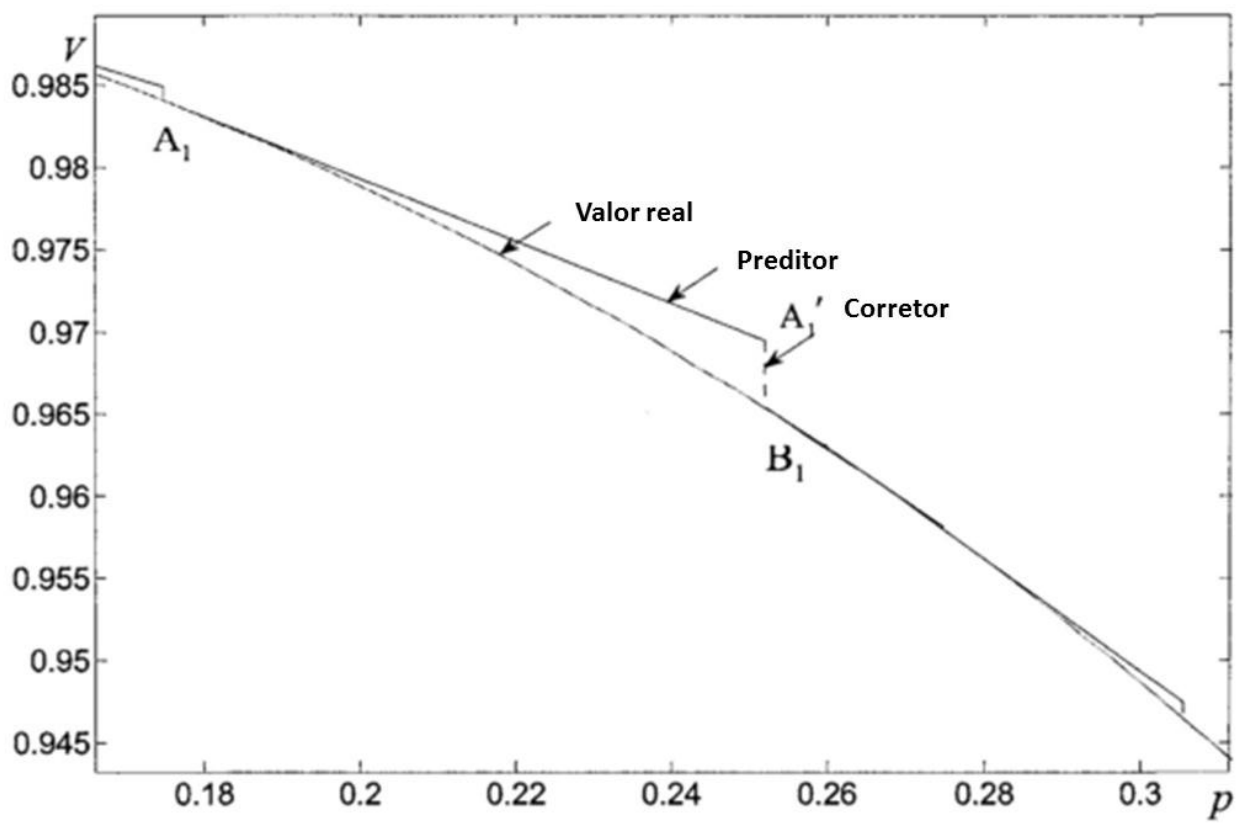

Fonte: Ajjarapu, 2006.

Segundo Ajjarapu e Christy (1992), a escolha do parâmetro de continuação deve ser feita tomando o critério da maior componente do vetor t.

$$
x_{k}=\max \left\{\left|t_{1}\right|,\left|t_{2}\right|,\left|t_{3}\right| \ldots\left|t_{n}\right|\right\}
$$

O ponto de bifurcação é identificado quando o vetor $\mathrm{t}$ tem a componente $d \rho$ igual a zero. A mesma componente se converte em negativa na região inferior da curva PV. 
A figura 8 mostra o processo de predição e correção.

Figura 8: Processo preditor - corretor na região de bifurcação

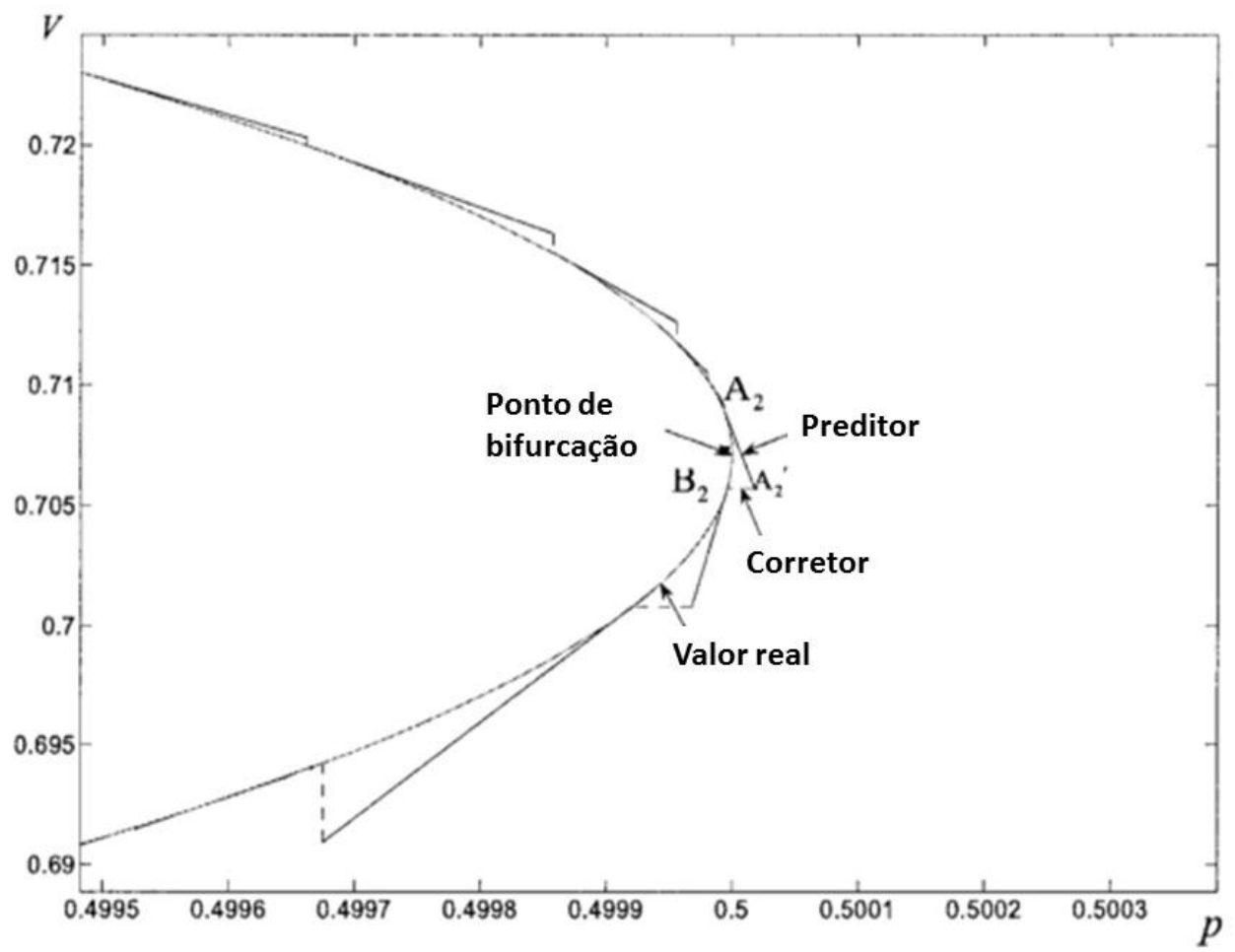

Fonte: Ajjarapu, 2007. 


\section{CAPÍTULO 4}

\section{Redes neurais artificiais}

\subsection{Introdução}

Nas últimas décadas, as Redes Neurais Artificiais (RNA's) têm sido utilizadas em quase todas as áreas do conhecimento, sobretudo na engenharia e, também, na área de sistemas elétricos de potência.

Existe uma grande quantidade de literatura referente às redes neurais artificiais. No que diz respeito a este tema, este texto se divide em duas partes:

a) Breve resumo das definições e conceitos básicos das redes neurais artificiais enfatizando a arquitetura utilizada em sistemas de potência, mais propriamente no utilizado neste trabalho.

b) Revisão bibliográfica referente a trabalhos de estabilidade de tensão utilizando RNA's.

\subsection{Conceitos iniciais}

As RNA's são modelos matemáticos computacionais inspirados no processo de aprendizagem do sistema nervoso de seres vivos, que é composto por neurônios. Possuem a capacidade de aprendizagem de conhecimento por meio de exemplos. Os neurônios estão interligados com outros neurônios por muitas interconexões formando a sinapse, que na forma artificial é representada por vetores/matrizes de pesos sinápticos (SILVA et al., 2016).

As características principais das RNA's são (SILVA et al., 2016):

a) Adaptação por experiência: os pesos sinápticos são adaptados por apresentação sucessiva de exemplos.

b) Capacidade de aprendizagem: os exemplos são usados para o treinamento da rede. 
c) Habilidade de generalização: a rede é capaz de encontrar resultados até então desconhecidos, por sua capacidade de generalizar o conhecimento adquirido.

d) Organização de dados: a rede pode se organizar com o objetivo de agrupar padrões com particularidades em comum.

e) Tolerância a falhas: a rede neural pode manter seu bom desempenho com parte da sua estrutura interna sensivelmente corrompida, devido ao fato da rede estar altamente interconectada.

f) Armazenamento distribuído: se eventuais neurônios ficassem inoperantes, a rede se mantém robusta, devido ao fato do conhecimento estar distribuído entre as diversas sinapses.

g) Facilidade de prototipagem: a rede pode ser facilmente prototipada em hardware ou software.

Uma rede neural deriva seu poder de computação, em primeiro lugar, de sua estrutura distribuída massivamente paralela e, em segundo lugar, de sua capacidade de aprender e, portanto, generalizar. A generalização refere-se à produção da rede neural de resultados razoáveis para os insumos não encontrados durante o treinamento (aprendizado). Esses dois recursos de processamento de informações possibilitam que as redes neurais encontrem boas soluções aproximadas para problemas complexos (em larga escala).

\subsubsection{O neurônio biológico}

As funcionalidades do cérebro humano, tais como pensar e memorizar, são regidas por processadores biológicos que operam em paralelo.

O neurônio é a célula elementar do sistema nervoso e tem a função de conduzir impulsos sob determinadas condições de operação (SILVA et al., 2016).

O neurônio tem 3 partes: o corpo celular, os dendritos e o axônio.

Os dendritos são terminais receptivos nervosos com forma de árvore que transmitem sinais elétricos ao corpo celular. O corpo celular recebe os sinais elétricos e os soma 
efetivamente. Logo, o axônio recebe o sinal elétrico do corpo celular e o transmite para outro neurônio.

O contato entre o axônio de um neurônio e os dendritos de outro neurônio é chamado sinapse.

Na figura 9 é mostrado o neurônio biológico e a suas partes.

Figura 9: O neurônio biológico.

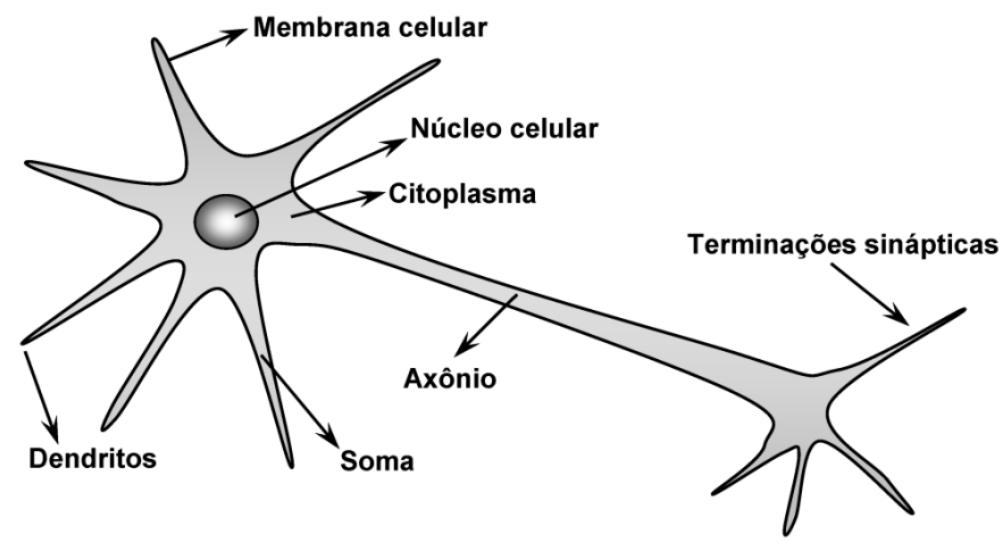

Fonte: SILVA et al., 2016.

A sinapse é a conexão entre o axônio de um neurônio para os dendritos de outros neurônios, como ilustrado na figura 10.

Não existe contato físico na sinapse. Os elementos neurotransmissores liberados são os responsáveis pela ponderação e transmissão dos impulsos elétricos entre um neurônio e outro (SILVA et al., 2016).

Os neurônios biológicos são os responsáveis por todos os processamentos executados e gerenciados pelo cérebro humano e, estima-se que a rede biológica é composta por 100 bilhões de neurônios: cada neurônio interligado, por conexão sináptica, a 6000 neurônios, perfazendo um total de 600 trilhões de sinapses em nossos cérebros (SILVA et al., 2016). 
Figura 10: Sinapse entre neurônios.

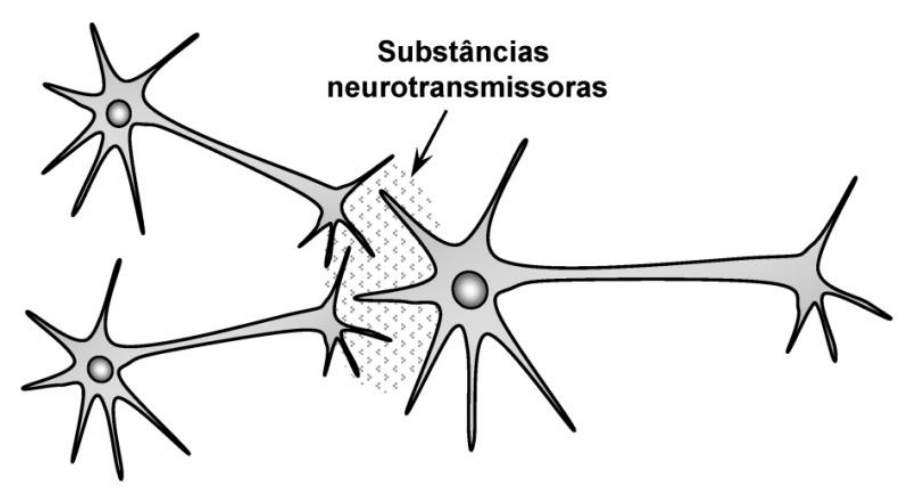

Fonte: SILVA et al., 2016.

\subsubsection{O neurônio artificial}

A estrutura do neurônio artificial foi inspirada no neurônio biológico, a partir da análise da geração e propagação dos impulsos elétricos através deles.

O modelo do neurônio matemático mais simples foi proposto por McCulloc \& Pitts (1943), e foi a base para o modelo mais conhecido, chamado Perceptron, proposto por Rosenblatt (1958), no qual consta de um só neurônio e será estudado mais adiante.

O modelo matemático do neurônio artificial proposto por McCulloc \& Pitts pode ser visto na Figura 11.

Figura 11: Modelo matemático do neurônio.

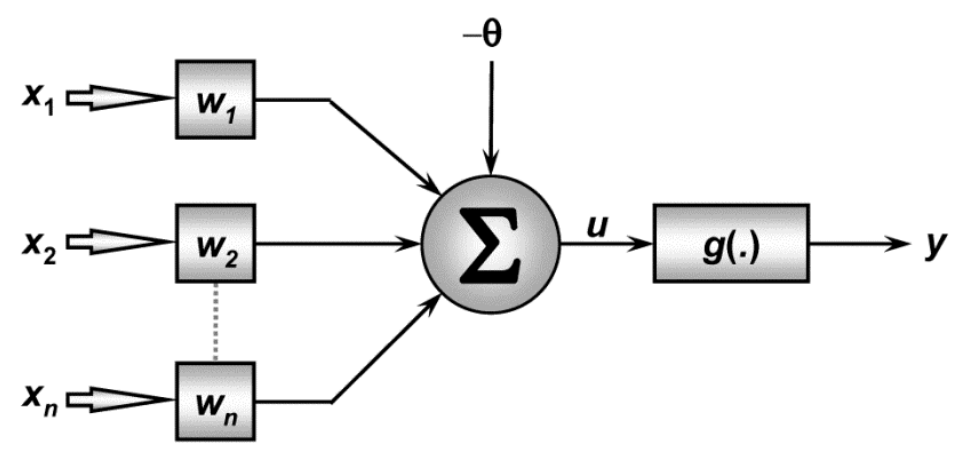

Fonte: SILVA et al., 2016. 
Os sinais de entrada $x_{i}$ (entrada) são multiplicados pelos pesos sinápticos $w_{i}$ formando $x_{i} w_{i}$

Logo todos os $x_{i} w_{i}$ são somados (no corpo celular) junto com o limiar $\theta$ que tem a função de aumentar ou diminuir a entrada líquida, dando como resultado a entrada u para a função de ativação.

A função de ativação $g(u)$ (também chamado função de transferência) processa o sinal de acordo com a função e produz a saída $y$.

O funcionamento deste neurônio pode ser descrito matematicamente pelas seguintes equações:

$$
\begin{gathered}
u=\sum_{i=1}^{n} w_{i} x_{i}-\theta \\
y=g(u)
\end{gathered}
$$

onde:

$u$, é o potencial de ativação que a soma ponderada junto ao limiar do neurônio $i$ é o índice das entradas do neurônio.

$\theta$ é o limiar aplicado ao neurônio.

$x_{i}$ são os sinais de entrada do neurônio.

$w_{i}$ são os pesos sinápticos do neurônio.

$g($.$) é a função de ativação do neurônio.$

$y$ é o sinal de saída do neurônio.

\subsubsection{Tipos de funções de ativação}

A função de ativação $g(u)$ tem a função de processar o potencial de ativação $u$ para produzir a saída final do neurônio $y$. 
Existem muitos tipos de funções de ativação. A seguir serão descritos apenas os principais e os mais utilizados.

a) Função de degrau (heaviside), limita a saída do neurônio a apenas o valor 0 ou 1 , dependendo do valor do potencial de ativação. Normalmente é utilizada para criar neurônios que tomem decisões binárias. A seguir a definição matemática desta função e o gráfico dela:

$$
g(u)=\left\{\begin{array}{l}
0 \rightarrow u<0 \\
1 \rightarrow u \geq 0
\end{array}\right.
$$

Figura 12: Função degrau

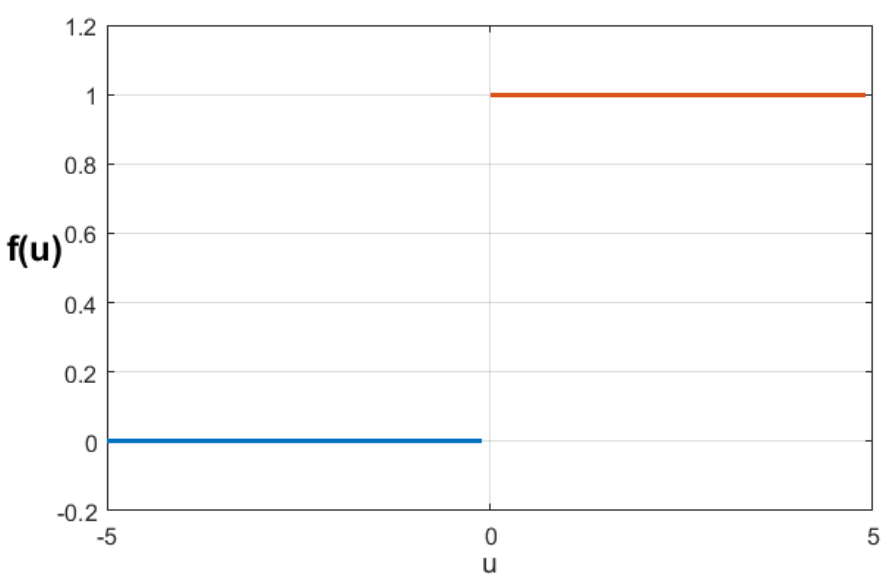

Fonte: Autor

b) Função degrau bipolar, limita a saída aos valores 1 e -1, dependendo do valor da potência de ativação. Possui a seguinte definição e gráfico:

$$
g(u)=\left\{\begin{array}{c}
0 \rightarrow u=0 \\
1 \rightarrow u>0 \\
-1 \rightarrow u<0
\end{array}\right.
$$


Figura 13: Função degrau bipolar

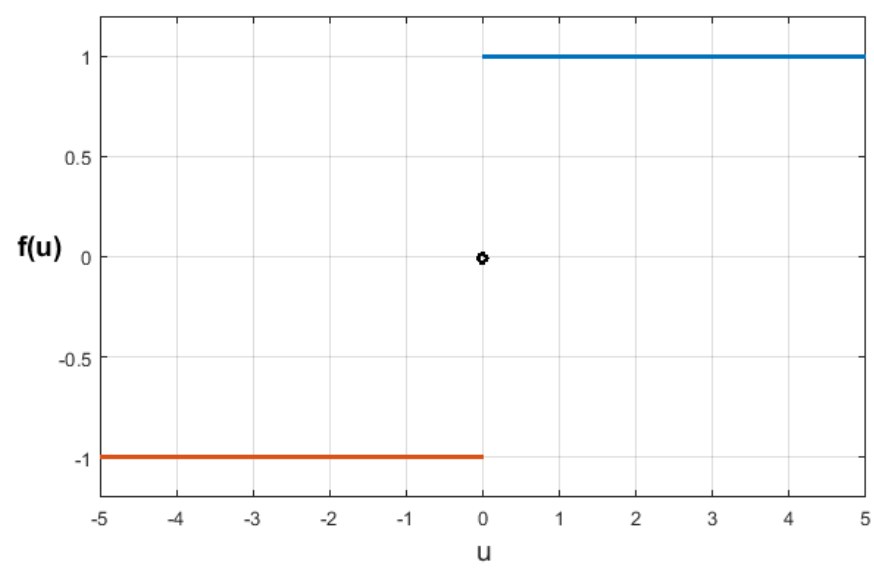

Fonte: Autor

c) Função linear, também chamada de função PURELIN (na ferramenta Matlab) produz um valor de saída igual a o valor de potencial de ativação, possui a seguinte definição e gráfico:

$$
g(u)=u
$$

Figura 14: Função linear

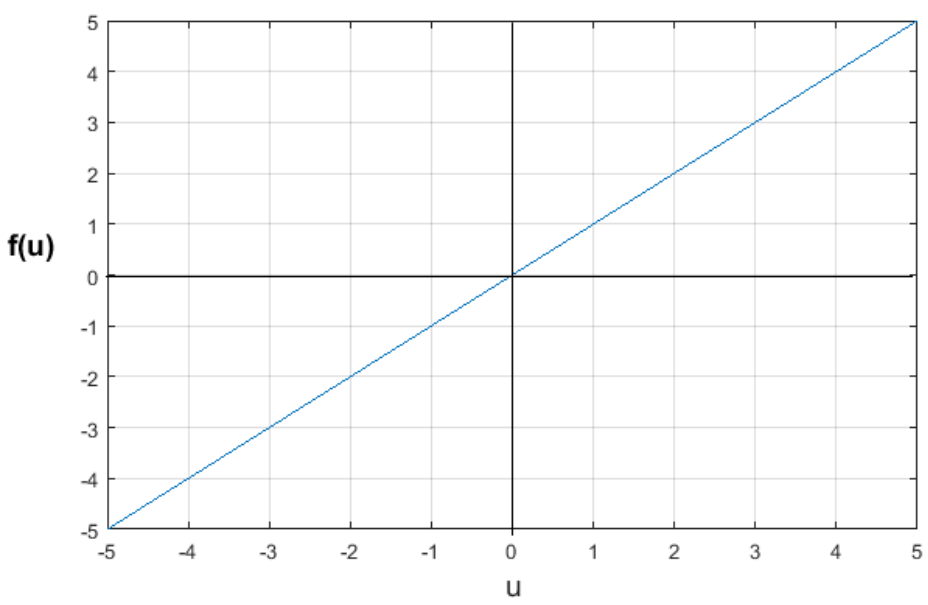

Fonte: Autor

d) Função logística é a função mais utilizada na construção de RNA's de camada múltipla. É definida como uma função estritamente crescente que exibe um equilíbrio entre comportamento linear e não-linear. Possui a seguinte definição: 


$$
g(u)=\frac{1}{1+e^{-a u}}
$$

Onde a é o parâmetro de inclinação da função e com valor unitário tem o seguinte gráfico:

Figura 15: Função logística

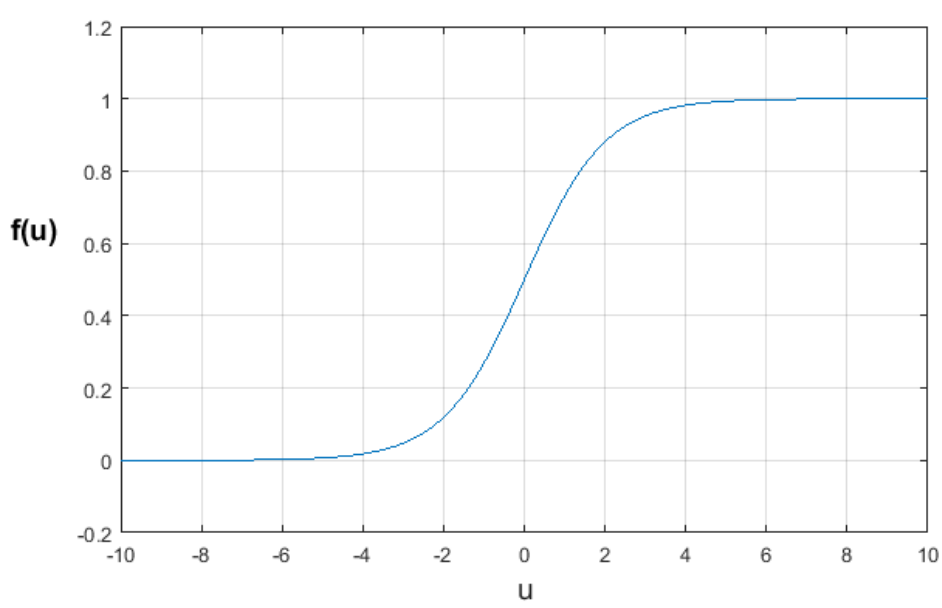

Fonte: Autor

No toolbox de redes neurais da ferramenta Matlab esta função é chamada "LOGSIG".

e) Função tangente hiperbólica, Algumas vezes é desejável que a função de ativação se estenda de $-1 \mathrm{a}+1$, assumindo neste caso uma forma antissimétrica em relação à origem. Possui a seguinte definição:

$$
g(u)=\frac{1-e^{-a u}}{1+e^{-a u}}
$$

Onde a é o parâmetro de inclinação da função e com valor unitário tem o seguinte gráfico: 
Figura 16: Função tangente hiperbólica

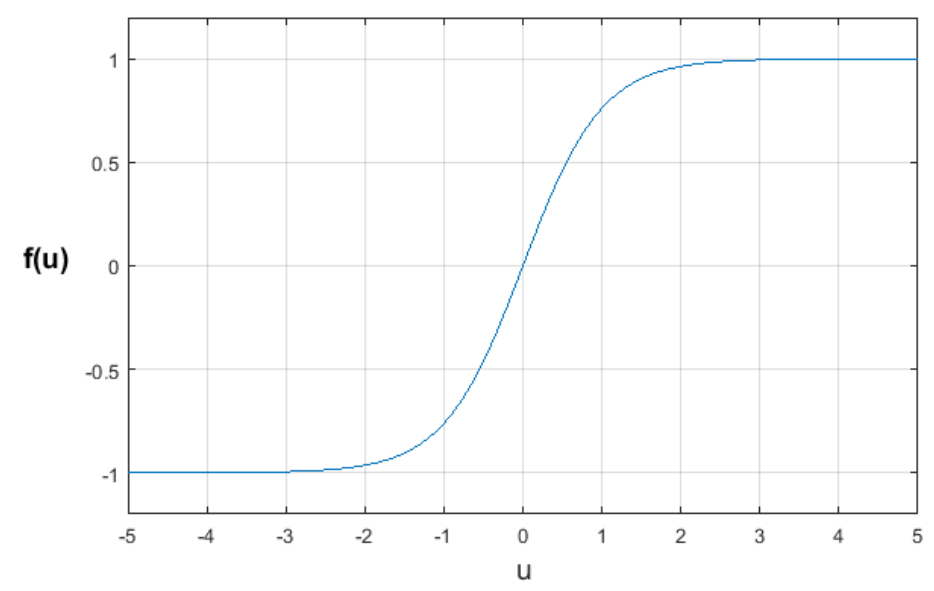

Fonte: Autor

No toolbox de redes neurais da ferramenta Matlab esta função é chamada "TANSIG".

\subsection{Arquitetura de redes neurais}

Mais de um neurônio trabalhando em paralelo forma uma camada.

Uma rede neural pode ter 3 tipos de camadas (SILVA et al., 2016) que são as seguintes:

a) Camada de entrada que é basicamente os dados de entrada do sistema, são os dados para os quais se quer calcular o processo. Os dados de entrada geralmente são normalizados com o objetivo de evitar saturação da rede.

b) Camadas ocultas, escondidas ou intermediárias, que são as camadas responsáveis pelo processamento dos dados.

c) Camada de saída, que é a responsável por reproduzir os resultados do processamento final da rede.

As principais arquiteturas tomando em conta a disposição dos neurônios e sua forma de interligação, podem ser divididas em:

a) Feedforward* de camada simples 
b) Feedforward de camadas múltiplas

c) Redes recorrentes

d) Redes reticuladas

* O termo feedforward significa alimentação a frente.

\subsubsection{Redes feedforward de camada simples}

Este tipo de arquitetura pode ser visto na Figura 17. Tem-se apenas uma camada de entradas e uma única camada de neurônios que é a própria camada de saída.

O número de saídas coincide com o número de neurônios.

Este tipo de arquitetura é utilizado geralmente em problemas de classificação de padrões e filtragem linear (SILVA et al., 2016).

Figura 17: Rede feedforward de camada simples.

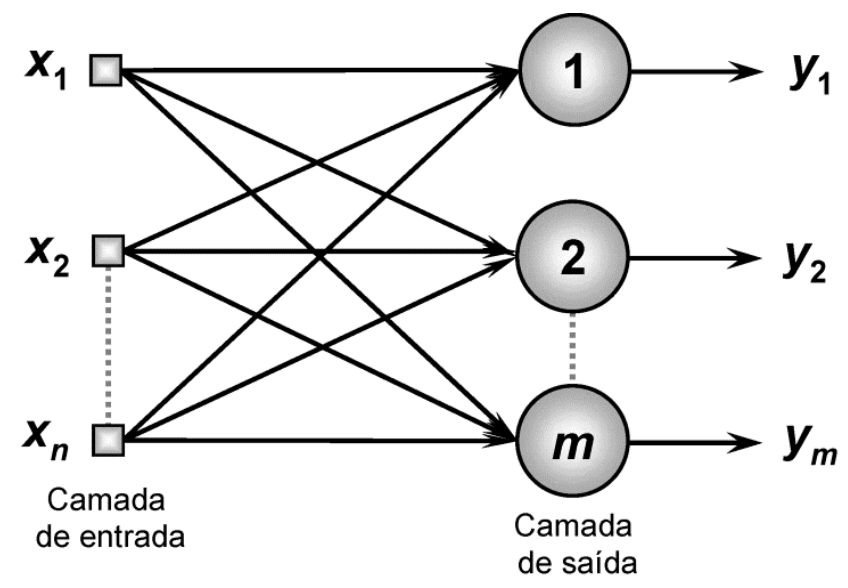

Fonte: SILVA et al., 2016. 


\subsubsection{Redes feedforward de camadas múltiplas}

Nesta segunda classe de arquitetura existem camadas intermediárias entre a camada de entrada e saída. Essas camadas intermediárias também são chamadas 'escondidas' ou 'ocultas'.

Os valores de entrada das camadas ocultas são os vetores de saída da camada que o precede.

Este tipo de rede é utilizado em uma diversa variedade de problemas, entre os mais comuns: para aproximação de funções, otimização, robótica, controle de processos, etc.

Neste trabalho será utilizada este tipo de arquitetura.

A Figura 18 apresenta esta arquitetura.

Figura 18: Rede feedforward de camadas múltiplas

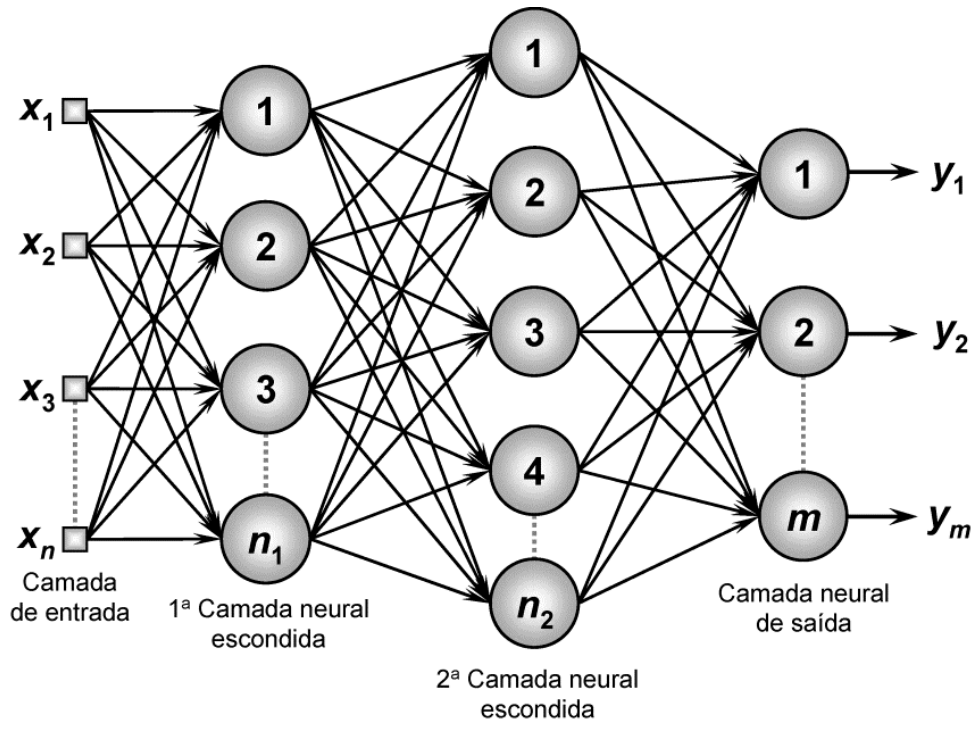

Fonte: SILVA et al., 2016. 


\subsubsection{Redes recorrentes}

As redes neurais recorrentes são diferenciadas das outras já explicadas por ter pelo menos um laço de realimentação.

Este tipo de rede é utilizado para o processamento dinâmico de informações o que permite resolver problemas variantes no tempo como previsão de séries temporais, controle de processos, etc.

A Figura 19 apresenta uma rede deste tipo.

Figura 19: Rede neural recorrente

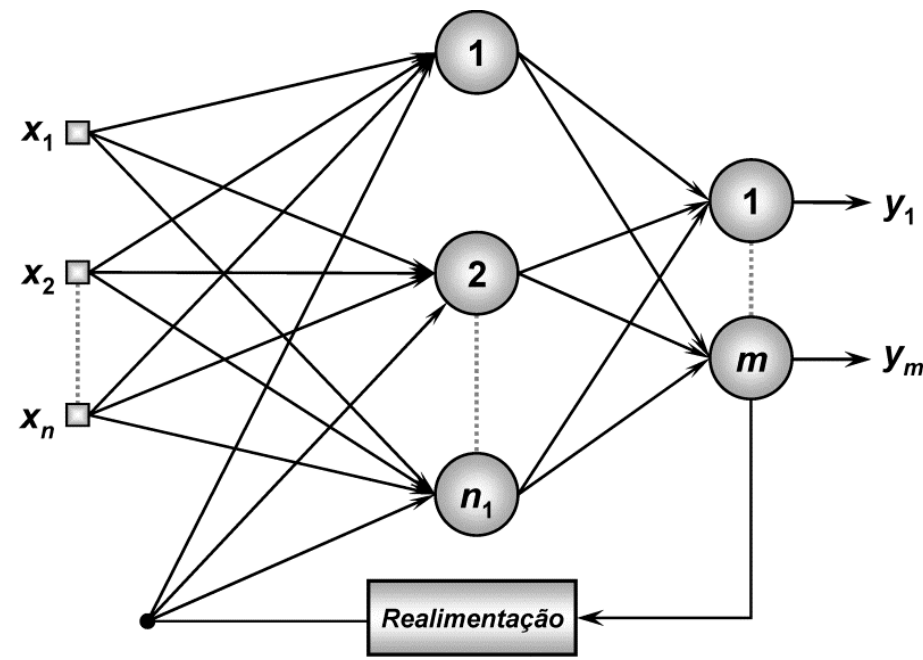

Fonte: SILVA et al., 2016.

\subsubsection{Redes reticuladas}

Este tipo de rede é caracterizada pela disposição espacial dos neurônios, com o propósito de extração de características que estão relacionadas com o processo de ajuste dos pesos sinápticos e limiares.

Esta arquitetura é aplicada em problemas de agrupamento, reconhecimento de padrões, grafos, etc. 
A figura 20 mostra este tipo de arquitetura.

Figura 20: Rede neural reticulada

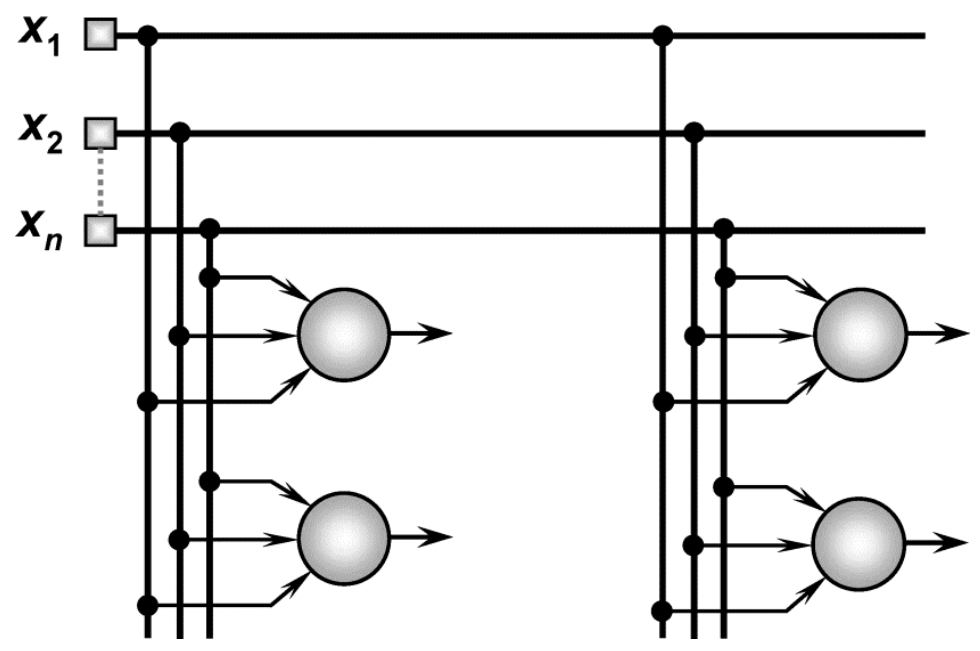

Fonte: SILVA et al., 2016.

\subsection{Tipos de aprendizagem}

Uma das características principais das redes neurais é que ela aprende com exemplos ou amostras. Logo após a rede ter aprendido, ela reproduz saídas muito próximas a realidade de dados que não formaram parte no processo de aprendizagem.

O Objetivo do processo de aprendizagem é o treino da rede neural para ter resultados satisfatórios.

O processo de aprendizagem consiste em um conjunto de passos ordenados para o ajuste dos pesos sinápticos e limiares, o que é chamado de algoritmo de aprendizagem.

Num sentido amplo, podemos categorizar os processos de aprendizagem através dos quais as redes neurais funcionam da seguinte forma: aprendizado supervisionado e aprendizagem não supervisionada. 
Essas diferentes formas de aprendizagem realizadas em redes neurais são parecidas às do aprendizado humano

A seguir serão apresentadas as principais metodologias de aprendizagem.

\subsubsection{Aprendizado supervisionado}

O aprendizado supervisionado é o algoritmo de aprendizagem que utiliza os dados de entrada e saída como os exemplos para o processo de aprendizagem da rede.

Os resultados da rede neural a partir dos dados de entrada são comparados com os dados de saída (valores desejados). O algoritmo de aprendizagem é usado, então, para ajustar os pesos sinápticos e os limiares com o objetivo de igualar ou aproximar os valores obtidos da rede neural com os valores de saída dos exemplos do conjunto de dados de treinamento (resultado alvo).

\subsubsection{Aprendizagem não supervisionada}

Na aprendizagem não supervisionada os pesos sinápticos e os limiares são ajustados em função dos dados de entrada apenas, ou seja, não se tem um resultado alvo.

Na primeira instância, parece que não é prático treinar uma rede sem ter um resultado alvo, contudo, a maioria desses algoritmos executam algum tipo de agrupamento, classificando por categorias e em valores os dados de entrada.

\subsection{Redes Perceptron}

A partir do modelo que McCulloc \& Pitts desenvolveram em 1943 (exposto no ponto 4.2.2), foi que Rosenblatt desenvolveu, em 1958, o PERCEPTRON. 
Rosenblatt desenvolveu um algoritmo para adaptação dos pesos sinápticos do Perceptron e demostrou a convergência do algoritmo quando os padrões são linearmente separáveis.

O Perceptron é a forma mais simples de uma rede neural utilizada para classificação de padrões que se diz linearmente separáveis.

Ele consiste de um único neurônio com pesos sinápticos e limiar ajustável.

Rosenblatt provou que, se os padrões (vetores) usados para treinar o Perceptron fossem projetados a partir de duas classes linearmente separáveis, o algoritmo Perceptron converge e posiciona a superfície de decisão na forma de um hiperplano entre as duas classes. A prova da convergência do algoritmo é conhecida como o teorema da convergência Perceptron.

O Perceptron, construído em torno de um único neurônio, é limitado à realização de classificação de padrões com apenas duas classes. Ao expandir a camada de saída (computação) do Perceptron para incluir mais de um neurônio, podemos realizar classificação correspondente com mais de duas classes.

No entanto, as classes devem ser linearmente separáveis para que o Perceptron funcione corretamente. O ponto importante é que, na medida em que a teoria básica do Perceptron como um classificador de padrões está em causa, precisamos considerar apenas o caso de um único neurônio.

O Perceptron pertence a arquitetura feedfordward de camada única e pode ser visto na figura 21 .

Para implementação computacional o limiar de ativação $\theta$ foi assumido como um peso sináptico $w_{0}$, tendo-se a unidade negativa como valor de entrada para esse peso sináptico. 
Figura 21: O Perceptron

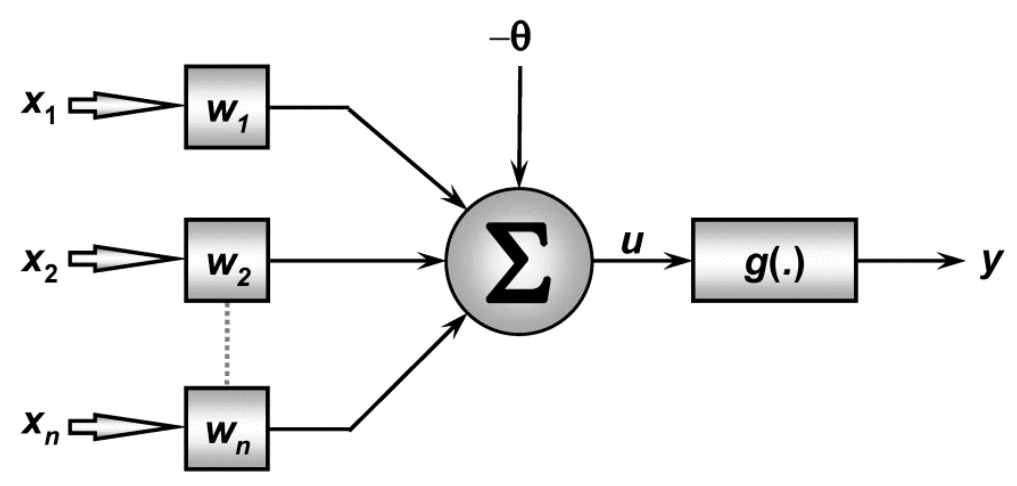

Fonte: SILVA et al., 2016.

\subsubsection{Principio de funcionamento do Perceptron}

Em termos matemáticos, o Perceptron pode ser definido da seguinte maneira:

$$
\begin{gathered}
u=\sum_{i=1}^{n} w_{i} x_{i}-\theta \\
y=g(u)
\end{gathered}
$$

Devido as características funcionais do Perceptron, as funções de ativação mais usadas são o degrau e o degrau bipolar.

As entradas $x_{i}$ podem tomar qualquer valor, dependendo do tipo de problema a ser resolvido pelo Perceptron, lembrando que os padrões têm que ser linearmente separáveis.

O ajuste dos pesos sinápticos e do limiar é realizado através de um algoritmo de treinamento supervisionado, ou seja, para cada amostra se tem o valor desejado.

O ajuste dos pesos sinápticos é feito segundo o seguinte algoritmo matemático:

$$
w^{\text {atual }}=w^{\text {anterior }}+\eta\left(d^{(k)}-y\right) x^{k}
$$

Onde: 
$w=\left[\begin{array}{lll}\theta & w_{1} & w_{2} \ldots \ldots w_{n}\end{array}\right]^{T}$ é o vetor contendo o limiar e os pesos sinápticos.

$x^{(k)}=\left[\begin{array}{lll}-1 & x_{1}^{(k)} & x_{2}^{(k)} \ldots \ldots . . x_{n}^{(k)}\end{array}\right]^{T}$ é a k-ésima amostra de treinamento.

$d^{(k)}$ é o valor desejado para a k-ésima amostra de treinamento.

$y$ é o valor de saída produzida pelo Perceptron

$\eta$ é uma constante que define a taxa de aprendizagem da rede, sendo normalmente um valor compreendido entre $0<\eta<1$.

Widrow (1962) e seus colaboradores desenvolveram, o Adaline que é, basicamente, o Perceptron com um algoritmo de aprendizagem baseado no mínimo erro quadrático, também chamado delta generalizado, o qual será estudado mais adiante.

\subsection{Redes Perceptron multicamada}

Um Perceptron multicamadas (MPC) consiste em uma rede com pelo menos uma camada oculta de neurônios.

As redes PMC são muito versáteis e tem uma ampla variedade de aplicação em quase todas as áreas do conhecimento

Entre as áreas mais utilizadas se destacam as seguintes (SILVA et al., 2016):

- Aproximação universal de funções

- Reconhecimento de padrões

- Identificação e controle de processos

- Previsão de séries temporais

- Otimização de sistemas

A rede PMC cai dentro da classificação de arquitetura feedforward de camada múltipla com treinamento supervisionado que pode ser observado na figura 22. 
Figura 22: Perceptron multicamada

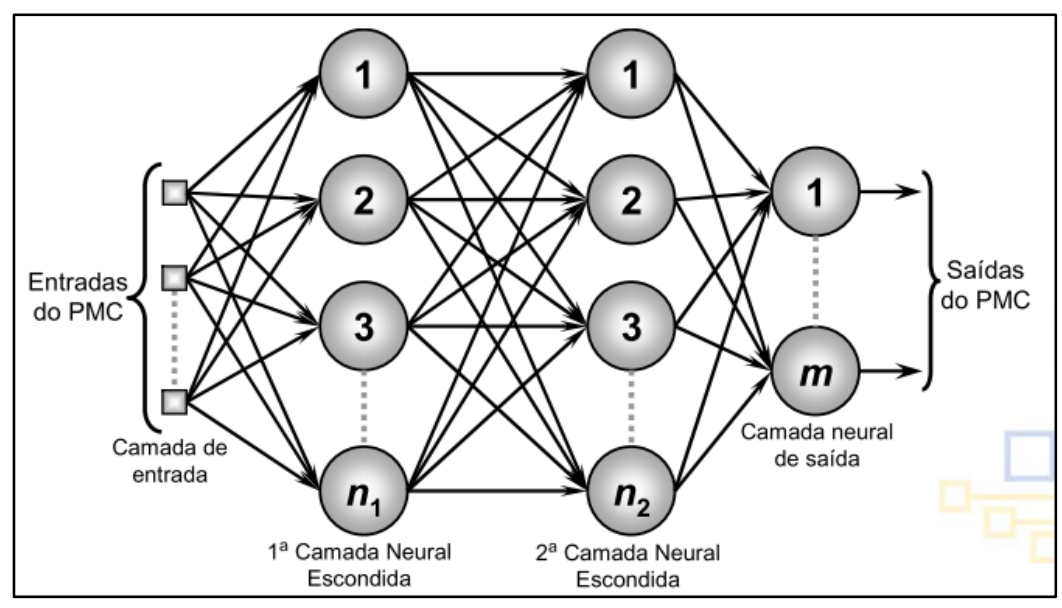

Fonte: SILVA et al., 2016.

A diferença entre o Perceptron e o Adaline: a rede PMC pode ter na sua camada de saída mais de um neurônio, sendo que cada neurônio de saída representa uma das saídas do processo a ser mapeado pela rede PMC.

A configuração topológica de uma rede PMC, tais como o número de camadas, e o número de neurônios por camada a ser utilizada, dependera de vários fatores tais como, a distribuição espacial das amostras de treinamento e os valores iniciais atribuídos as matrizes de pesos (SILVA et al., 2016)

\subsubsection{Algoritmos de aprendizagem supervisionada do PMC}

A popularidade da rede Perceptron multicamadas se deu nos anos 80 , quando foi exposto o algoritmo de aprendizagem chamado backpropagation, o qual permitiu o ajuste dos pesos sinápticos de forma eficiente, e permitiu a implementação desse tipo de redes.

Os algoritmos de aprendizagem são também encontrados na literatura como funções de treinamento. 
Os algoritmos de aprendizagem são um conjunto de regras pré-estabelecidas para o ajuste dos pesos sinápticos, e de modo a poder reproduzir a saída desejada com o menor erro possível.

Esses algoritmos também podem ser entendidos como um caso especial de aproximação de funções, onde não é levado em consideração nenhum modelo explícito dos dados.

Antes de iniciar o treinamento, os pesos sinápticos são determinados inicialmente de maneira aleatória, de modo que ao final do processo o conjunto de pesos obtido seja útil à solução do problema.

O treinamento começa com a introdução de um conjunto de dados na entrada da rede, para os quais se espera que a saída atribua um valor que já é previamente conhecido. Como este valor de saída é conhecido, então o treinamento é do tipo supervisionado.

Existem muitos algoritmos com suas próprias particularidades, apresentando vantagens e desvantagens uns sobre outros entre elas. As que seguem na lista abaixo são do algoritmo backpropagation e de suas versões melhoradas

- Algoritmo padrão (backpropagation, regra delta generalizada ou gradiente descendente)

- Backpropagation com inserção do momentum.

- Método resilient-propagation

- Método de Levenberg-Marquardt

Nesta dissertação serão apresentados somente dois algoritmos: O algoritmo padrão (backpropagation) e o que será utilizado neste trabalho: o algoritmo de aprendizagem Levenberg-Marquardt, encontrado na ferramenta Matlab.

\subsubsection{Algoritmo backpropagation}

O algoritmo padrão é chamado backpropagation, regra delta generalizada ou gradiente descendente, baseado no modelo de aprendizado supervisionado, que retro propaga o erro da 
camada de saída até a camada de entrada, permitindo a atualização dos pesos sinápticos entre as camadas intermediárias (ocultas).

Este aprendizado supervisionado é baseado no método de minimização de erros quadráticos LMS (least mean square), buscando minimizar o erro global da camada de saída.

O algoritmo tem duas fases, a propagação adiante e a propagação reversa.

\subsection{Fase de propagação adiante}

Inicialmente pesos aleatórios são escolhidos e é reproduzida a saída Y na última camada. A saída Y terá uma diferença com o valor desejado da amostra.

A notação é definida segundo a figura 23.

Figura 23: Notação matemática

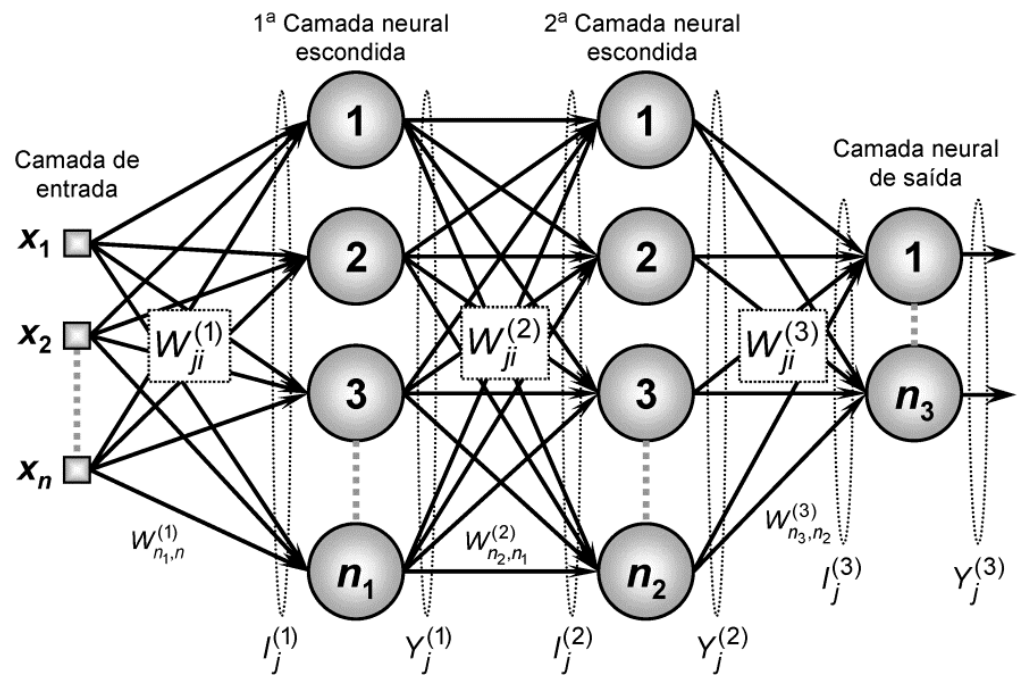

Fonte: SILVA et al., 2016.

Onde $w_{j i}^{(n)}$ significa o peso sináptico conectando neurônio $\mathrm{j}$ da camada $\mathrm{n}$ e o dado i que entra ao neurônio.

$I_{j}^{(n)}$ é a entrada ponderada do neurônio j da camada n e é definido por: 


$$
I_{j}^{(n)}=\sum_{i=0}^{n} w_{j i}^{(n)} x_{i}
$$

$Y_{j}^{(n)}$ é a saída do neurônio j da camada n e é definido por:

$$
Y_{j}^{(n)}=g\left(I_{j}^{(n)}\right)
$$

O valor de saída Y é comparado com o valor desejado da amostra de treinamento, e é calculado o erro quadrático E, que é definido como:

$$
E(k)=\frac{1}{2} \sum_{i=1}^{n_{3}}\left(d_{j}(k)-Y_{j}^{(3)}(k)\right)^{2}
$$

Onde $Y_{j}^{(3)}(k)$ é a saída produzida no neurônio $j$ da camada 3 (saída da rede) para a $\operatorname{amostra} k$.

O erro quadrático médio produzido por todas as amostras é:

$$
E_{M}=\frac{1}{\rho} \sum_{i=1}^{\rho} E(k)
$$

Onde $p$ e o número de amostras e $E(k)$ é o valor obtido em (45).

Logo após produzir a saída $Y$ e calcular o erro quadrático médio na última camada, procede-se com a realização da fase da propagação reversa.

\subsection{Fase de propagação reversa}

O ajuste dos pesos da camada de saída é feito minimizando a função (45), ou seja, derivando o erro em relação ao peso w, que pela regra da cadeia tem-se:

$$
\nabla E^{(3)}=\frac{\partial E}{\partial w_{j i}^{(3)}}=\frac{\partial E}{\partial Y_{j}^{(3)}} \frac{\partial Y_{j}^{(3)}}{\partial I_{j}^{(3)}} \frac{\partial I_{j}^{(3)}}{\partial w_{j i}^{(3)}}
$$




$$
\begin{gathered}
\frac{\partial E}{\partial w_{j i}^{(3)}}=-\left(d_{j}-Y_{j}^{(3)}\right) g^{\prime}\left(I_{j}^{(3)}\right) Y_{i}^{(2)} \\
\delta_{j}^{(3)}=-\left(d_{j}-Y_{j}^{(3)}\right) g^{\prime}\left(I_{j}^{(3)}\right)
\end{gathered}
$$

Deste modo, a atualização do peso $\left(\Delta \omega_{i j}\right)$ é proporcional ao negativo da derivada parcial do erro com relação ao próprio peso:

$$
\Delta w_{j i}^{(3)}=-\eta \frac{\partial E}{\partial w_{j i}^{(3)}}=\eta \delta_{j}^{(3)} Y_{i}^{(2)}
$$

Onde $\eta$ é a taxa de aprendizado, e $\delta_{j}^{(3)}$ é chamado gradiente local em relação ao neurônio $j$ da camada 3 (saída).

Como o processo é iterativo a expressão (50) pode se escrever como segue:

$$
w_{j i}^{(3)}(t+1)=w_{j i}^{(3)}(t)+\eta \delta_{j}^{(3)} Y_{i}^{(2)}
$$

Onde $t$ é o número de iteração.

Para o ajuste dos pesos de camadas intermediárias não se tem um valor desejado, pelo que nesta situação o ajuste é efetuado por meio de estimativas dos erros produzidos na camada posterior.

Assim o ajuste dos pesos da segunda camada é feito como segue:

$$
\nabla E^{(2)}=\frac{\partial E}{\partial w_{j i}^{(2)}}=\frac{\partial E}{\partial Y_{j}^{(2)}} \frac{\partial Y_{j}^{(2)}}{\partial I_{j}^{(3)}} \frac{\partial I_{j}^{(2)}}{\partial w_{j i}^{(2)}}
$$

Desenvolvendo:

$$
\begin{gathered}
\frac{\partial E}{\partial Y_{j}^{(2)}}=\sum_{k=1}^{n 3} \frac{\partial E}{\partial I_{k}^{(3)}} w_{k j}^{(3)}=\sum_{k=1}^{n 3} \delta_{j}^{(3)} w_{k j}^{(3)} \\
\frac{\partial E}{\partial w_{j i}^{(3)}}=-\left(\sum_{k=1}^{n 3} \delta_{j}^{(3)} w_{k j}^{(3)}\right) g^{\prime}\left(I_{j}^{(2)}\right) Y_{i}^{(1)}
\end{gathered}
$$


Definindo a gradiente da $\delta_{j}^{(2)}$ (Camada 2) como:

$$
\delta_{j}^{(2)}=-\left(\sum_{k=1}^{n 3} \delta_{j}^{(3)} w_{k j}^{(3)}\right) g^{\prime}\left(I_{j}^{(2)}\right)
$$

Então:

$$
\Delta w_{j i}^{(2)}=\eta \delta_{j}^{(2)} Y_{i}^{(1)}
$$

Em notação para o procedimento iterativo:

$$
w_{j i}^{(2)}(t+1)=w_{j i}^{(2)}(t)+\eta \delta_{j}^{(2)} Y_{i}^{(1)}
$$

O procedimento para o ajuste de pesos da primeira camada escondida é similar ao da segunda camada. Desenvolvendo, o ajuste dos pesos é feito como segue:

$$
w_{j i}^{(1)}(t+1)=w_{j i}^{(1)}(t)+\eta \delta_{j}^{(1)} x_{i}
$$

Onde:

$$
\delta_{j}^{(1)}=-\left(\sum_{k=1}^{n 2} \delta_{j}^{(2)} w_{k j}^{(2)}\right) g^{\prime}\left(I_{j}^{(1)}\right)
$$

Depois de ajustar os pesos de todas as camadas na fase de propagação reversa, o ciclo para a amostra $k$ é concluído, e um novo ciclo é calculado com uma nova amostra e se faz o cálculo da saída e do erro quadrático médio, com uma nova amostra e com os pesos ajustados anteriormente e assim por diante.

O processo é parado quando o erro quadrático médio global de uma época (cálculo de todas as amostras) anterior é menor em relação à precisão estabelecida $\varepsilon$ com a época atual.

O ciclo de aplicação do algoritmo na fase adiante e reversa para todas as amostras é chamado de época.

Para cada época sucessiva o erro quadrático médio global é menor porque os pesos vão se ajustando até chegar a um erro quadrático mínimo. 
Uma figura ilustrativa muito utilizada é o comportamento do erro quadrático médio em função do número de épocas como mostra a figura 24.

Figura 24: Erro x Época

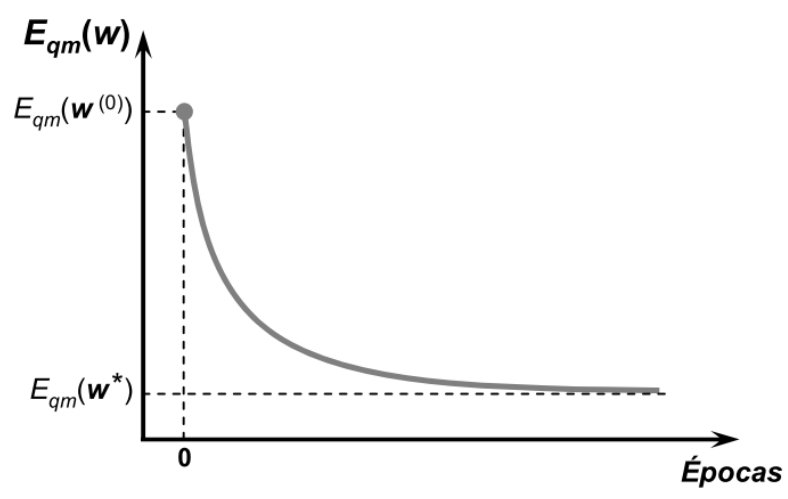

Fonte: SILVA et al., 2016.

Passos do algoritmo computacional:

1. Obter o conjunto de dados de treinamento, cada amostra com o respectivo valor desejado.

2. Iniciar os pesos $w_{i j}^{(1)}, w_{i j}^{(2)}$ e $w_{i j}^{(3)}$ com valores aleatórios pequenos.

3. Especificar a taxa de aprendizagem $\eta$ e a precisão $\varepsilon$

4. Iniciar o contador de épocas

5. Comparar $E_{M}$ actual $\operatorname{com} E_{M}$ anterior

6. Propagar o sinal adiante e obter a saída

7. Calcular o erro na camada de saída

8. Propagar de forma reversa ajustando os pesos

9. Repetir desde o passo 5 até obter a precisão requerida

\subsubsection{Algoritmo Levenberg-Marquardt}

O algoritmo Levenberg-Marquardt é um dos algoritmos mais utilizados em redes Perceptron multicamadas. É também conhecido como o método dos mínimos quadrados para 
modelo não lineares. $\mathrm{O}$ método é uma otimização do backpropagation, e pode ser de10 até 100 vezes mais rápido que ele.

As funções de erro quadrático e erro quadrático médio, apresentado nas equações 41 e 42 respetivamente, podem ser expressas conjuntamente pela equação 51 a partir das seguintes equações.

Ainda levando em conta que a rede neural pode ter múltiplos neurônios na camada de saída.

$$
\begin{gathered}
V=\frac{1}{2 p} \sum_{k=1}^{p} \sum_{j=1}^{n 3}\left(d_{j}(k)-Y_{j}^{(3)}(k)\right)^{2} \\
V=\frac{1}{2 p} \sum_{k=1}^{p}\left(\boldsymbol{d}_{j}(k)-\boldsymbol{Y}_{j}^{(3)}(k)\right)^{T}\left(\boldsymbol{d}_{j}(k)-\boldsymbol{Y}_{j}^{(3)}(k)\right) \\
V=\frac{1}{2 p} \sum_{k=1}^{p}\left(\boldsymbol{E}^{T}(k) \boldsymbol{E}(k)\right)
\end{gathered}
$$

A partir do método Newton-Gauss, pode ser demostrado que:

$$
\begin{gathered}
\Delta \boldsymbol{w}=-\left(\nabla^{2} f(w)\right)^{-1} \nabla f(w) \\
\nabla f(w)=\boldsymbol{J}^{T}(w) \boldsymbol{E} \\
\nabla^{2} f(w)=\boldsymbol{J}^{T}(w) \boldsymbol{J}(W)+\mu \boldsymbol{I}
\end{gathered}
$$

Inserindo a expressão (58) e (59) em (60) obtém-se o algoritmo iterativo do método de Levenberg-Marquardt para o ajuste dos pesos sinápticos:

$$
\Delta \boldsymbol{w}=\left(\boldsymbol{J}^{T}(w) \boldsymbol{J}(W)+\mu \boldsymbol{I}\right)^{-1} \boldsymbol{J}^{T}(w) \boldsymbol{E}
$$

Logo:

$$
\boldsymbol{w}(t+1)=\boldsymbol{w}(t)+\Delta \boldsymbol{w}
$$

Onde:

$$
w=\left[\begin{array}{lll}
w^{(1)} & w^{(2)} & w^{(3)}
\end{array}\right]^{T} \mathrm{e},
$$




$$
\begin{aligned}
& \boldsymbol{E}=[\boldsymbol{E}(1) \boldsymbol{E}(2) \ldots \boldsymbol{E}(p)]^{T} \text { é o vetor erro das p amostras de treinamento. } \\
& \boldsymbol{J}(\boldsymbol{w})=\left[\boldsymbol{J}\left(\boldsymbol{w}^{(1)}\right) \boldsymbol{J}\left(\boldsymbol{w}^{(2)}\right) \boldsymbol{J}\left(\boldsymbol{w}^{(3)}\right)\right]
\end{aligned}
$$

Exemplo do jacobiano para $\boldsymbol{J}\left(\boldsymbol{w}^{(1)}\right)$ :

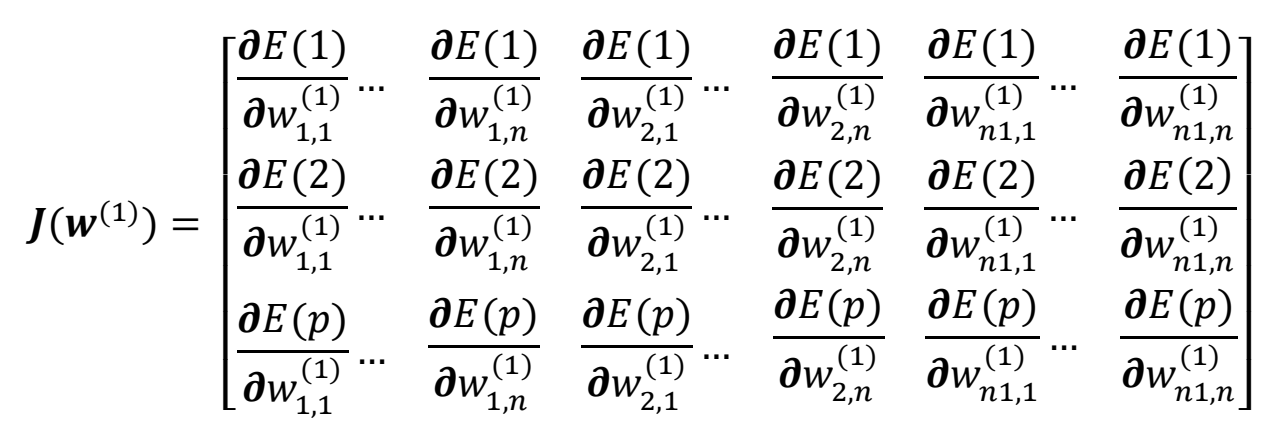

\subsubsection{Aspectos de topologia e treinamento}

Normalmente a topologia de uma rede neural (número de camadas escondidas e neurônios) é efetuada de forma empírica.

Uma das técnicas para escolher uma topologia, dentre várias candidatas, é o método de validação cruzada.

Um método de validação cruzada muito utilizado é chamado: random subsampling cross-validation e divide as amostras de forma aleatória para treinamento e para teste (80\% treinamento e $20 \%$ para teste, por exemplo).

São realizadas várias divisões aleatórias como mostra a figura 25. Logo, todas as topologias candidatas são treinadas para cada ensaio e será adotada a topologia que obtiver o melhor desempenho global para todos os ensaios. 
Figura 25: Amostragem aleatória para validação cruzada

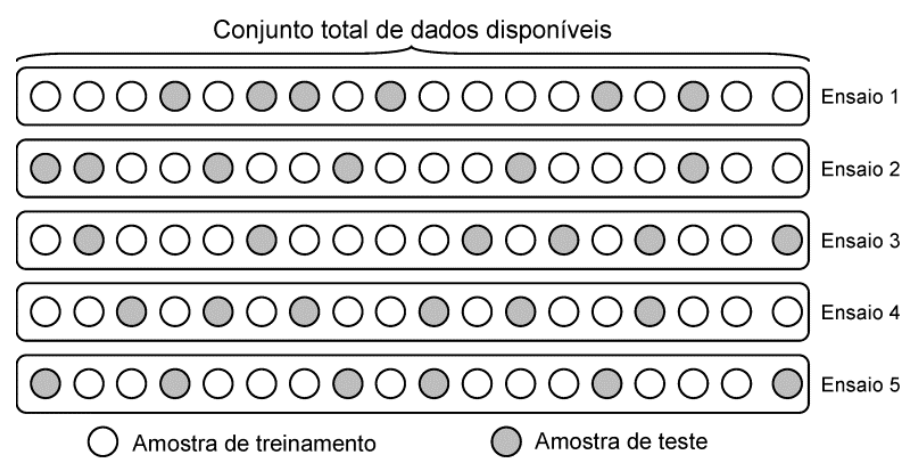

Fonte: SILVA et al., 2016.

Neste ponto deve-se ter cuidado para que a rede não tenha overfitting ou underfitting. O que definira se a rede apresenta aspectos de overfitting ou underfitting, são os resultados dos erros no subconjunto de teste, principalmente.

Deve-se garantir que o subconjunto de treinamento tenha os valores máximos e mínimos das variáveis de entrada para que a rede tenha um bom desempenho, caso isso não aconteça, essas amostras com valores máximos e mínimos irão no subconjunto de teste e o desempenho pode ser insatisfatório por estar fora do domínio de treinamento.

Todas as amostras devem ser normalizadas, por exemplo, com o teorema de Tales, para que os valores de entrada das amostras estejam no intervalo [-1 1] e os valores desejados no intervalo [l 1 1] e [-1 1] para as funções logística e tangente hiperbólica, respectivamente. 


\section{CAPÍTULO 5}

\section{Metodologia adotada}

\subsection{Introdução}

A metodologia adotada para este trabalho foi uma das referidas na revisão bibliográfica. Ela foi proposta por Balasubramanian e Singh (2011).

A metodologia propõe o uso da margem de potência reativa nas barras mais críticas como índice para determinar a proximidade do colapso. A margem de potência reativa é calculada usando o fluxo de potência continuado para determinar o nariz da curva V-Q. A análise modal é feita para determinar as 5 barras mais críticas do sistema.

Como é sabido, o fluxo de potência continuado é o método mais exato para determinar o ponto de bifurcação. Porém, tem sido usado como ferramenta para estudos de planejamento (offline), já que precisa de um alto custo computacional, sendo inviável para monitoramento online.

Com ajuda das RNA's é possível obter o monitoramento online, devido ao baixo esforço computacional, e com resultados com erros mínimos.

A arquitetura da rede proposta é Perceptron Multicamadas com duas camadas escondidas, e sua função neste caso é de aproximador funcional.

A rede também pode ser treinada com casos de alteração de configuração da rede, onde só é preciso de uma RNA.

O fato de que a margem de potência reativa seja usada como medida de monitoramento online é uma grande vantagem, já que é uma grandeza com a que estamos muito familiarizados. Também, o fato de que a rede seja treinada com dados obtidos a partir do fluxo de potência continuado, o método mais preciso a converte numa metodologia atrativa de ser utilizada. 


\subsection{Descrição da metodologia}

Para a avaliação da metodologia, será estudado o sistema de 30 barras do IEEE.

Os dados do sistema de 30 barras são mostrados no apêndice A.

Para o treinamento da RNA é calculado o fluxo de carga para diferentes fatores multiplicadores de carga, tanto para a configuração normal, como para duas situações de contingência.

Os carregamentos iniciam no caso base y e vão até o ponto de máximo carregamento para as situações de configuração normal e de contingência.

Para este propósito foi programado em Matlab (2015) o fluxo de potência continuado (FPC) segundo a metodologia explicada na seção 3.1. O FPC fornecerá dados como o fator multiplicador de carga, os resultados do fluxo de carga para cada fator de carga, assim como o ponto de bifurcação.

Para cada fator de carga são calculados os 5 mínimos autovalores, e para cada um deles são calculados as 5 barras com os máximos índices de participação de barras (BPF).

A análise modal foi implementada em Matlab junto com o fluxo de potência continuado.

Logo, são escolhidas as 5 barras que mais aparecem tendo os maiores índices BPF para cada fator multiplicador de carga. Isto determina as 5 barras mais críticas do sistema.

Para cada fator de carga é calculado a margem de potência reativa DVC (distance to voltage colapse) para as 5 barras mais críticas do sistema.

O DVC é calculado usando o fluxo de potência continuado, o qual determina o ponto de bifurcação da curva Q-V segundo explicado na seção 3.1. O fluxo de potência continuado para determinar a curva V-Q foi implementado em Matlab.

Logo, é calculado os momentos de potência para cada barra crítica, e para cada fator multiplicador de carga que será utilizado como entrada do treinamento das RNA. Isso será explicado mais adiante. 
Todos os cálculos de fluxo de carga feitos incluem o limite de geração de potência reativa dos geradores com os tap's de transformadores fixos, e o modelo de carga é de potência constante. 


\section{CAPÍTULO 6}

\section{Simulações e resultados}

\subsection{Cálculo do fluxo de carga para cada fator de carga}

Com o método do fluxo de potência continuado foi calculado a seguinte quantidade de fluxos de carga:

1. Configuração normal: 130 fatores de carga desde o caso base com fator multiplicador de carga $=1$, até o ponto de bifurcação com fator $1+\rho=1,53690254$.

2. Contingência do gerador 2: 122 fatores de carga desde o caso base até o ponto de bifurcação com fator $1+\rho=1,4731$.

3. Contingência da linha 2-5: 79 fatores de carga desde o caso base até o ponto de bifurcação com fator $1+\rho=1,1387$.

4. Contingência do gerador 8: 94 fatores de carga desde o caso base até o ponto de bifurcação com fator $1+\rho=1,4467$.

5. Contingência do gerador 11: 94 fatores de carga desde o caso base até o ponto de bifurcação com fator $1+\rho=1,4715$.

Então, o número total de amostras para o treino da RNA é de 519.

\subsection{Análise modal para determinação das barras críticas}

Para cada um dos 519 fatores de multiplicação de carga foram calculados os 5 mínimos autovalores da matriz jacobiana reduzida. 
A continuação, na tabela 2, mostra-se todos os autovalores para o caso base e configuração normal.

Tabela 2: Autovalores caso base

\begin{tabular}{c|c|c|c}
\hline Barra & Autovalor $(\boldsymbol{\lambda})$ & Barra & Autovalor $(\boldsymbol{\lambda})$ \\
\hline 3 & 110,3349468 & 19 & 13,9799385 \\
\hline 4 & 101,3921237 & 20 & 13,72476253 \\
\hline 6 & 66,23680083 & 21 & 11,28572733 \\
\hline 7 & 59,84764968 & 22 & 0,509604057 \\
\hline 9 & 38,01776114 & 23 & 1,038604388 \\
\hline 10 & 35,50247796 & 24 & 1,794482286 \\
\hline 12 & 23,51919966 & 25 & 8,829377705 \\
\hline 14 & 23,2270769 & 26 & 7,652152607 \\
\hline 15 & 19,85063505 & 27 & 3,611296767 \\
\hline 16 & 19,34065508 & 28 & 4,078409828 \\
\hline 17 & 18,30191317 & 29 & 6,291742336 \\
\hline 18 & 16,74496178 & 30 & 5,530419908 \\
\hline
\end{tabular}

Fonte: Autor

Como pode se ver na tabela 2, é evidente que os 5 mínimos autovalores são das barras $22,23,24,27$ e 28 .

Na Tabela 3, é mostrado o índice de participação de barras BPF para esses 5 mínimos autovalores encontrados. 
Tabela 3: Índices de participação de barras para os 5 mínimos autovalores

\begin{tabular}{c|c|c|c|c|c}
\hline Barra & $\lambda=0,509$ & $\lambda=1,038$ & $\lambda=1,794$ & $\lambda=3,6113$ & $\lambda=4,0784$ \\
\hline 3 & 0,0003471 & 0,0005528 & $5,78 \mathrm{E}-05$ & 0,0003739 & 0,0004741 \\
\hline 4 & 0,0005084 & 0,0007849 & $7,84 \mathrm{E}-05$ & 0,0004496 & 0,0005512 \\
\hline 6 & 0,0005637 & 0,0003742 & $4,59 \mathrm{E}-05$ & 0,0006352 & $2,86 \mathrm{E}-05$ \\
\hline 7 & 0,0002077 & 0,0001453 & $1,93 \mathrm{E}-05$ & 0,0003265 & $1,55 \mathrm{E}-05$ \\
\hline 9 & 0,0038381 & 0,0123777 & 0,0004878 & 0,0174228 & 0,0158533 \\
\hline 10 & 0,0124557 & 0,04278 & 0,001519 & 0,0435531 & 0,0412526 \\
\hline 12 & 0,0038913 & 0,0179505 & 0,0013218 & 0,0001952 & 0,050203 \\
\hline 14 & 0,0083785 & 0,0421716 & 0,0034969 & 0,003406 & 0,3135085 \\
\hline 15 & 0,0114526 & 0,0484601 & 0,0031375 & 0,0055966 & 0,1294607 \\
\hline 16 & 0,0082643 & 0,0385052 & 0,0025009 & 0,0471276 & 0,001605 \\
\hline 17 & 0,0118707 & 0,0473248 & 0,0021599 & 0,0711385 & 0,0283175 \\
\hline 18 & 0,0170711 & 0,1038914 & 0,0129002 & 0,1708644 & $9,78 \mathrm{E}-05$ \\
\hline 19 & 0,0184862 & 0,115623 & 0,014844 & 0,1811753 & 0,0504919 \\
\hline 20 & 0,0178147 & 0,1051025 & 0,0123352 & 0,1076279 & 0,0760935 \\
\hline 21 & 0,018101 & 0,0484406 & 0,0005382 & 0,097567 & 0,047848 \\
\hline 22 & 0,0194875 & 0,0474942 & 0,0003069 & 0,1010087 & 0,0408645 \\
\hline 23 & 0,0245559 & 0,0516882 & 0,0001063 & 0,0185324 & 0,194848 \\
\hline 24 & 0,0404462 & 0,0298731 & 0,0031583 & 0,0837768 & 0,0053217 \\
\hline 25 & 0,1064388 & 0,0017897 & 0,0568417 & 0,0056827 & 0,0006374 \\
\hline 26 & 0,1713856 & 0,0051797 & 0,6214855 & 0,0386489 & 0,0020579 \\
\hline 27 & 0,1045227 & 0,0232186 & 0,0010202 & 0,0010352 & 0,0001519 \\
\hline 28 & 0,0026447 & $2,44 \mathrm{E}-06$ & $7,89 \mathrm{E}-05$ & 0,0006306 & $1,14 \mathrm{E}-05$ \\
\hline 29 & 0,1901113 & 0,098989 & 0,1099 & 0,0008201 & $5,25 \mathrm{E}-05$ \\
\hline 30 & 0,2071215 & 0,1172515 & 0,1517346 & 0,0023715 & 0,0002257 \\
\hline & & & & \\
\hline
\end{tabular}

Fonte: Autor

Como pode se ver para o mínimo autovalor $\lambda=0,5096$, as barras com os 5 maiores índices de participação são as barras 25, 26, 27, 29 e 30.

Já as barras que mais se repetem, com maior índice BPF para os 5 mínimos autovalores, são as barras 19, 20, 26, 29 e 30.

O cálculo é feito para os 519 cenários de carregamento e configuração de rede, e as barras que mais vezes aparecem com o maior índice de participação de rede são as barras 14, 19, 26, 29 e 30. Portanto, essas barras são consideradas como as barras críticas do sistema e, para essas barras, é que será calculada a margem de potência reativa para os 519 cenários. 


\subsection{Dados de entrada para o treino da rede neural}

Para esta metodologia aplicada ao sistema de 30 barras é necessário um vetor de 80 dados de entrada para cada amostra que são listados abaixo:

1. 5 dados de potência reativa de reserva dos 5 geradores $(2,5,8,11$ e 13). A barra slack não conta.

2. 6 dados de Momento Q (6 geradores) para cada uma das 5 barras críticas o que soma um total de 30 Momento Q.

3. 6 dados de Momento P (6 geradores) para cada uma das 5 barras críticas o que soma um total de 30 Momento P.

4. Módulo da tensão para cada uma das 5 barras críticas.

5. Dado da potência ativa $P$ retirada em cada uma das 5 barras críticas.

6. Dado da potência reativa $Q$ retirada em cada uma das 5 barras críticas.

Todos esses dados de entrada somam um total de 80 dados por amostra.

Para os 80 dados de entrada tem-se 5 valores desejados de saída (objetivo de saída da rede neural) que são as margens de potência reativa para as 5 barras críticas.

\subsection{Potência reativa de reserva dos geradores}

Na tabela 4 é mostrada, para o caso base a potência reativa gerada pelos geradores, $\mathrm{o}$ limite de cada um deles e a margem de potência reativa que é a diferença entre o limite e o gerado. Esse cálculo é feito para cada um dos 519 cenários. 
Tabela 4: Potência reativa de reserva dos geradores.

\begin{tabular}{c|c|c|c}
\hline Gerador & $\begin{array}{c}\text { Q gerado } \\
\text { (MVAr) }\end{array}$ & $\begin{array}{c}\text { Limite Q } \\
\text { (MVAr) }\end{array}$ & $\begin{array}{c}\text { Q reserva } \\
\text { (MVAr) }\end{array}$ \\
\hline 2 & 49,56 & 50 & 0,44 \\
\hline 5 & 36,94 & 40 & 3,06 \\
\hline 8 & 37,22 & 40 & 2,78 \\
\hline 11 & 16,18 & 24 & 7,82 \\
\hline 13 & 10,63 & 24 & 13,37 \\
\hline
\end{tabular}

Fonte: Autor

\subsection{Cálculo dos momentos de potência}

A definição dos momentos de potência é:

$P_{\text {Mom }}=\operatorname{real}\left(S_{f o r} Z_{t h}\right)$

$Q_{\text {Mom }}=\operatorname{imag}\left(S_{\text {for }} Z_{\text {th }}\right)$ Onde:

$S_{f o r}$ é a potência complexa fornecida por um gerador a uma barra de carga.

$Z_{t h}$ é a impedância de Thevenin equivalente entre um gerador e uma barra de carga.

Esses cálculos são explicados a seguir.

\subsection{Cálculo da contribuição individual de cada gerador}

No presente trabalho, o algoritmo proposto por Teng (2005) foi escolhido para o cálculo de contribuição individual de cada gerador e para uma barra de carga específica. 
Este algoritmo envolve essencialmente a conversão das cargas para impedância shunt equivalente e, depois, para ser incluídas na formação da matriz Z-barra da rede. A técnica utilizada é a injeção de corrente, um por vez, em cada gerador, deixando os outros abertos para avaliar a contribuição deste gerador, considerando as impedâncias oferecidas por vários caminhos entre o gerador e as barras de carga.

A injeção de corrente equivalente de cada gerador pode ser calculada como:

$$
I=\left(\frac{P+j Q}{V}\right)^{*}
$$

Onde $\mathrm{P}+\mathrm{jQ}$ é a potência complexa fornecida ao sistema pelo gerador e $\mathrm{V}$ é a tensão complexa na barra do gerador.

A impedância shunt equivalente de uma barra de carga pode ser calculada como:

$$
Z=\left(\frac{|V|^{2}}{P-j Q}\right)
$$

Onde $|V|$ é o módulo da tensão na barra de carga e P-jQ é o conjugado da potência complexa da carga.

Essa impedância equivalente é incluída na matriz Z-barra, e é obtida a matriz Z-barra'.

A tensão considerada como despacho individual do gerador é:

$$
\Delta V=[\text { Zbarra' }] x \operatorname{Ig}
$$

Onde Ig é o vetor coluna com só um elemento, o qual não é zero, que é a corrente equivalente do gerador que está fazendo o despacho desse delta de tensão.

A tensão na barra é a soma dos deltas de tensão aportados por todos os geradores:

$$
V=\sum_{i=1}^{N G} \Delta V
$$

Onde NG é o número de geradores do sistema incluindo a barra slack. 
A corrente contribuída por um gerador a uma carga é:

$$
\Delta I=\frac{\Delta V}{Z}
$$

Então a potência complexa contribuída pelo gerador é:

$$
\Delta S=V(\Delta I)^{*}
$$

$\mathrm{Na}$ tabela 5, é mostrado o despacho dos geradores para as 5 barras críticas no caso base.

Tabela 5: Contribuição individual dos geradores às barras críticas.

\begin{tabular}{c|c|c|c|c|c|c|c|c|c|c|c|c|c|c}
\hline \multirow{2}{*}{ BARRA } & \multicolumn{2}{|c|}{ Gerador 1 } & \multicolumn{2}{c|}{ Gerador 2 } & \multicolumn{2}{c|}{ Gerador 5 } & \multicolumn{2}{c|}{ Gerador 8 } & \multicolumn{2}{c|}{ Gerador 11 } & \multicolumn{2}{c|}{ Gerador 13 } & \multicolumn{3}{c}{ Total } \\
\cline { 2 - 15 } & $\mathbf{M W}$ & MVAr & MW & MVAr & MW & MVAr & MW & MVAr & MW & MVAr & MW & MVAr & MW & MVAr \\
\hline 14 & 5,44 & 0,29 & 0,77 & 1,09 & $-0,11$ & 0,76 & $-0,03$ & 0,81 & 0,01 & 0,35 & 0,05 & 0,26 & $\mathbf{6 , 1 2}$ & $\mathbf{3 , 5 6}$ \\
\hline 19 & 8,46 & 1,35 & 1,03 & 1,84 & $-0,29$ & 1,17 & $-0,18$ & 1,27 & $-0,01$ & 0,57 & 0,00 & 0,39 & $\mathbf{9 , 0 0}$ & $\mathbf{6 , 6 0}$ \\
\hline 26 & 3,30 & 1,37 & 0,24 & 0,85 & $-0,23$ & 0,45 & $-0,19$ & 0,51 & $-0,07$ & 0,22 & $-0,05$ & 0,14 & $\mathbf{3 , 0 0}$ & $\mathbf{3 , 5 3}$ \\
\hline 29 & 2,16 & 0,38 & 0,26 & 0,48 & $-0,07$ & 0,30 & $-0,04$ & 0,52 & $-0,02$ & 0,14 & $-0,01$ & 0,09 & $\mathbf{2 , 2 6}$ & $\mathbf{1 , 7 2}$ \\
\hline 30 & 9,20 & 0,08 & 1,40 & 1,79 & $-0,11$ & 1,30 & 0,04 & 1,40 & 0,02 & 0,58 & 0,01 & 0,39 & $\mathbf{1 0 , 5 5}$ & $\mathbf{5 , 5 5}$ \\
\hline
\end{tabular}

Fonte: Autor

Da tabela pode se ver que a soma das contribuições é levemente diferente da carga das barras, o que é devido as perdas das linhas, o que significa que o despacho de cada gerador leva em conta as perdas nas linhas para chegar as barras.

Também pode ser observado que os geradores 5, 8, 11 e 13 são só geradores de potência reativa (compensadores síncronos) e têm um pequeno despacho negativo, ou positivo, de potência ativa nas barras devido ao efeito da impedância equivalente da rede (SULAIMAN et al., 2007). 


\subsection{Cálculo da impedância equivalente de Thevenin entre duas barras}

Para o cálculo dos momentos também é preciso calcular a impedância equivalente entre os geradores e as barras críticas.

O cálculo da impedância equivalente entre duas barras foi feito com a ferramenta computacional "ANAFAS".

O cálculo foi feito ignorando o efeito de impedância dos geradores e as cargas.

A partir da matriz de impedância Z-barra do sistema é possível calcular a impedância equivalente entre duas barras com a seguinte equação:

$$
Z_{e q}=Z_{L L}+Z_{K K}-2 Z_{K L}
$$

Onde $Z_{L L}$ e $Z_{K K}$ são os elementos da diagonal da matriz de impedância Z-barra.

$Z_{K L}$ é o elemento $(\mathrm{K}, \mathrm{L})$ da matriz de impedâncias $Z_{b u s}$ que também poderia ser o elemento $(\mathrm{L}, \mathrm{K})$ já que a matriz é simétrica.

A tabela 6, mostra as impedâncias equivalentes para a configuração normal entre os geradores e as barras críticas. 
Tabela 6: Impedância equivalente em p.u. entre os geradores e as barras críticas para a configuração normal.

\begin{tabular}{|c|c|c|c|c|c|c|c|c|c|c|}
\hline & \multicolumn{2}{|c|}{ Barra 14} & \multicolumn{2}{|c|}{ Barra 19} & \multicolumn{2}{|c|}{ Barra 26} & \multicolumn{2}{|c|}{ Barra 29} & \multicolumn{2}{|c|}{ Barra 30} \\
\hline & $\begin{array}{c}\mathbf{r} \\
\text { (p.u.) }\end{array}$ & $\begin{array}{c}\mathbf{x} \\
\text { (p.u.) }\end{array}$ & $\begin{array}{c}\mathbf{r} \\
\text { (p.u.) }\end{array}$ & $\begin{array}{c}\mathbf{x} \\
\text { (p.u.) }\end{array}$ & $\begin{array}{c}\mathbf{r} \\
\text { (p.u.) }\end{array}$ & $\begin{array}{c}\mathbf{x} \\
\text { (p.u.) }\end{array}$ & $\begin{array}{c}\mathbf{r} \\
\text { (p.u.) }\end{array}$ & $\begin{array}{c}\mathbf{x} \\
\text { (p.u.) }\end{array}$ & $\begin{array}{c}\mathbf{r} \\
\text { (p.u.) }\end{array}$ & $\begin{array}{c}\mathbf{x} \\
\text { (p.u.) }\end{array}$ \\
\hline Gerador1 & 0,129 & 0,354 & 0,110 & 0,354 & 0,385 & 0,788 & 0,237 & 0,686 & 0,268 & 0,744 \\
\hline Gerador2 & 0,122 & 0,519 & 0,102 & 0,329 & 0,377 & 0,762 & 0,229 & 0,660 & 0,260 & 0,718 \\
\hline Gerador5 & 0,142 & 0,390 & 0,120 & 0,386 & 0,394 & 0,816 & 0,245 & 0,712 & 0,276 & 0,770 \\
\hline Gerador8 & 0,120 & 0,319 & 0,096 & 0,311 & 0,364 & 0,731 & 0,214 & 0,624 & 0,245 & 0,682 \\
\hline Gerador11 & 0,122 & 0,521 & 0,083 & 0,468 & 0,371 & 0,957 & 0,227 & 0,882 & 0,258 & 0,940 \\
\hline Gerador13 & 0,090 & 0,283 & 0,103 & 0,380 & 0,393 & 0,907 & 0,250 & 0,840 & 0,281 & 0,897 \\
\hline
\end{tabular}

Fonte: Autor

A tabela 7 mostra as impedâncias equivalentes para a configuração de contingência (perda linha 2-5) entre os geradores e as barras críticas.

Tabela 7: Impedância equivalente em p.u. entre os geradores e as barras críticas para a configuração de contingência.

\begin{tabular}{|c|c|c|c|c|c|c|c|c|c|c|}
\hline & \multicolumn{2}{|c|}{ Barra 14} & \multicolumn{2}{|c|}{ Barra 19} & \multicolumn{2}{|c|}{ Barra 26} & \multicolumn{2}{|c|}{ Barra 29} & \multicolumn{2}{|c|}{ Barra 30} \\
\hline & $\begin{array}{c}\mathbf{r} \\
\text { (p.u.) }\end{array}$ & $\begin{array}{c}\mathbf{x} \\
\text { (p.u.) }\end{array}$ & $\begin{array}{c}\mathbf{r} \\
\text { (p.u.) }\end{array}$ & $\begin{array}{c}\mathbf{x} \\
\text { (p.u.) }\end{array}$ & $\begin{array}{c}\mathbf{r} \\
\text { (p.u.) }\end{array}$ & $\begin{array}{c}\mathbf{x} \\
\text { (p.u.) }\end{array}$ & $\begin{array}{c}\mathbf{r} \\
\text { (p.u.) }\end{array}$ & $\begin{array}{c}\mathbf{x} \\
\text { (p.u.) }\end{array}$ & $\begin{array}{c}\mathbf{r} \\
\text { (p.u.) }\end{array}$ & $\begin{array}{c}\mathbf{x} \\
\text { (p.u.) }\end{array}$ \\
\hline Gerador1 & 0,13 & 0,36 & 0,112 & 0,3608 & 0,387 & 0,796 & 0,24 & 0,694 & 0,2707 & 0,752 \\
\hline Gerador2 & 0,125 & 0,34 & 0,106 & 0,34 & 0,381 & 0,774 & 0,233 & 0,672 & 0,2641 & 0,73 \\
\hline Gerador5 & 0,182 & 0,483 & 0,158 & 0,4749 & 0,43 & 0,901 & 0,281 & 0,797 & 0,3116 & 0,855 \\
\hline Gerador8 & 0,12 & 0,319 & 0,096 & 0,3113 & 0,364 & 0,731 & 0,214 & 0,624 & 0,2448 & 0,682 \\
\hline Gerador11 & 0,122 & 0,521 & 0,083 & 0,4682 & 0,371 & 0,957 & 0,227 & 0,882 & 0,2582 & 0,94 \\
\hline Gerador13 & 0,09 & 0,283 & 0,104 & 0,38 & 0,393 & 0,908 & 0,25 & 0,84 & 0,2812 & 0,897 \\
\hline
\end{tabular}

Fonte: Autor

Os momentos de potência $\mathrm{P}$ e Q para o caso base e configuração normal são mostrados na tabela 8 . 
Tabela 8: Momentos P e Q para o caso base, configuração normal

\begin{tabular}{l|c|c|c|c|c|c|c|c|c|c}
\hline & \multicolumn{2}{|c|}{ Barra 14 } & \multicolumn{2}{c|}{ Barra 19 } & \multicolumn{2}{c|}{ Barra 26 } & \multicolumn{2}{c}{ Barra 29 } & \multicolumn{2}{c}{ Barra 30 } \\
\hline & Mom & Mom & Mom & Mom & Mom & Mom & Mom & Mom & Mom & Mom \\
& $\mathbf{P}$ & $\mathbf{Q}$ & $\mathbf{P}$ & $\mathbf{Q}$ & $\mathbf{P}$ & $\mathbf{Q}$ & $\mathbf{P}$ & $\mathbf{Q}$ & $\mathbf{P}$ & $\mathbf{Q}$ \\
\hline Gerador1 & 1,96 & 0,60 & 3,14 & 0,45 & 3,13 & 0,19 & 1,57 & 0,25 & 6,87 & 2,40 \\
\hline Gerador2 & 0,39 & $-0,27$ & 0,53 & $-0,50$ & 0,50 & $-0,55$ & 0,28 & $-0,26$ & 1,47 & $-0,92$ \\
\hline Gerador5 & 0,06 & $-0,31$ & 0,03 & $-0,49$ & $-0,01$ & $-0,46$ & 0,02 & $-0,23$ & 0,27 & $-1,03$ \\
\hline Gerador8 & 0,08 & $-0,26$ & 0,06 & $-0,41$ & 0,04 & $-0,44$ & 0,04 & $-0,22$ & 0,37 & $-0,95$ \\
\hline Gerador11 & 0,05 & $-0,18$ & 0,04 & $-0,27$ & 0,01 & $-0,24$ & 0,02 & $-0,13$ & 0,17 & $-0,54$ \\
\hline Gerador13 & 0,04 & $-0,07$ & 0,04 & $-0,15$ & 0,01 & $-0,15$ & 0,01 & $-0,08$ & 0,11 & $-0,35$ \\
\hline
\end{tabular}

Fonte: Autor

\subsection{Valores desejados de saídas}

São os valores objetivos a ser calculados que neste caso são as margens de potência reativa das barras críticas. As margens são calculadas com o método do fluxo de potência continuado e a RNA treinada terá que ser capaz de simular esses valores, com erros mínimos.

A continuação na figura 26 mostra-se a curva Q-V para o caso base e configuração normal da barra 14.

Figura 26: Curva V-Q da barra 14 para o caso base

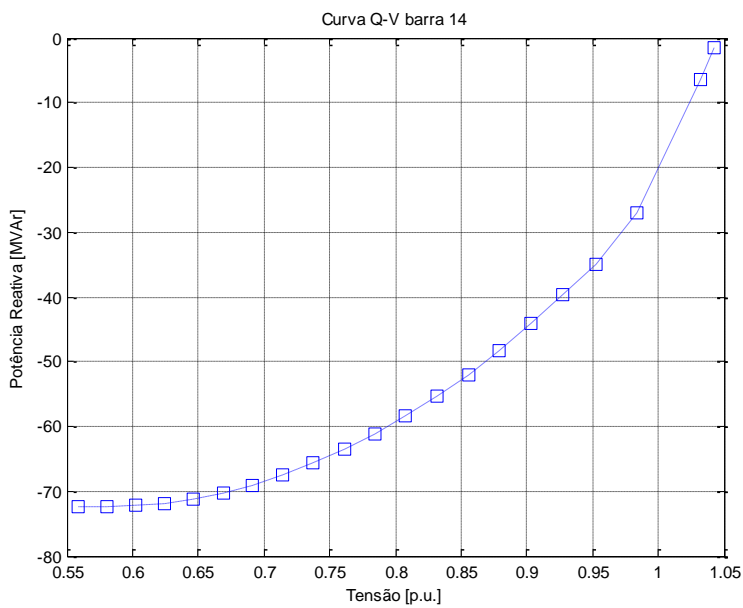

Fonte: Autor 
O gráfico mostra que para a situação normal (1,6 MVAr), a tensão da barra é 1.042 p.u., e o colapso ocorre quando a potência reativa é 72,34 MVAr, e a tensão é 0.58 p.u.

Ou seja, a margem de potência reativa para a barra 14 no cenário descrito é 70.739 MVAr.

A tabela 8 mostra a margem de potência reativa para as barras críticas no mesmo cenário de caso base e configuração normal que corresponde as saídas da rede neural (valores desejados).

Tabela 8: Margem de potência reativa das barras críticas para o caso base

\begin{tabular}{c|c}
\hline Barra & $\begin{array}{c}\text { Margem } \\
\text { (MVAr) }\end{array}$ \\
\hline 14 & 70,740 \\
\hline 19 & 66,729 \\
\hline 26 & 28,985 \\
\hline 29 & 34,100 \\
\hline 30 & 30,699 \\
\hline
\end{tabular}

Fonte: Autor

Para o treinamento da RNA, são calculados os valores desejados para os 519 cenários.

\subsection{Arquitetura da rede neural artificial}

A arquitetura da rede usada neste trabalho é uma sugestão dos autores Balasubramanian e Singh (2011), que foi produto de um processo de validação cruzada.

A arquitetura da Rede Neural é uma Feedforward Multicamadas com duas camadas escondidas e neste caso se desempenha como um aproximador universal de funções.

A rede tem 80 dados de entrada para cada cenário;

A primeira camada escondida conta com 40 neurônios e a segunda com 20 neurônios.

A camada de saída contém 5 neurônios correspondente a margem de potência reativa das cinco barras de carga mais vulneráveis do sistema de teste IEEE 30 barras. 
As funções de ativação tangente hiperbólica foram usadas para os neurônios nas camadas ocultas, e a função de ativação linear para os neurônios na camada de saída.

O algoritmo Levemberg-Marquardt é utilizado para o treinamento da rede neural que é uma versão aperfeiçoada do algoritmo padrão backpropagation.

Para evitar cair num mínimo local, rede foi treinada 5 vezes e os pesos escolhidos foram os que apresentaram o menor erro MSE.

Na figura 27 é mostrada a arquitetura utilizada para a rede neural.

Figura 27: Arquitetura da Rede Neural

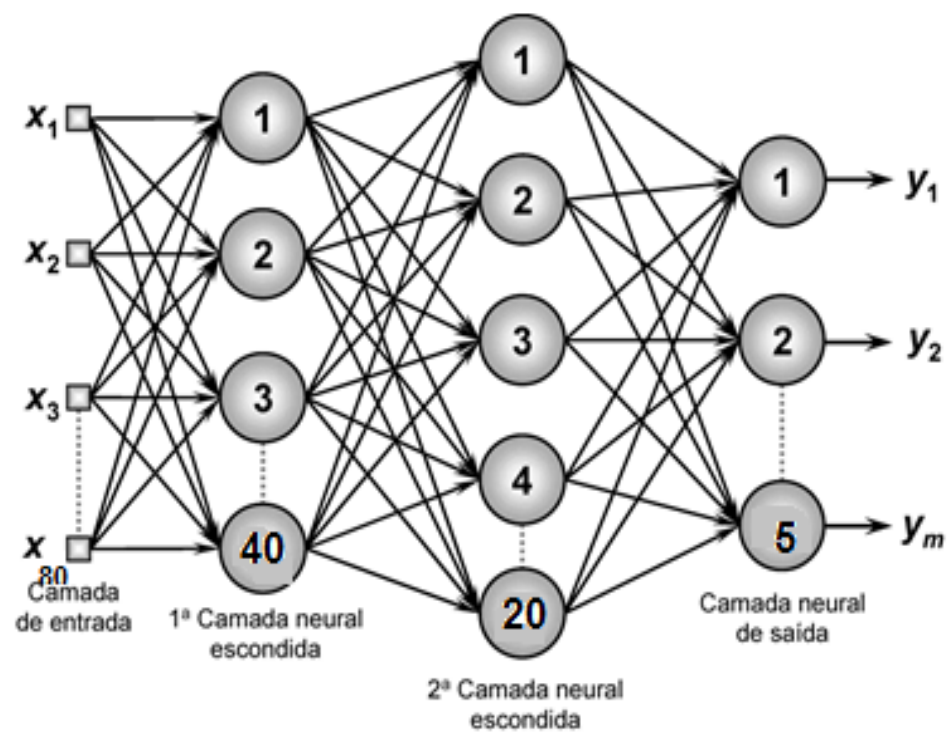

Fonte: Autor 


\subsection{Resultados do treinamento da RNA}

Na figura 28 é mostrada o desempenho do treino da RNA, onde pode se ver que o erro quadrático médio (EQM) alcançado foi de 4.3e-4 em 48 épocas.

Figura 28: Desempenho do treinamento da rede neural.

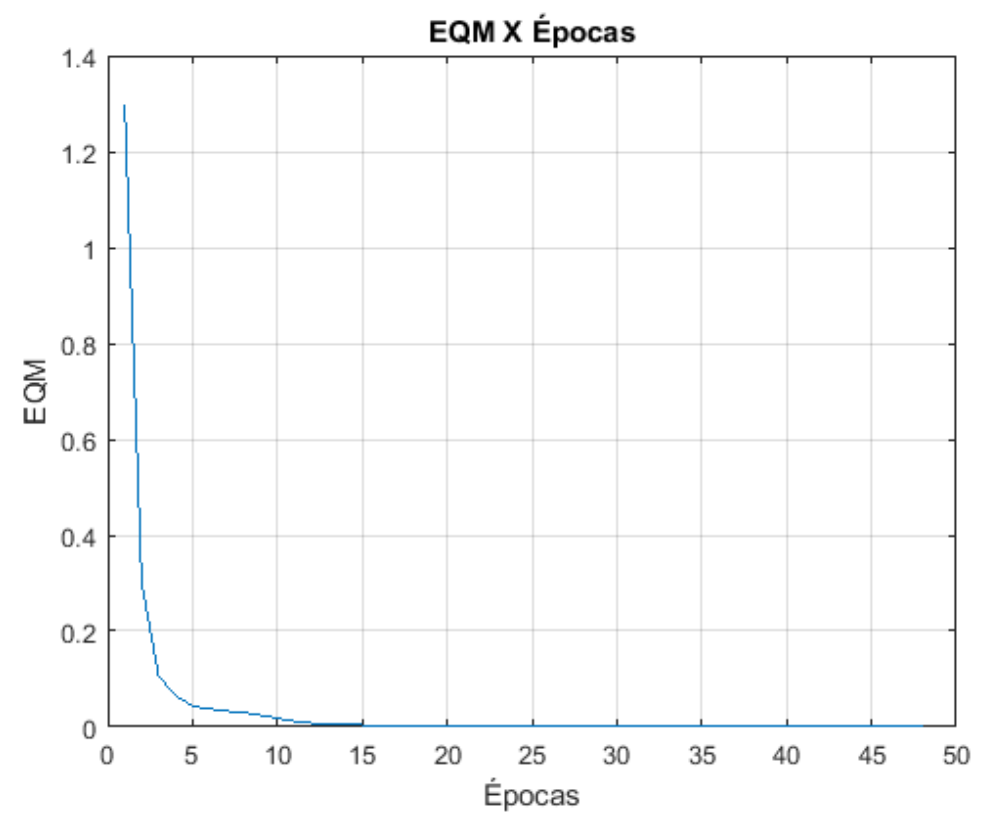

Fonte: Autor

Para testar o desempenho da rede neural, foram introduzidas 94 amostras, os quais não foram utilizados no treinamento da rede neural. Esses novos 94 cenários (amostras) são a contingência do gerador 11, desde o caso de carregamento base até o Ponto de bifurcação.

As figuras 29 e 30 mostram os resultados das margens de carregamento da barra 14 e 30 respetivamente, para estes novos 94 cenários obtidos com a rede Perceptron multicamada (PMC) versus o resultado exato calculado com o programa de fluxo continuado.

Pode-se ver que os resultados obtidos com a rede PMC estão muito próximos que os obtidos com o fluxo de potência continuado. O erro da rede PMC é mínimo para as amostras de teste, o que significa que a rede não apresentou overfitting nem underfitting. 
Figura 29: Teste da RNA versus o resultado real (FPC) para a barra 14

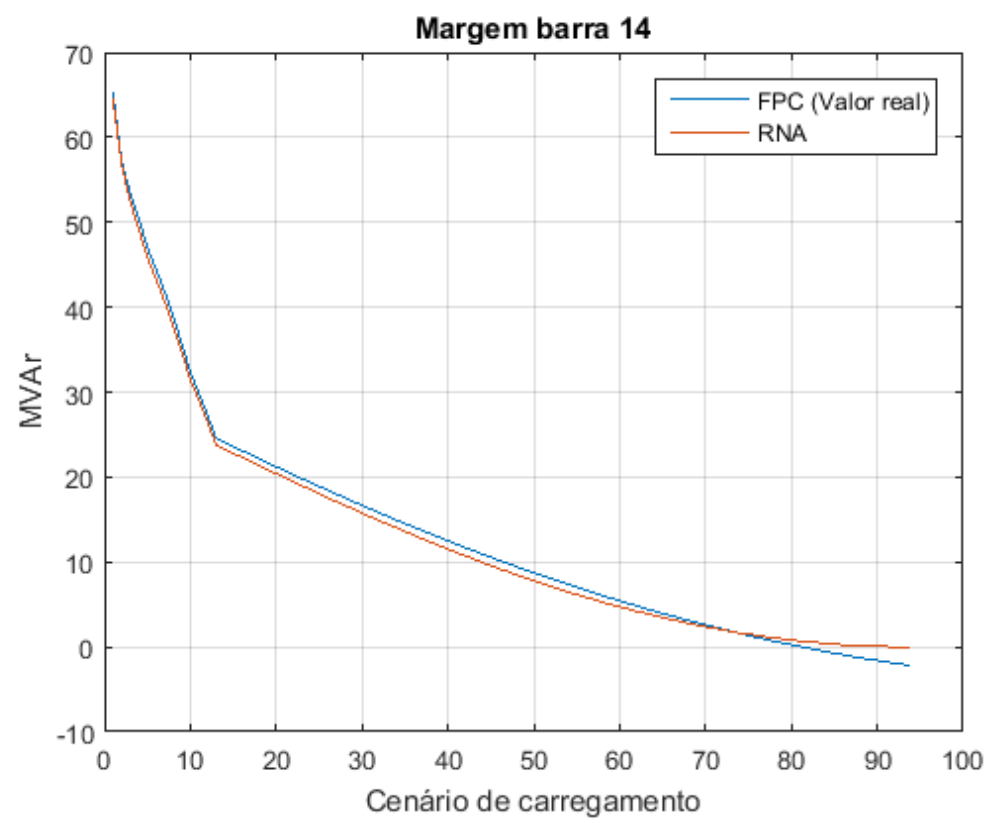

Fonte: Autor

Figura 30: Teste da RNAversus o resultado real (FPC) para a barra 19

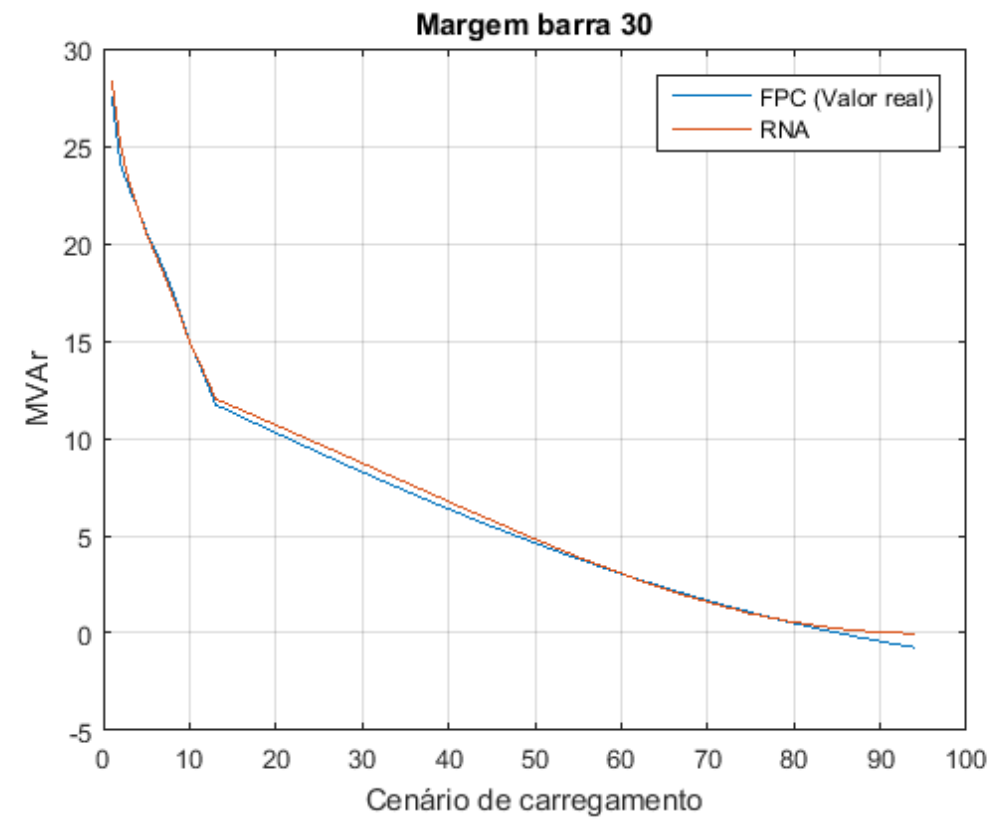

Fonte: Autor

A partir da entrada 80, com a rede bastante carregada, pode-se ver que o sistema está entrando na região do colapso, já que a margem de potência reativa é quase zero. 
A tabela 9 mostra os erros máximos (absolutos) dos 94 cenários para as 5 barras críticas.

Tabela 9: Erro máximo dos 94 cenários

\begin{tabular}{c|c}
\hline Barra & Erro Máximo (MVAR) \\
\hline 14 & 2,11 \\
\hline 19 & 2,01 \\
\hline 26 & 0,84 \\
\hline 29 & 0,904 \\
\hline 30 & 0,94 \\
\hline
\end{tabular}

Fonte: Autor

O tempo de computação com a ferramenta matlab e um processador i5, da rede PMC para os dados de teste que calcula as 5 saídas (das 5 barras críticas) para esses 94 cenários foi de 0,157 segundos, o que corresponde a um tempo adequado para cálculos em tempo real, considerando que para tempo real é necessário o cálculo de apenas 1 cenário $(O$ cenário do tempo real) . Já o tempo de computação com a mesma ferramenta e processador, para o cálculo da margem de apenas uma barra com o fluxo de potência continuado foi de 46,77 seg.

\subsection{Sugestões para aplicação em centros de controle}

No contexto de aplicação em tempo real, as seguintes sugestões podem ser úteis:

1. As potências ativas e reativas das cargas, a magnitude da tensão e as margens de potência reativa disponíveis em todos os geradores, usadas como dado de entrada para a RNA desenvolvida, podem ser obtidas diretamente do sistema SCADA, com preferencia dados do estimador de estado online.

2. O cálculo das contribuições individuais de potência ativa e reativa dos diferentes geradores para as barras de carga envolvem apenas poucas multiplicações de ponto flutuante, pois esta computação envolve apenas a modificação do Z-barra da rede para incluir o efeito de cargas. O Z-barra modificado poderia ser calculado a partir da matriz Z-barra pré-calculada da rede completa do sistema (sem consideração das 
cargas) e, apenas, modificando a matriz em tempo real para representar as cargas no ponto de operação atual.

3. As impedâncias equivalentes entre os geradores e as barras críticas poderiam ser précalculadas, e mantidas na memória do computador para a configuração completa do sistema, e poderiam ser modificadas em tempo real, cuidando de quaisquer alterações topológicas.

4. A simples multiplicação de contribuições de potência dos geradores com as impedâncias equivalentes também representam um cálculo de baixo esforço computacional.

5. A rede PMC, deve ser treinada sempre que uma alteração definitiva aconteça no sistema, como a inclusão de uma nova subestação por exemplo, que causara uma nova distribuição de carga nas barras. As matrizes de impedância pré-calculadas também devem ser atualizadas. 


\section{CAPÍTULO 7}

\section{Conclusões}

A rede neural apresentada foi testada para um conjunto de 94 cenários de carregamento da rede de 30 barras do IEEE, com contingência do gerador 11, desde o caso base de carga até o ponto de máximo carregamento. Esses 94 cenários não foram usados para o treinamento da rede.

O desempenho dos resultados obtidos da rede PMC a partir do conjunto de dados de teste foi satisfatório, no sentido de que o maior erro nos 94 cenários e das 5 barras críticas foi de 2,11 MVAr tendo uma média de 0,101 MVAr de erro.

O tempo de cálculo da rede PMC para obter os resultados para esses 94 novos cenários (dados de teste) foi baixo, adequando-se para um requerimento de implementação em tempo real.

A Rede Neural não apresentou sintomas de overfitting nem underfitting, pois os resultados obtidos com o conjunto de dados de teste foram satisfatórios.

O bom desempenho da rede neural em termos de precisão dos resultados, baixo tempo e esforço computacional demostra que o método adotado pode ser utilizado para monitoramento em tempo real da margem de estabilidade nos centros de controle das concessionárias de energia elétrica.

A rede PMC demostrou boa generalização do problema já que foi capaz de calcular de forma eficiente as margens de estabilidade para uma contingencia do sistema, cenário que não foi parte das amostras de treinamento.

A análise modal foi de crucial importância para a determinação das barras mais críticas do sistema, já que o cálculo da margem de potência reativa para todas as barras não é prático.

Foi observado que para carregamentos muito altos do sistema, os geradores a exceção do gerador da barra "slack", ficam com momentos P e Q iguais a zero, devido ao fato de 
operarem como barras PQ, o que significa que para essas instâncias muitos dados de entrada são iguais a zero. Este fato não pode ser considerado como uma desvantagem pelo fato de que a metodologia é aplicada para tempo real, ou seja, não se espera incrementos de carga muito acima das máximas históricas.

A análise modal demostrou que para cada cenário as barras mais críticas mudam, contudo existem as barras predominantemente fracas que aparecem com mais frequência nos cenários com alto índice BPF.

\subsection{Perspectivas para trabalhos futuros}

Neste trabalho foram utilizadas as 5 barras críticas predominantes de todos os cenários analisados, e essas barras foram mantidas constantes para todo o estudo, em outras palavras as barras críticas são pré-calculadas e não atualizadas em tempo real. Para trabalhos futuros uma melhoria significativa consistiria em calcular as 5 barras mais críticas em tempo real.

É necessário testar o desempenho da rede levando em conta diferentes direções de crescimento de carga. Neste trabalho a carga é aumentada de forma constante em todas as barras, ou seja, em apenas uma direção de crescimento de carga.

É desejável também que para o crescimento de carga, os despachos dos geradores sejam mais próximos da realidade, já que para o modelo clássico do fluxo de potência continuado apenas o gerador da barra slack é quem absorve o crescimento da carga. 


\title{
Referências bibliográficas
}

\begin{abstract}
AJJARAPU, V. COMPUTATIONAL TECHNIQUES FOR VOLTAGE STABILITY ASSESSMENT AND CONTROL (POWER ELECTRONICS AND POWER SYSTEMS). Proceedings... Berlin: Heidelberg, 2007. p. 49-115.
\end{abstract}

AJJARAPU, V.; CHRISTY, C. The continuation power flow: a tool for steady state voltage stability analysis. IEEE Transactions on Power Systems, v. 7, n. 1, p. 416-423, Feb. 1992.

BAHMANYAR, A. R.; KARAMI, A. Power system voltage stability monitoring using artificial neural networks with a reduced set of inputs. International Journal of Electrical Power \& Energy Systems. v. 58, p. 246-256, jun. 2014.

BALAMOUROUGAN, V.; SIDHU, T. S.; SACHDEV, M. S. Technique for online prediction of voltage collapse. IEE Proceedings - Generation, Transmission and Distribution. v. 151, n. 4, July 2004.

BALASUBRAMANIAN, R.; SINGH, R. Power system voltage stability analysis using ANN and continuation power flow methods. In: INTERNATIONAL CONFERENCE ON INTELLIGENT SYSTEM APPLICATION TO POWER SYSTEMS (ISAP), 16. Proceedings... 2011, p. 1-7, set. 2011.

BAO, L.; HUANG, Z.; XU, W. Online voltage stability monitoring using VAr reserves. IEEE Transactions on Power Systems. v. 18, n. 4, Nov. 2003.

CHAKRABARTI, S.; JEYASURYA, B. On-line voltage stability monitoring using artificial neural network. In: LARGE ENGINEERING SYSTEMS CONFERENCE ON POWER ENGINEERING, 2004. Proceedings... 2004.

COSI, S.; TARANTO, G. N. A Real-time voltage instability identification algorithm based on local phasor measurements. IEEE Transactions on Power Systems, v. 23, n. 3, Aug. 2008.

CUTSEM, T. V.; VOURNAS, C. Voltage Stability of Electric Power Systems. Dordrecht: Kluwer Academic Publishers, 1998. 
El-KEIB, A. A.; MA, X. Application of artificial neural networks in voltage stability assessment. IEEE Transactions on Power Systems, v. 10, n. 4, Nov., 1995.

GOH, H.H. et al. Evaluation for voltage stability indices in power system using artificial neural network. Procedia Engineering, v. 118, p. 1127-1136, 2015.

IEEE/CIGRE. Definition and classification of power system stability on stability terms and definitions. IEEE Transactions on Power Systems, v.19, n. 3, Ago. 2004.

JEYASURYA, B. Power system voltage stability monitoring with artificial neural networks. In: INTERNATIONAL CONFERENCE INDUSTRIAL \& ENGINEERING, 7. Proceedings...1994, Austin, p. 57-62. Austin: 1994.

KUNDUR, P. Power System Stability and Control. New York: McGraw Hill, 1994.

LA SCALA, M.; TROVATO, M.; TORELLI, F. A neural network-based method for voltage security monitoring. IEEE Transactions on Power Systems, v. 11, n. 3, Aug. 1996.

LATON, M. Z.; MUSIRIN, I.; RAHMAN, T. K. A. Voltage stability assessment via continuation power flow method. Journal of Electrical and Electronic Systems Research, v.1, Jun., 2008.

LOF, P. A.; HILL, D. J. ARNBORG, S.; ANDERSSON, G.; On the analysis of long-term voltage stability. International Journal of Electrical Power \& Energy Systems, v. 15, n.4, Aug. 1993.

LEONARDI, B.; AJJARAPU V. Development of Multilinear Regression Models for Online Voltage Stability Margin Estimation. IEEE Transactions on Power Systems, v. 26, n. 1, Feb. 2011.

LIU, H.; BOSE, A.; VENKATASUBRAMANIAN, V. A fast voltage security assessment method using adaptive bounding. IEEE Transactions on Power Systems. v. 15, n. 3, Aug. 2000.

MOGHAVVEMI, M.; FARUQUE. M. Technique for contingency monitoring and voltage collapse prediction. IEE Proceedings - Generation, Transmission and Distribution, v. 145, n. 6, Nov. 1998. 
MOGHAVVEMI, M.; FARUQUE. M. Real-time contingency evaluation and ranking technique. IEE Proceedings-Generation Transmission and Distribution, v. 145, n. 5, p. 517-524, 1998.

MONTICELli, A. J. Fluxo de carga em redes de energia elétrica. São Paulo: Edgard Blucher, 1983.

MORI, H. Voltage stability monitoring with artificial neural networks. In: INDUSTRY: PROCEEDINGS OF THE 1992 INNS, WORKSHOP. Proceedings... 1992, p. 101-106, Kawasaki, 1992.

NAKAWIRO, W.; ERLICH, I. Online voltage stability monitoring using artificial neural network. In: INTERNATIONAL CONFERENCE ON ELECTRIC UTILITY DEREGULATION AND RESTRUCTURING AND POWER TECHNOLOGIES CONF., 3. Proceedings... 2008. p. 941-947, Local, 2008.

OVERBYE, T. J. Use of energy methods for on-line assessment of power system voltage security - Power Systems. IEEE Transactions on Power Systems, v. 8, n. 2, May 1993.

RAHI, O.P et al. Power system voltage stability assessment through artificial neural network. In: INTERNATIONAL CONFERENCE ON COMMUNICATION TECHNOLOGY AND SYSTEM DESIGN, Proceedings... Local, 2011.

SEYDEL, R. From equilibrium to chaos. New York: Elsevier Science, 1988.

SILVA, I. N.; SPATTI, D. H.; FLAUZINO, R. A. Redes neurais artificiais para engenharia e ciências aplicadas. São Paulo: Artliber Editora. 2016.

SOUZA, A.C.Z.; CANIZARES, C. A.; QUINTANA V. H. New techniques to speed up voltage collapse computations using tangent vectors. IEEE Transactions on Power Systems v. 12, n. 4. Aug. 1997.

SOUZA, A. C. Z.; SOUZA, J. C. S.; SILVA A. M. L. On-line voltage stability monitoring. IEEE Transactions on Power Systems. v. 15, n. 4. Nov. 2000. 
SULAIMAN, M. H.; ALIMAN, O.; MUSTAFA, M. W. Tracing generators output in transmission. In: STUDENT CONFERENCE ON RESEARCH AND DEVELOPMENTSCORED, 5. Proceedings... 2007 Selangor: 2007.

SUTHAR, B.; BALASUBRAMANIAN, R. A novel ANN based method for online voltage stability assessment. In: INTERNATIONAL IEEE CONFERENCE ON INTELLIGENT SYSTEM APPLICATIONS TO POWER SYSTEMS (ISAP), 2007, Proceedings... Niigata, 2007. p. 1-6.

SUTHAR, B.; BALASUBRAMANIAN, R. Application of an ANN based voltage stability assessment tool to restructured power systems. In: IREP INTERNATIONAL CONFERENCE ON BULK POWER SYSTEM DYNAMICS AND CONTROL, 7. 2007, Proceedings... Charleston. Charleston: IREP, p. 19-24, 2007.

TENG, J.H. Power flow and loss allocation for deregulated transmission systems. Electrical Power and Energy Systems, v. 27, n. 4, p 327-333, Jan. 2005.

THAKKU, P.; SAJITH, R. P. Voltage stability assessment in power systems using artificial neural networks. In: ANNUAL INTERNATIONAL CONFERENCE ON EMERGING RESEARCH AREAS: MAGNETICS, MACHINES AND DRIVES, Proceedings... Kottayam 2014.

TIRANUCHIT, A.; THOMAS R. J. A posturing strategy against voltage instabilities in electric power systems. IEEE Transactions on Power Systems, v. 3, n. 1, Feb. 1988.

VEERANJANEYULU, P. A.; PURNA, C. B. D. Analysis of continuous power flow method, model analysis, linear regression and ANN for voltage stability assessment for different loading condition. Procedia Computer Science, v. 47, p. 168-178, 2015.

ZHOU, D. Q.; ANNAKKAGE, U. D.; RAJAPAKSE A. D. Online monitoring of voltage stability margin using an artificial neural network. IEEE Transactions on Power Systems, v. 25, n. 3, August 2010. 
Apêndices 


\section{Apêndice A}

\section{Diagrama sistema IEEE - 30 barras}

Figura 31: Sistema IEEE de 30 barras THAEE WINOIHG TRANSFORMER EOUIVALENTS

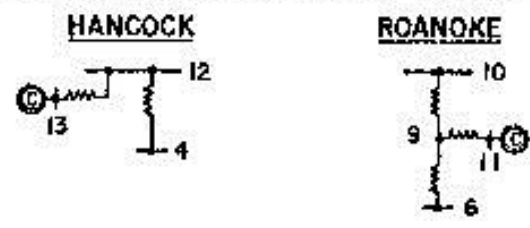
ROANOKE

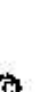




\section{Apêndice B}

\section{Dados sistema IEEE - 30 barras}

Tabela 10: Dados de barras sistema IEEE 30-barras

\begin{tabular}{|c|c|c|c|c|c|c|}
\hline $\begin{array}{c}\text { De } \\
\text { barra }\end{array}$ & $\begin{array}{c}\text { Tipo de } \\
\text { Barra }\end{array}$ & MW & MVAr & $\begin{array}{l}\text { Gen } \\
\text { MW }\end{array}$ & \begin{tabular}{|c|} 
Gen \\
Max \\
MVAr \\
\end{tabular} & Tensão \\
\hline 1 & 3 & 0 & 0 & & & 1,06 \\
\hline 2 & 2 & 21,7 & 12,7 & 40 & 50 & 1,045 \\
\hline 3 & 0 & 2,4 & 1,2 & 0 & 0 & \\
\hline 4 & 0 & 7,6 & 1,6 & 0 & 0 & \\
\hline 5 & 2 & 94,2 & 19 & 0 & 40 & 1,01 \\
\hline 6 & 0 & 0 & 0 & 0 & 0 & \\
\hline 7 & 0 & 22,8 & 10,9 & 0 & 0 & \\
\hline 8 & 2 & 30 & 30 & 0 & 40 & 1,01 \\
\hline 9 & 0 & 0 & 0 & 0 & 0 & \\
\hline 10 & 0 & 5,8 & 2 & 0 & 0 & \\
\hline 11 & 2 & 0 & 0 & 0 & 25 & 1,082 \\
\hline 12 & 0 & 11,2 & 7,5 & 0 & 0 & \\
\hline 13 & 2 & 0 & 0 & 0 & 25 & 1,071 \\
\hline 14 & 0 & 6,2 & 1,6 & 0 & 0 & \\
\hline 15 & 0 & 8,2 & 2,5 & 0 & 0 & \\
\hline 16 & 0 & 3,5 & 1,8 & 0 & 0 & \\
\hline 17 & 0 & 9 & 5,8 & 0 & 0 & \\
\hline 18 & 0 & 3,2 & 0,9 & 0 & 0 & \\
\hline 19 & 0 & 9,5 & 3,4 & 0 & 0 & \\
\hline 20 & 0 & 2,2 & 0,7 & 0 & 0 & \\
\hline 21 & 0 & 17,5 & 11,2 & 0 & 0 & \\
\hline 22 & 0 & 0 & 0 & 0 & 0 & \\
\hline 23 & 0 & 3,2 & 1,6 & 0 & 0 & \\
\hline 24 & 0 & 8,7 & 6,7 & 0 & 0 & \\
\hline 25 & 0 & 0 & 0 & 0 & 0 & \\
\hline 26 & 0 & 3,5 & 2,3 & 0 & 0 & \\
\hline 27 & 0 & 0 & 0 & 0 & 0 & \\
\hline 28 & 0 & 0 & 0 & 0 & 0 & \\
\hline 29 & 0 & 2,4 & 0,9 & 0 & 0 & \\
\hline 30 & 0 & 10,6 & 1,9 & 0 & 0 & \\
\hline
\end{tabular}

Fonte: https://www2.ee.washington.edu 
Tabela 11: Dados de linhas e transformadores do sistema IEEE 30-barras

\begin{tabular}{|c|c|c|c|c|c|}
\hline $\begin{array}{c}\text { De } \\
\text { barra }\end{array}$ & $\begin{array}{c}\text { A } \\
\text { barra }\end{array}$ & $\begin{array}{c}\mathbf{r} \\
\text { (p.u.) }\end{array}$ & $\begin{array}{c}x \\
\text { (p.u.) } \\
\end{array}$ & $b / 2$ & $\mathbf{a}$ \\
\hline 1 & 2 & 0,0192 & 0,0575 & 0,0528 & 1 \\
\hline 1 & 3 & 0,0452 & 0,1652 & 0,0408 & 1 \\
\hline 2 & 4 & 0,057 & 0,1737 & 0,0368 & 1 \\
\hline 3 & 4 & 0,0132 & 0,0379 & 0,0084 & 1 \\
\hline 2 & 5 & 0,0472 & 0,1983 & 0,0418 & 1 \\
\hline 2 & 6 & 0,0581 & 0,1763 & 0,0374 & 1 \\
\hline 4 & 6 & 0,0119 & 0,0414 & 0,009 & 1 \\
\hline 5 & 7 & 0,046 & 0,116 & 0,0204 & 1 \\
\hline 6 & 7 & 0,0267 & 0,082 & 0,017 & 1 \\
\hline 6 & 8 & 0,012 & 0,042 & 0,009 & 1 \\
\hline 6 & 9 & 0 & 0,208 & 0 & 0,978 \\
\hline 6 & 10 & 0 & 0,556 & 0 & 0,969 \\
\hline 9 & 11 & 0 & 0,208 & 0 & 1 \\
\hline 9 & 10 & 0 & 0,11 & 0 & 1 \\
\hline 4 & 12 & 0 & 0,256 & 0 & 0,932 \\
\hline 12 & 13 & 0 & 0,14 & 0 & 1 \\
\hline 12 & 14 & 0,1231 & 0,2559 & 0 & 1 \\
\hline 12 & 15 & 0,0662 & 0,1304 & 0 & 1 \\
\hline 12 & 16 & 0,0945 & 0,1987 & 0 & 1 \\
\hline 14 & 15 & 0,221 & 0,1997 & 0 & 1 \\
\hline 16 & 17 & 0,0524 & 0,1923 & 0 & 1 \\
\hline 15 & 18 & 0,1073 & 0,2185 & 0 & 1 \\
\hline 18 & 19 & 0,0639 & 0,1292 & 0 & 1 \\
\hline 19 & 20 & 0,034 & 0,068 & 0 & 1 \\
\hline 10 & 20 & 0,0936 & 0,209 & 0 & 1 \\
\hline 10 & 17 & 0,0324 & 0,0845 & 0 & 1 \\
\hline 10 & 21 & 0,0348 & 0,0749 & 0 & 1 \\
\hline 10 & 22 & 0,0727 & 0,1499 & 0 & 1 \\
\hline 21 & 22 & 0,0116 & 0,0236 & 0 & 1 \\
\hline 15 & 23 & 0,1 & 0,202 & 0 & 1 \\
\hline 22 & 24 & 0,115 & 0,179 & 0 & 1 \\
\hline 23 & 24 & 0,132 & 0,27 & 0 & 1 \\
\hline 24 & 25 & 0,1885 & 0,3292 & 0 & 1 \\
\hline 25 & 26 & 0,2544 & 0,38 & 0 & 1 \\
\hline 25 & 27 & 0,1093 & 0,2087 & 0 & 1 \\
\hline 28 & 27 & 0 & 0,396 & 0 & 0,968 \\
\hline 27 & 29 & 0,2198 & 0,4153 & 0 & 1 \\
\hline 27 & 30 & 0,3202 & 0,6027 & 0 & 1 \\
\hline 29 & 30 & 0,2399 & 0,4533 & 0 & 1 \\
\hline 8 & 28 & 0,0636 & 0,2 & 0,0428 & 1 \\
\hline 6 & 28 & 0,0169 & 0,0599 & 0,013 & 1 \\
\hline
\end{tabular}

Fonte: https://www2.ee.washington.edu 